\title{
A model-based assessment of the TrOCA approach for estimating anthropogenic carbon in the ocean
}

\author{
A. Yool ${ }^{1}$, A. Oschlies ${ }^{2}$, A. J. G. Nurser ${ }^{1}$, and N. Gruber ${ }^{3}$ \\ ${ }^{1}$ National Oceanography Centre, Southampton; University of Southampton Waterfront Campus, European Way, \\ Southampton SO14 3ZH, UK \\ ${ }^{2}$ IFM-GEOMAR, Leibniz Institute of Marine Sciences; Düsternbrooker Weg 20, 24105 Kiel, Germany \\ ${ }^{3}$ ETH Zürich, Inst. of Biogeochemistry and Pollutant Dynamics; Universitätstrasse 16, 8092 Zürich, Switzerland
}

Received: 11 June 2009 - Published in Biogeosciences Discuss.: 21 July 2009

Revised: 8 February 2010 - Accepted: 9 February 2010 - Published: 24 February 2010

\begin{abstract}
The quantification of the amount of anthropogenic carbon $\left(\mathrm{C}_{\mathrm{ant}}\right)$ that the ocean has taken up from the atmosphere since pre-industrial times is a challenging task because of the need to deconvolute this signal from the natural, unperturbed concentration of dissolved inorganic carbon (DIC). Nonetheless, a range of techniques have been devised that perform this separation using the information implicit in other physical, biogeochemical, and man-made ocean tracers. One such method is the TrOCA approach, which belongs to a group of back-calculation techniques, but relative to other methods employs a simple parameterization for estimating the preformed, pre-industrial concentration, the key quantity needed to determine $\mathrm{C}_{\text {ant }}$. Here we examine the theoretical foundation of the TrOCA approach and test its accuracy by deconvoluting the known distribution of $\mathrm{C}_{\mathrm{ant}}$ from an ocean general circulation model (OGCM) simulation of the industrial period (1864-2004). We reveal that the TrOCA tracer reflects the air-sea exchange of both natural and anthropogenic $\mathrm{CO}_{2}$ as well as that of $\mathrm{O}_{2}$. Consequently, the determination of the anthropogenic $\mathrm{CO}_{2}$ flux component requires an accurate determination not only of the contribution of the natural (pre-industrial) $\mathrm{CO}_{2}$ flux component, but also of the $\mathrm{O}_{2}$ flux component. The TrOCA method attempts to achieve this by assuming that the concentration changes invoked by these two air-sea flux components scale with temperature and alkalinity. While observations support a strong exponential scaling of the oxygen flux component with temperature, there exists no simple relationship of the natural $\mathrm{CO}_{2}$ flux component with temperature and/or alkalinity. This raises doubts whether the sum of these two components can
\end{abstract}

Correspondence to: A. Yool (axy@noc.soton.ac.uk) be adequately parameterized with a single function. The analyses of the model support this conclusion, even when $\mathrm{C}_{\mathrm{ant}}$ is deconvoluted using parameter values that were optimized on the basis of the synthetic dataset from the model. Application of an optimal, but globally uniform set of parameters for the estimation of $\mathrm{C}_{\mathrm{ant}}$ results in a global positive bias in the inventory of more than a factor of two, suggesting that a "universal" TrOCA parameterisation is not achieveable. Even the application of regionally specific sets of parameters causes, on average, a global positive bias of more than $50 \%$. This is substantially larger than the potential positive bias of $7 \%$ identified for the $\Delta \mathrm{C}^{*}$ method using a similar model-based assessment method.

\section{Introduction}

Since the beginning of the Industrial Revolution, atmospheric $\mathrm{CO}_{2}$ concentrations have been rising in response to human activities such as fossil fuel combustion, deforestation, land-use changes and cement production (IPCC, 2007). However, the rise in atmospheric $\mathrm{CO}_{2}$ has not paralleled anthropogenic emissions, since a significant fraction of the $\mathrm{CO}_{2}$ released to the atmosphere has been removed to reservoirs on the land and, particularly, in the ocean (Revelle and Suess, 1957). Since $C_{\text {ant }}$ that is transferred to land or into the ocean no longer causes global warming (though it does cause ocean acidification; e.g. Orr et al., 2005) there is continuing interest in establishing the capacity and uptake rate of these reservoirs (e.g. Siegenthaler and Sarmiento, 1993; Sarmiento and Gruber, 2002; IPCC, 2007; Le Quéré et al., 2009). On time-scales of a thousand years and more, nearly all of the emitted $\mathrm{C}_{\text {ant }}$ will be absorbed by the ocean primarily

Published by Copernicus Publications on behalf of the European Geosciences Union. 
through dissolution, but enhanced by processes including the shoaling of the calcium carbonate saturation depth and silicate weathering (Archer, 2005). But on shorter time-scales, only a fraction of this long-term capacity is achieved, mostly owing to the slow rate with which anthropogenic $\mathrm{CO}_{2}$ is transported from the surface to depth by ocean circulation and mixing (Sarmiento et al., 1992). Future climate change likely will alter this transport, potentially causing substantial changes in the rate at which the ocean will take up anthropogenic $\mathrm{CO}_{2}$ from the atmosphere. In addition, feedbacks between a changing climate and the global carbon cycle can liberate additional $\mathrm{CO}_{2}$ into the atmosphere, leading to further warming and changes in ocean circulation and biogeochemistry (e.g. Sarmiento et al., 1998; Joos et al., 1999). While a consensus is emerging that the feedback between the ocean carbon cycle and climate is likely positive (IPCC, 2007), there is still considerable uncertainty in how strong the ocean sink will be in the near future for a given atmospheric burden of anthropogenic $\mathrm{CO}_{2}$, and how positive the feedback with climate will be (Friedlingstein et al., 2006).

A key aspect of understanding the future behaviour of the ocean as a sink for $\mathrm{CO}_{2}$ is determining this role in the recent past. Fossil fuel $\mathrm{CO}_{2}$ has been accumulating in the atmosphere for more than two hundred years, with the majority of this increase occurring during the twentieth century. Consequently, the ocean has been absorbing this $\mathrm{C}_{\mathrm{ant}}$ over the corresponding period. However, quantifying the ocean's role is complicated by the difficulty of separating $\mathrm{C}_{\mathrm{ant}}$ from that of the natural carbon cycle (which, given relatively stable atmospheric $p \mathrm{CO}_{2}$ prior to the Industrial Revolution, is assumed to be in quasi-equilibrium). While there are signals in the distributions of the carbon isotopes ${ }^{13} \mathrm{C}$ (Sonnerup et al., 2007) and ${ }^{14} \mathrm{C}$ (Fallon et al., 2003), most methodologies for distinguishing $\mathrm{C}_{\mathrm{ant}}$ utilise physical, biogeochemical and/or man-made tracers to guide them.

The first methods devised constitute so-called backcalculation methods (e.g. Brewer, 1978; Chen and Millero, 1979; see Sabine and Tanhua, 2010 for nomenclature). These methods start with measured dissolved inorganic carbon (DIC) concentration and then use oxygen, nutrient and alkalinity concentrations, together with a series of biogeochemical assumptions, to estimate the associated preformed DIC concentration, i.e. the concentration that this water parcel had when it was last in contact with the atmosphere. The assumptions used relate to biogeochemical processes including calcium carbonate precipitation and dissolution, and the production and remineralisation of organic material. In the second step, $\mathrm{C}_{\mathrm{ant}}$ is computed by subtracting from this preformed DIC an estimate of the preformed DIC in pre-industrial times, i.e. a time when atmospheric $\mathrm{CO}_{2}$ had been relatively constant for thousands of years (Indermühle et al., 1999). These methods, with some varying details, have been used in a number of studies for different locations, and for a range of different applications, including Chen and Pytkowicz (1979), Papaud and Poisson (1986), Goyet and
Brewer (1993), Tsunogai et al. (1993), Perez et al. (2002), Lo Monaco et al. (2005a) and Lo Monaco et al. (2005b). Although the biogeochemical back-calculation approach involves a substantial number of assumptions and methodological challenges, the most uncertain aspect is associated with the estimation of the preformed, pre-industrial DIC concentration. In the original work by Brewer (1978) and Chen and Millero (1979), they used waters from the deep ocean presumed to be free of anthropogenic $\mathrm{CO}_{2}$ and extrapolated them to all waters using a simple parameterization. This assumption, plus several others were heavily criticised (e.g. Broecker et al., 1985), resulting in these estimates not finding general acceptance.

This latter aspect of estimating the preformed, preindustrial DIC concentration was fundamentally improved upon by the development of the $\Delta \mathrm{C}^{*}$ method (Gruber et al., 1996), which separates this concentration into an equilibrium part, which can be computed with high accuracy, and a disequilibrium part, which reflects the fact that surface water $\mathrm{CO}_{2}$ is seldom in equilibrium with the atmosphere at the point when a water parcel becomes isolated from the airsea interface. In the $\Delta C^{*}$ method, this disequilibrium term is estimated separately for each isopycnal slab, using either deep water values or additional information about the age of the water parcel. This makes this method time-consuming, and also usually requires a basin-scale perspective. The $\Delta \mathrm{C}^{*}$ approach, initially developed using North Atlantic observations, has been modified for the Indian (Sabine et al., 1999) and Pacific (Sabine et al., 2002) basins and for the global ocean (Key et al., 2004). Subsequent work has both introduced improvements to the method (e.g., Gruber, 1998) and evaluated uncertainties with $\Delta C^{*}$ (Matsumoto and Gruber, 2005). It also formed the basis for the first global estimate of the oceanic uptake and distribution of anthropogenic $\mathrm{CO}_{2}$ in the ocean (Sabine et al., 2004), as well as provided data for an inverse estimate of the uptake flux of anthropogenic $\mathrm{CO}_{2}$ and its subsequent transport in the ocean interior (e.g. Gloor et al., 2003; Mikaloff-Fletcher et al., 2006).

Recently, an alternative back-calculation method was introduced by Touratier and Goyet (2004b), termed the TrOCA method, which takes its name from the Tracer combining Oxygen, inorganic Carbon and total Alkalinity (TrOCA). TrOCA was initially developed as a conservative tracer to aid the distinguishing of watermasses, that was complementary to other composite tracers such as $\Delta \mathrm{C}^{*}$ (Touratier and Goyet, 2004a). The TrOCA method has subsequently been used to quantify $\mathrm{C}_{\mathrm{ant}}$ in the Atlantic (Touratier and Goyet, 2004b; Touratier et al., 2005) Indian (Touratier et al., 2007; Alvarez et al., 2009) and Southern (Lo Monaco et al., 2005a; Lo Monaco et al., 2005b; Sandrini et al., 2007) oceans, and to infer regional air-sea fluxes of anthropogenic $\mathrm{CO}_{2}$ (Gerber et al., 2009). The key difference to the other back-calculation methods is that TrOCA proposes that the pre-industrial, preformed concentration can be estimated reliably with an empirical function with only four parameters. This results in the 
advantage that once the parameters of this empirical function are determined, $\mathrm{C}_{\mathrm{ant}}$ can be determined very quickly for any water parcel for which the necessary observations have been taken. However, no global estimate has been published to date.

Even more recently, an entirely independent method has been developed on the basis of the consideration that the uptake and subsequent transport of anthropogenic $\mathrm{CO}_{2}$ by the ocean is a purely physical process, i.e. it does not involve biology. Thus, the only information necessary to estimate anthropogenic $\mathrm{CO}_{2}$ in the ocean is knowledge about the time-dependent evolution of anthropogenic $\mathrm{CO}_{2}$ in the surface ocean, and the rate at which this surface boundary condition is transported and mixed into the ocean's interior. This is the basis for the Transient-time distribution (TTD) method developed by Waugh and Hall (e.g. Waugh et al., 2004), and later improved upon by Khatiwala et al. (2009). The TTD method and the $\Delta C^{*}$ method arrived at rather similar global (excluding Arctic and marginal seas) estimates of the anthropogenic $\mathrm{CO}_{2}$ inventory (106 $\pm 21 \mathrm{Pg} \mathrm{C}$ vs. $114 \pm 22$ for 1994; Sabine et al., 2004; Khatiwala et al., 2009), although with notable differences in the actual distribution, particularly with regard to the depth profiles.

Given the development of a large number of competing methods to estimate the amount and distribution of $\mathrm{C}_{\mathrm{ant}}$ in the ocean, it is highly desirable to know exactly the strengths and weaknesses of each method, and also have an estimate of the accuracy of the reconstructed $\mathrm{C}_{\mathrm{ant}}$ fields. Sabine and Tanhua (2010) compared the pros and cons of the different methods, but did not venture into making a full assessment. Studying $\mathrm{CO}_{2}$ exchange through the Strait of Gibraltar, Huertas et al. (2009) compared $\Delta C^{*}$ and TrOCA estimates of $\mathrm{C}_{\mathrm{ant}}$, and found large differences with TrOCA estimating increases with depth. Reasoning from Mediterranean circulation patterns and dissolved CFC concentrations, they concluded that the TrOCA parameter values optimised in Touratier et al. (2007) should be adapted for this location. Vázquez-Rodríguez et al. (2009) compared the results from five different methods for a few representative sections. They came to the conclusion that while most methods appear to produce similar results for the low- and mid-latitudes, large differences exist at high latitudes, particularly the Southern Ocean (see also Lo Monaco et al., 2005b). Since it is not possible to directly discern $\mathrm{C}_{\text {ant }}$ from natural DIC in observational data, it was not possible to determine which method is more accurate and why. As a result, these studies had to remain inconclusive.

An alternative approach to test the reconstruction methods for anthropogenic $\mathrm{CO}_{2}$ is to use synthetic data from an ocean carbon cycle model, for which the amount and distribution of $\mathrm{C}_{\text {ant }}$ is accurately known. Any difference in the $\mathrm{C}_{\mathrm{ant}}$ inferred from the synthetic data and the directly simulated results then reflects a bias in the reconstruction method. A strong advantage of this assessment approach is that even when the modeled fields providing the synthetic data differ from the observations, the approach still provides a good estimate of the accuracy of the reconstruction method, since the comparison is done in an internally consistent manner. So far, this method has only been applied to the $\Delta C^{*}$ method (Matsumoto and Gruber, 2005). These authors showed that this method tends to overestimate $\mathrm{C}_{\text {ant }}$ in central thermocline waters, but tends to underestimate $\mathrm{C}_{\text {ant }}$ in the deep ocean, with a likely positive bias of about $7 \%$.

Here, the TrOCA method is examined using synthetic data generated via this latter mode. But before assessing the accuracy of the TrOCA method, we review the method on a theoretical basis in order to put it into the context of prior work and more clearly understand the differences. In particular, we are interested in pointing out some of the inherent key assumptions that have been made in the development of the TrOCA method. Then, using the model, we assess the method quantitatively, and also investigate the regional and global applicability of the TrOCA parameterization.

The paper is organised as follows. First, the TrOCA method is introduced, with a focus on its key parameters and its calibration from observational data. The TrOCA method is then analysed from a theoretical standpoint, to illuminate its relationship with $\Delta C^{*}$ and the air-sea fluxes of $\mathrm{CO}_{2}$ and $\mathrm{O}_{2}$. Next, the OCCAM model used to provide the synthetic dataset is introduced, including its physical and biogeochemical representation of the ocean, and details of the simulation. The Results and Discussion section describes the application of the TrOCA method to the synthetic dataset. In the first instance, the default parameterisation of TrOCA is used with OCCAM output and observational data. Next, the TrOCA method's parameters are recalibrated using the synthetic data, and several sensitivity analyses assess its performance. Finally, the paper concludes with a summary of our findings and some suggestions for future progress.

\section{The TrOCA method}

\subsection{Overview}

This section provides an overview of the TrOCA method, and discusses the most important assumptions and implied consequences on a theoretical basis. The method described here is based upon the most recent version of the TrOCA method (Touratier et al., 2007), but see also the original formulation (Touratier and Goyet, 2004a) for a more comprehensive description.

The TrOCA tracer is derived from the Redfield relationships that occur between carbon, oxygen and key nutrients. Equation (1) shows an example of this stoichiometry for the processes of organic production (left to right) and remineralisation (right to left):

$$
\begin{array}{r}
106 \mathrm{CO}_{2}+16 \mathrm{NO}_{3}^{-}+\mathrm{HPO}_{4}^{2-}+122 \mathrm{H}_{2} \mathrm{O}+18 \mathrm{H}^{+} \rightleftharpoons \\
\left(\mathrm{C}_{106} \mathrm{H}_{263} \mathrm{O}_{110} \mathrm{~N}_{16} \mathrm{P}\right)+138 \mathrm{O}_{2}
\end{array}
$$


This equation can be rewritten to express the relationships between its coefficients:

$$
\begin{aligned}
& \psi_{\mathrm{C}} \mathrm{CO}_{2}+\psi_{\mathrm{N}} \mathrm{NO}_{3}^{-}+\psi_{\mathrm{P}} \mathrm{HPO}_{4}^{2-}+\psi_{\mathrm{H}_{2} \mathrm{O}} \mathrm{H}_{2} \mathrm{O}+\psi_{\mathrm{H}} \mathrm{H}^{+} \rightleftharpoons \\
& \quad\left[\mathrm{C}_{\left(\psi_{\mathrm{C}}\right)} \mathrm{H}_{\left(\psi_{\mathrm{P}}+2 \psi_{\mathrm{H}_{2} \mathrm{O}}+\psi_{\mathrm{H}}\right)} \mathrm{O}_{\left(2 \psi_{\mathrm{C}}+3 \psi_{\mathrm{N}}+4 \psi_{\mathrm{P}}+\psi_{\mathrm{H}_{2}} \mathrm{O}-2 \psi_{\mathrm{O}_{2}}\right)} \mathrm{N}_{\left(\psi_{\mathrm{N}}\right)} \mathrm{P}_{\left(\psi_{\mathrm{P}}\right)}\right] \\
& \quad+\psi_{\mathrm{O}_{2}} \mathrm{O}_{2}
\end{aligned}
$$

At depth, variations in the concentration of DIC are ascribed to respiration of organic material (the backward reaction above) and the dissolution of carbonate biominerals. Applying Eq. (2), and accounting for this dissolution of calcium carbonate (estimated from changes to alkalinity, $\mathrm{A}_{\mathrm{T}}$; Brewer, 1978), the biotically-driven change in the concentration of DIC at depth, $\Delta \mathrm{C}_{\mathrm{T}}$, is approximated as:

$\Delta \mathrm{C}_{\mathrm{T}}=\frac{\psi_{\mathrm{C}}}{\psi_{\mathrm{O}_{2}}} \cdot \Delta \mathrm{O}_{2}+\frac{1}{2} \cdot\left(\Delta \mathrm{A}_{\mathrm{T}}+\frac{\left(\psi_{\mathrm{H}}-\psi_{\mathrm{P}}\right)}{\psi_{\mathrm{O}_{2}}} \cdot \Delta \mathrm{O}_{2}\right)$

The above relationship between biotically induced changes in $\mathrm{C}_{\mathrm{T}}, \mathrm{O}_{2}$ and $\mathrm{A}_{\mathrm{T}}$ can be used to define an approximately conservative "Tracer combining Oxygen, inorganic Carbon and total Alkalinity" (TrOCA):

$\operatorname{TrOCA}=\mathrm{O}_{2}+a \cdot\left(\mathrm{C}_{\mathrm{T}}-\frac{\mathrm{A}_{\mathrm{T}}}{2}\right)$,

where:

$a=\frac{\psi_{\mathrm{O}_{2}}}{\psi_{C}+\frac{1}{2} \cdot\left(\psi_{\mathrm{H}}-\psi_{\mathrm{P}}\right)}$

In the absence of $\mathrm{C}_{\mathrm{ant}}$, the natural (=background) value of TrOCA, TrOCA ${ }^{0}$, is defined as a function of the natural (=background) concentrations of carbon, $\mathrm{C}_{\mathrm{T}}^{0}$, oxygen, $\mathrm{O}_{2}^{0}$, and alkalinity, $\mathrm{A}_{\mathrm{T}}^{0}$ :

$\operatorname{TrOCA}^{0}=\mathrm{O}_{2}^{0}+a \cdot\left(\mathrm{C}_{\mathrm{T}}^{0}-\frac{\mathrm{A}_{\mathrm{T}}^{0}}{2}\right)$

Using TrOCA and $\operatorname{TrOCA}^{0}$, and assuming that neither oxygen nor alkalinity fields are substantially perturbed by anthropogenic effects (which is not exactly correct in the case of oxygen; Manning and Keeling, 2006), $\mathrm{C}_{\mathrm{ant}}$ can then be estimated:

$\mathrm{C}_{\mathrm{ant}}^{\mathrm{TrOCA}}=\frac{\operatorname{TrOCA}-\operatorname{TrOCA}^{0}}{a}$

In the original definition of the TrOCA method, $\operatorname{TrOCA}^{0}$ was fitted as a function of potential temperature, $\theta$ (Touratier and Goyet, 2004a), but this was extended by Touratier et al. (2007) to include $A_{T}$. The fitting procedure requires datasets in which $\mathrm{C}_{\text {ant }}$ is known, and this is achieved here utilising watermass age information present in $\Delta{ }^{14} \mathrm{C}$ and CFC-11.

Firstly, $\Delta{ }^{14} \mathrm{C}$ is used to identify watermasses that are unambiguously free of $\mathrm{C}_{\mathrm{ant}}$. Waters with a value less than $175 \%$ are much older ( $>1000$ years) than the industrial era ( $\simeq 250$ years), so should contain no $C_{\text {ant }}$ (i.e. it is assumed that $\mathrm{C}_{\mathrm{ant}}=0$ ). The values of $\mathrm{C}_{\mathrm{T}}, \mathrm{A}_{\mathrm{T}}$ and $\mathrm{O}_{2}$ in these watermasses are used with Eqs. (4) and (5) to calculate TrOCA ${ }^{0}$.

Next, estimated atmospheric CFC-11 partial pressure (pptv) is back-calculated from ambient oceanic concentrations of CFC-11 (assuming oceanic saturation; Warner and Weiss, 1985), and used to identify waters in contact with the atmosphere at the time of peak atmospheric CFC-11 concentration (1992-1995; approximately 263-271 pptv). The values of $\theta, \mathrm{S}$ and $\mathrm{A}_{\mathrm{T}}$ in these watermasses are then used to calculate saturation $\mathrm{C}_{\mathrm{T}}$ concentrations for the corresponding atmospheric $p \mathrm{CO}_{2}, \mathrm{C}_{\mathrm{T}}^{\mathrm{p} 357}(1992-1995$; approximately $357 \mu \mathrm{atm}$ ), and for pre-industrial conditions, $\mathrm{C}_{\mathrm{T}}^{\mathrm{p} 280}$ (approximately $280 \mu \mathrm{atm}$ ). Although $\mathrm{C}_{\mathrm{T}}$ may not be at saturation concentration, this calculation instead assumes that local disequilibrium is the same under pre-industrial and anthropogenic transient conditions. The saturation concentrations are then used to estimate local $C_{\text {ant }}$ for the period 1992-1995:

$\mathrm{C}_{\text {ant92/95 }}^{\mathrm{TrOCA}}=\mathrm{C}_{\mathrm{T}}^{\mathrm{p} 357}-\mathrm{C}_{\mathrm{T}}^{\mathrm{p} 280}$

$\operatorname{TrOCA}^{0}$ can then be calculated for these watermasses using TrOCA from Eq. (4). The resulting $\operatorname{TrOCA}^{0}$ dataset is then fitted as an exponential function of $\theta$ and $\mathrm{A}_{\mathrm{T}}$ :

$\operatorname{TrOCA}^{0}=f \cdot \exp \left(b+c \cdot \theta+\frac{d}{\mathrm{~A}_{\mathrm{T}}^{2}}\right)$

The choice of this functional relationship with $\theta$ is based on its strong correlation with the TrOCA tracer, a relationship that was found to be fitted best with an exponential form (Touratier and Goyet, 2004b). The extension of this form to include $\mathrm{A}_{\mathrm{T}}$ was found to further improve it (Touratier et al., 2007). The equation shown above differs slightly from that described in Touratier et al. (2007), in that it includes an additional coefficient, $f=1 \mu \mathrm{mol} \mathrm{kg}{ }^{-1}$, to dimensionalise $\operatorname{TrOCA}^{0}$. Note that parameters $c$ and $d$ respectively have units of $\left({ }^{\circ} \mathrm{C}\right)^{-1}$ and $\left.(\mu \mathrm{mol} \mathrm{kg})^{-1}\right)^{2}$.

Combining Eqs. (8) and (9) creates the following expression:

$$
\begin{aligned}
\mathrm{C}_{\text {ant92/95 }}^{\text {TrOCA }} & =\frac{\operatorname{TrOCA}-\operatorname{TrOCA}^{0}}{a} \\
& =\frac{\mathrm{O}_{2}+a \cdot\left(\mathrm{C}_{\mathrm{T}}-\frac{\mathrm{A}_{\mathrm{T}}}{2}\right)-f \cdot \exp \left(b+c \cdot \theta+\frac{d}{\mathrm{~A}_{\mathrm{T}}^{2}}\right)}{a}
\end{aligned}
$$

Using appropriate observations sampled from the GLODAP world ocean database, Touratier et al. (2007) optimised the values of parameters $a, b, c$ and $d$. Parameter $a$ 's value (nominally 1.205 from Eqs. 1 and 5) was varied between 1.0 and 1.5, with the others optimised for each $a$. The best set of parameters obtained in this way was:

$$
\begin{aligned}
& a=1.279 \mathrm{~mol}(\mathrm{~mol})^{-1} \\
& b=7.511 \\
& c=-1.087 \times 10^{-2}\left({ }^{\circ} \mathrm{C}\right)^{-1}
\end{aligned}
$$




$$
\begin{aligned}
d & \left.=-7.81 \times 10^{5}(\mu \mathrm{mol} \mathrm{kg})^{-1}\right)^{2} \\
(f & \left.=1.0 \mu \mathrm{mol} \mathrm{kg}^{-1}\right)
\end{aligned}
$$

Touratier et al. (2007) then used these values to estimate $\mathrm{C}_{\mathrm{ant}}$ in the northern Indian Ocean using the following TrOCA expression:

$$
\begin{aligned}
\mathrm{C}_{\mathrm{ant}}^{\mathrm{TrOCA}} & =\frac{\mathrm{O}_{2}+1.279\left[\mathrm{C}_{\mathrm{T}}-\frac{\mathrm{A}_{\mathrm{T}}}{2}\right]}{1.279} \\
- & \frac{1.0 \cdot \exp \left(7.511-\left(1.087 \times 10^{-2}\right) \theta+\frac{-7.81 \times 10^{5}}{\mathrm{~A}_{\mathrm{T}}^{2}}\right)}{1.279}
\end{aligned}
$$

Where concentrations are expressed in $\mu \mathrm{mol} \mathrm{kg}{ }^{-1}$, and $\theta$ is in ${ }^{\circ} \mathrm{C}$.

\subsection{TrOCA and $\Delta \mathrm{C}^{*}$}

Though Touratier and Goyet presented the TrOCA method as an alternative to other techniques such as $\Delta \mathrm{C}^{*}$, by rearranging the equations above, it can be shown that the TrOCA tracer is actually a rescaled version of the tracer $C^{*}$ introduced by Gruber et al. (1996). Equation (11) of the latter defines $\mathrm{C}^{*}$ as follows:

$\mathrm{C}^{*}=\mathrm{C}_{\mathrm{T}}-r_{\mathrm{C}: \mathrm{O}_{2}} \cdot \mathrm{O}_{2}-\frac{1}{2} \cdot\left(\mathrm{A}_{\mathrm{T}}+r_{\mathrm{N}: \mathrm{O}_{2}} \cdot \mathrm{O}_{2}\right)$

This expression can be rearranged to group the terms relating to oxygen together:

$\mathrm{C}^{*}=\mathrm{C}_{\mathrm{T}}-\left(r_{\mathrm{C}: \mathrm{O}_{2}}+\frac{1}{2} \cdot r_{\mathrm{N}: \mathrm{O}_{2}}\right) \cdot \mathrm{O}_{2}-\frac{1}{2} \cdot \mathrm{A}_{\mathrm{T}}$

Dividing through by the oxygen factor yields:

$\frac{\mathrm{C}^{*}}{\left(r_{\mathrm{C}: \mathrm{O}_{2}}+\frac{1}{2} \cdot r_{\mathrm{N}: \mathrm{O}_{2}}\right)}=-\mathrm{O}_{2}+\frac{\mathrm{C}_{\mathrm{T}}-\frac{1}{2} \cdot \mathrm{A}_{\mathrm{T}}}{\left(r_{\mathrm{C}: \mathrm{O}_{2}}+\frac{1}{2} \cdot r_{\mathrm{N}: \mathrm{O}_{2}}\right)}$

In the equations above, $r_{\mathrm{C}: \mathrm{O}_{2}}$ is defined as negative (i.e. 117:-170) whereas Touratier and Goyet (2004a) define their corresponding ratio, $R_{\mathrm{C}: \mathrm{O}_{2}}$, as being positive (i.e. 123:165). Thus, $R_{\mathrm{C}: \mathrm{O}_{2}}=-r_{\mathrm{C}: \mathrm{O}_{2}}$ and $R_{\mathrm{N}: \mathrm{O}_{2}}=-r_{\mathrm{N}: \mathrm{O}_{2}}$. Substituting in these positive stoichiometric ratios yields:

$$
\frac{\mathrm{C}^{*}}{\left(R_{\mathrm{C}: \mathrm{O}_{2}}+\frac{1}{2} \cdot R_{\mathrm{N}: \mathrm{O}_{2}}\right)}=\mathrm{O}_{2}+\frac{\mathrm{C}_{\mathrm{T}}-\frac{1}{2} \cdot \mathrm{A}_{\mathrm{T}}}{\left(R_{\mathrm{C}: \mathrm{O}_{2}}+\frac{1}{2} \cdot R_{\mathrm{N}: \mathrm{O}_{2}}\right)}
$$

Comparing this with Eq. (4) above, this shows:

$\operatorname{TrOCA}=\frac{\mathrm{C}^{*}}{\left(R_{\mathrm{C}: \mathrm{O}_{2}}+\frac{1}{2} \cdot R_{\mathrm{N}: \mathrm{O}_{2}}\right)}$

Then, using the Touratier et al. (2007) definition of parameter $a$ as:

$a=\frac{1}{R_{\mathrm{C}: \mathrm{O}_{2}}+\frac{1}{2} \cdot R_{\mathrm{N}: \mathrm{O}_{2}}}$
This finally yields:

$\operatorname{TrOCA}=a \cdot \mathrm{C}^{*}$

This equivalance of TrOCA and $\mathrm{C}^{*}$ is further evident when Eq. (7) calculates $\mathrm{C}_{\mathrm{ant}}$ :

$$
\begin{aligned}
\mathrm{C}_{\mathrm{ant}}^{\text {TrOCA }} & =\frac{\operatorname{TrOCA}-\operatorname{TrOCA}^{0}}{a} \\
& =\mathrm{C}^{*}-\mathrm{C}_{\mathrm{pi}}^{*}
\end{aligned}
$$

Where $\mathrm{C}_{\mathrm{pi}}^{*}$ is $\mathrm{C}^{*}$ estimated for pre-industrial conditions. This equation directly corresponds to Eq. (13) in Gruber et al. (1996). This derivation identifies the TrOCA method as a classical back-calculation approach that corrects observed $\mathrm{C}_{\mathrm{T}}$ for the influence of biology and then subtracts the preindustrial preformed value.

\section{3 $\operatorname{TrOCA}^{0}$ and the air-sea fluxes of $\mathrm{CO}_{2}$ and $\mathrm{O}_{2}$}

As with all back-calculation techniques, the biggest challenge is the estimation of the preformed, pre-industrial value of the tracer under consideration. Touratier and Goyet (2004a) essentially follow Chen and Millero (1979) and Chen and Pytkowicz (1979) in using observations from (radiocarbon-estimated) old watermasses as a source of $\mathrm{C}_{\mathrm{ant}^{-}}{ }^{-}$ free data to which a relatively simple parameterisation is fitted. This parameterisation takes an a priori form based primarily on potential temperature (Touratier and Goyet, 2004a), with a limited dependence on alkalinity (Touratier et al., 2007). The resulting function is then applied to all observations to separate $\mathrm{C}_{\mathrm{ant}}$ from $\mathrm{C}_{\mathrm{T}}$. However, there are process-based considerations that suggest that the tracer relationships are not as straightforward as assumed.

In considering the distribution of $\mathrm{C}^{*}$, it is possible to linearly deconvolute this tracer into $\Delta \mathrm{C}_{\text {gasex }}$ and $\mathrm{O}_{2}^{*}$ components (notation as per Gruber et al., 2001; and Gruber and Sarmiento, 2002). Variations in $\Delta \mathrm{C}_{\text {gasex }}$ primarily reflect the air-sea exchange of $\mathrm{CO}_{2}$, while variations in $\mathrm{O}_{2}^{*}$ primarily reflect the air-sea exchange of $\mathrm{O}_{2}$. Because of the equivalence of $\mathrm{C}^{*}$ and TrOCA (as per Eq. 18), this means that variations in TrOCA reflect the combined effects of $\mathrm{CO}_{2}$ and $\mathrm{O}_{2}$ air-sea exchange (see also Appendix C). Fluxes of either gas into the ocean increase TrOCA, while fluxes out of the ocean decrease it.

Fitting $\mathrm{TrOCA}^{0}$ to tracer data from two age (i.e. depth) horizons (defined by ${ }^{14} \mathrm{C}$ and $\mathrm{CFC}-11$ criteria), and then applying this fit across watermasses from cold deep waters to warm surface waters assumes that the air-sea exchange signals of $\mathrm{CO}_{2}$ and $\mathrm{O}_{2}$ are the same regardless of temperature (since alkalinity acts as a small, secondary factor). In the case of $\mathrm{O}_{2}^{*}$, its gas exchange signal has a strong relationship with temperature (Gruber et al., 2001). However, biological processes can additionally modify $\mathrm{O}_{2}$ fluxes, and air-sea exchange of heat is faster than for $\mathrm{O}_{2}$, both of which act to create additional structure in $\mathrm{O}_{2}^{*}$. In strong contrast, there 
exists no discernible relationship between temperature and the natural $\mathrm{CO}_{2}$ air-sea exchange component, $\Delta \mathrm{C}_{\text {gasex }}$, primarily because the effects of biological processes and heat fluxes tend to act in opposition on the air-sea exchange of $\mathrm{CO}_{2}$. These differences between $\mathrm{O}_{2}^{*}$ and $\Delta \mathrm{C}_{\text {gasex }}$ are illustrated in Fig. 1.

These factors mean that biological processes act to decouple the air-sea exchanges of $\mathrm{CO}_{2}$ and $\mathrm{O}_{2}$ from those associated with heat fluxes. Further, since biological activity is not tightly correlated with heat fluxes (for a number of reasons), this decoupling is different over the range of oceanographic regions. Thus, as $\operatorname{TrOCA}^{0}$ is parameterised both as a fixed relationship between gas and heat fluxes, and using a limited set of observations, it is unlikely to successfully hold across all regions. We test this in the following sections using results from an ocean carbon cycle model.

\section{Assessing TrOCA with a model}

The strategy we employ to assess TrOCA is to undertake simulations with an ocean carbon cycle model and then use the results from these runs as synthetic data for applying the TrOCA method. More specifically, we use results from a simulation that runs from 1864 to 2004 and that includes two different DIC tracers. The first one is exposed to the historically-observed rise in atmospheric $\mathrm{CO}_{2}$, and one for which the atmospheric boundary conditions remains that of pre-industrial time. The difference between these two tracers directly corresponds to $\mathrm{C}_{\text {ant }}$. Model fields of various tracers from the second, historical simulation are then sampled as an observational program would, and then stored for subsequent analysis by the TrOCA method. The results from the application of the TrOCA method to these synthetic data are then compared to the "true" field of $\mathrm{C}_{\text {ant }}$ determined from the difference of the two DIC tracers. Any difference between these two $\mathrm{C}_{\mathrm{ant}}$ fields must then reflect a bias in the TrOCA method.

We next describe first the model and the simulations, and then present and discuss the results from this model-based assessment.

\subsection{Ocean carbon cycle model}

We use OCCAM, a global, medium-resolution, primitive equation, finite difference ocean general circulation model to which we have coupled a biogeochemical model that includes a full description of the ocean carbon cycle.

OCCAM's vertical resolution is 66 levels (with thickness ranging from $5 \mathrm{~m}$ at the surface to $200 \mathrm{~m}$ at the abyssal seafloor), with a horizontal resolution of typically $1^{\circ}$ (a highresolution version is described in Marsh et al., 2005). A distinctive feature of OCCAM is its organisation onto two horizontal grids to avoid grid-spacing difficulties close to the North Pole singularity. Grid 1 encompasses the Pacific, Indian, Southern and South Atlantic oceans, while grid 2 cov- ers the North Atlantic and Arctic sea. This arrangement brings the two grids into alignment along the equator in the Atlantic basin. A simple channel model connects the two grids at the Bering Straits. The prognostic variables of OCCAM's physical component are potential temperature, salinity, velocity and free-surface height.

OCCAM includes an elastic-viscous-plastic sea-ice scheme, a $K$-profile parameterisation (KPP) mixed layer and Gent-McWilliams eddy parameterisation. Advection is 4th order accurate (a modified split-quick scheme), and the model employs fractional bottom gridboxes to allow a more realistic representation of bathymetry. OCCAM is timeintegrated using a forward leapfrog scheme with a timestep of $1 \mathrm{~h}$. Surface fluxes of heat, freshwater and momentum are not specified directly, but are calculated using empirical formulae and NCEP-derived basic atmospheric boundary layer quantities (Large and Yeager, 2004). Local daylength is calculated and used in conjunction with daily-averaged irradiance to reconstruct a realistic diel cycle. To compensate for deficiencies in the freshwater flux balance, surface salinity is relaxed towards monthly observations.

Biogeochemical cycles of nitrogen, carbon, oxygen and alkalinity are embedded within OCCAM. These cycles are driven primarily by a nitrogen-based nutrient-phytoplanktonzooplankton-detritus (NPZD) model (Oschlies, 2001) that has been coupled to the other elemental cycles (Sinha and Yool, 2006; Yool and Sinha, 2006; following Anderson and Pondaven, 2003). The adaptations necessary for this coupling include: $\mathrm{C}: \mathrm{N}: \mathrm{O}_{2}$ Redfield relationships for phytoplankton and zooplankton (Anderson, 1995; Palmer and Totterdell, 2001); a separate state variable for detrital carbon (Anderson and Pondaven, 2003); a simplified scheme for biogenic calcium carbonate production and dissolution (Najjar and Orr, 1999; Najjar et al., 2007); and subroutines to calculate the air-sea exchange of $\mathrm{CO}_{2}$ and oxygen (Orr et al., 1999b; Najjar and Orr, 1999). The model also incorporates a variable detrital sinking velocity (Schmittner et al., 2005).

The resulting biogeochemical model component is comprised of eight tracer variables that are entirely passive and distributed throughout the model domain. A unified set of equations governs the biogeochemical tendencies throughout the water column, and these are described in Appendix A. Minor variants of this ecosystem model have previously been used within the OCCAM GCM in a number of unrelated studies, including Yool et al. (2007), Glessmer et al. (2008) and Yool et al. (2009).

In addition to the main biogeochemical tracers, OCCAM includes a series of natural, artificial and idealised tracers, including the radioisotope ${ }^{14} \mathrm{C}$, haloalkanes and numerical ventilation tracers. ${ }^{14} \mathrm{C}$ is modelled using the protocols defined by the OCMIP-2 project (Orr et al., 1999b), and is forced by the time-history of atmospheric ${ }^{14} \mathrm{C}$ (including both the Suess Effect and twentieth century nuclear tests). Modelled haloalkanes include CFC-11, CFC-12, CFC-113 and carbon tetrachloride $\left(\mathrm{CCl}_{4}\right)$, and these are forced by 

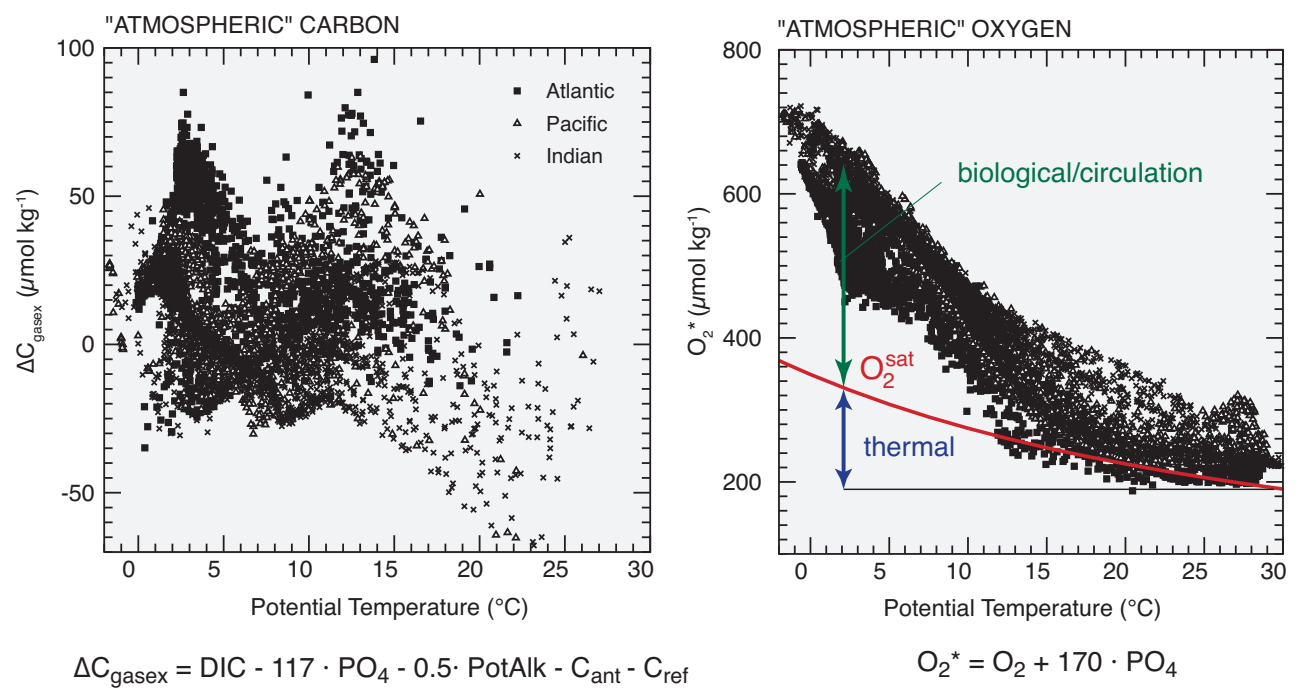

Fig. 1. Plots of $\Delta \mathrm{C}_{\text {gasex }}$ (left) and $\mathrm{O}_{2}^{*}$ (right) versus potential temperature for representative data from the global ocean. Data are taken from WOCE cruises A16, P16, and I9I8. See Gruber and Sarmiento (2002) and Gruber et al. (2001) for detailed discussions about $\Delta \mathrm{C}_{\mathrm{gasex}}$ and $\mathrm{O}_{2}^{*}$.

atmospheric time-histories from 1910 (when $\mathrm{CCl}_{4}$ first appears in the atmosphere; Walker et al., 2000). Air-sea exchange of haloalkanes uses the protocols defined by the OCMIP-2 project (Warner and Weiss, 1985; Zheng et al., 1998; Orr et al., 1999a). The idealised ventilation tracer ages one day per day throughout the model domain, but is destroyed at the ocean's surface.

\subsection{Simulation}

The OCCAM configuration described above was initialised from rest with tracer fields from the World Ocean Atlas 2001 (potential temperature, salinity, nitrate, oxygen; Conkright et al., 2002) and GLODAP (pre-industrial carbon, alkalinity, ${ }^{14} \mathrm{C}$; Key et al., 2004) climatologies. Biological tracers (phytoplankton, zooplankton, detritus) were initialised to arbitrary small values. CFC and ventilation tracer fields were initialised to zero.

The model was then run forward in time, with surface boundary conditions from a high resolution spatial and temporal dataset for the period January 1958 to December 2004 inclusive, using the unCorrected Interannual Forcing dataset (unCIAF; Large and Yeager, 2004). Upon reaching the end of this period, the model-state was "recycled" to 1958, i.e. the model's spin-up cycles made repeated use of this period. It was assumed that the climatic effects of $\mathrm{CO}_{2}$ on model forcing fields are relatively small during the period 19582004, so that this high quality forcing data can be used for periods pre-1958. Although this approach does tend to warm the ocean, in practice this trend is small (Yool and Sinha, 2006).
After an initial physical spin-up cycle (using surface forcing data from 1958-2004; see above), the simulation underwent three further forcing cycles during which the timehistory of atmospheric $\mathrm{CO}_{2}$ (and $\Delta^{14} \mathrm{C}$ ) from 1864 to 2004 was applied. In the final 5 years of the spin-up cycle, the average air-to-sea $\mathrm{CO}_{2}$ flux was $0.139 \mathrm{Pg} \mathrm{C}^{-1}$. As noted earlier, to account for this drift, a parallel "pre-industrial" DIC tracer was run alongside that exposed to the anthropogenic $\mathrm{CO}_{2}$ transient, to act as a control and to permit the separation of natural and anthropogenic carbon. Following a similar approach to that of Cox et al. (2000), this control experienced a constant atmospheric $p \mathrm{CO}_{2}$ of $288.4 \mu \mathrm{atm}$, that of the atmosphere at 1864 . This concentration is higher than the generally assumed pre-industrial value ( $278 \mu \mathrm{atm})$, but has the advantage of decreasing simulation duration by 100 years. This slightly decreases the total amount of anthropogenic $\mathrm{CO}_{2} \mathrm{ex}-$ pected in the ocean relative to a simulation that had extended over the full anthropogenic transient since the mid-18th century (see Appendix B). However, this has no impact for our evaluation of the TrOCA method, since the model-generated synthetic data are used to calibrate the method as well as test it. Atmospheric concentrations of haloalkanes increased according to their relevant time-histories from 1910.

Appendix B describes the validation of the OCCAM simulation for properties relevant to biogeochemistry and the carbon cycle.

\subsection{TrOCA and OCCAM}

To examine the skill of the TrOCA method in distinguishing $\mathrm{C}_{\mathrm{ant}}$ from background DIC, the method is used in a number of different ways to estimate $\mathrm{C}_{\mathrm{ant}}$ from OCCAM's simulation 

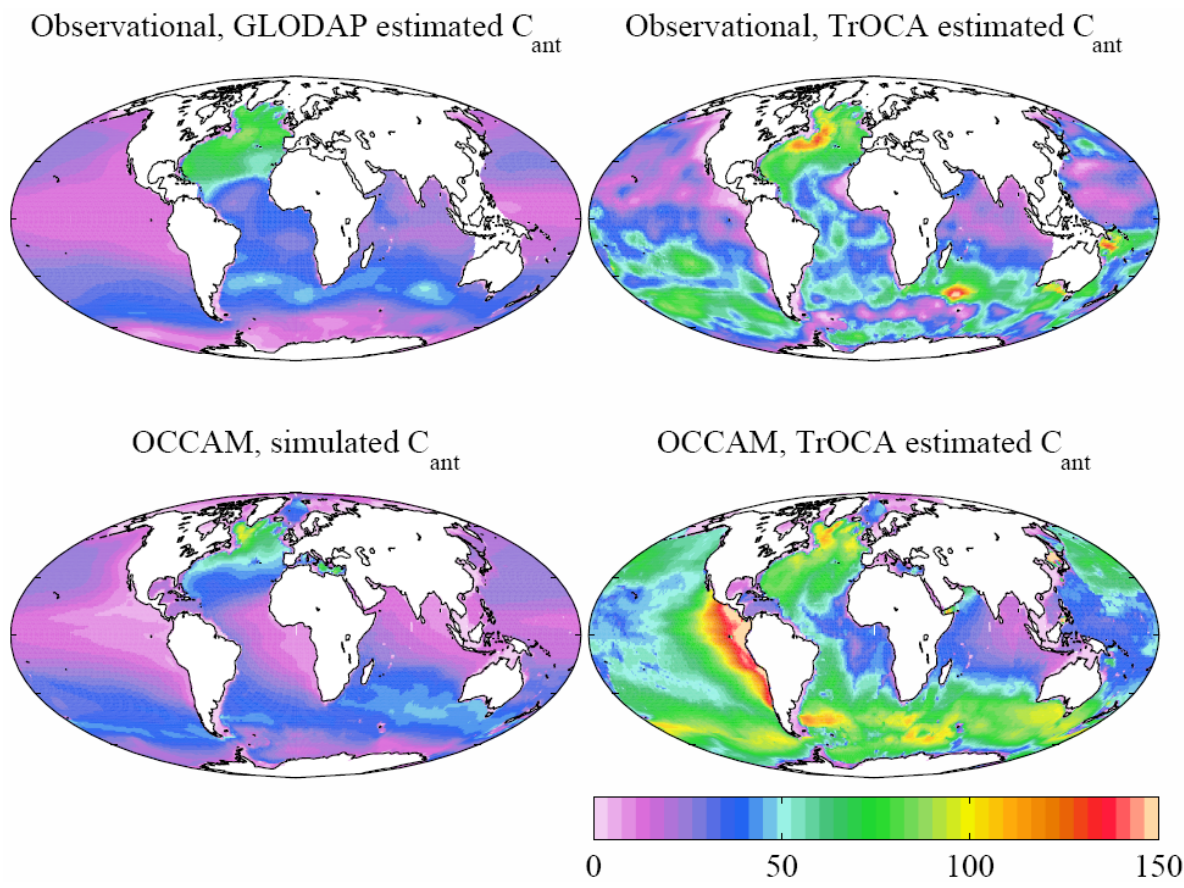

Fig. 2. Comparison of vertically-integrated $C_{\text {ant }}$ between observational (GLODAP-estimated; top left) and OCCAM simulated (bottom left) $\mathrm{C}_{\text {ant }}$ fields and those estimated by default TrOCA (top/bottom right). The observational field is that estimated by GLODAP (Key et al., 2004), and the corresponding TrOCA estimate is based on World Ocean Atlas (Conkright et al., 2002) and GLODAP (Key et al., 2004) climatology fields. Integrals are in $\mathrm{mol} \mathrm{m}^{-2}$. Note that negative values of estimated $\mathrm{C}_{\text {ant }}$ are set to zero before integration.

of the industrial period. Since the simulation includes a preindustrial DIC tracer, it is possible to separate natural and anthropogenic signals in modelled DIC, and to directly assess TrOCA's skill.

Firstly, reflecting the use of globally-distributed observations in the optimisation of the TrOCA method described in Touratier et al. (2007), the default parameterisation of TrOCA is used together with output from OCCAM and the World Ocean Atlas and GLODAP climatologies to estimate $\mathrm{C}_{\mathrm{ant}}$ at the global scale.

Next, given that the biogeochemical model used here does not fully represent the complexity of real world biogeochemistry, it is likely that the TrOCA parameters derived from field observations are not optimal for use with our model. To this end, the TrOCA method itself is re-optimised, using output from OCCAM as input to the calibration procedure described in Touratier et al. (2007). This calibration is performed using both global, basin and regional scale subsets of the model output in order to estimate the robustness and wider utility of the optimised variants of the TrOCA method.

The skill of the resulting variants is assessed in the context of assumptions underlying the TrOCA method. This assessment takes the form of a series of further experiments to examine aspects of TrOCA such as the assumption of constant air-sea disequilibrium of $\mathrm{CO}_{2}$ under pre-industrial and present day atmospheres, and the use of a heuristic function, Eq. (9), to approximate $\operatorname{TrOCA}^{0}$.

\section{Results and discussion}

\subsection{Default TrOCA}

The initial examination of TrOCA used the default values of its parameters determined by Touratier et al. (2007; see Eq. 11). These values were obtained by optimising the TrOCA method with observations from the GLODAP world ocean database. Here we applied the resulting TrOCA method to both observational data from global climatology datasets and to the synthetic data from OCCAM to estimate $\mathrm{C}_{\mathrm{ant}}$ taken up by the ocean during the industrial era. Fields of observational data were taken from the GLODAP (Key et al., 2004; DIC and alkalinity) and World Ocean Atlas (Conkright et al., 2002; potential temperature, salinity and oxygen) global climatology datasets.

Figure 2 shows the global distribution of $\mathrm{C}_{\mathrm{ant}}$ estimated for four instances: the GLODAP estimate based on the $\Delta \mathrm{C}^{*}$ method; the application of default TrOCA to the observational datasets; that simulated by OCCAM; and the application of default TrOCA to OCCAM's synthetic dataset. In each case $C_{a n t}$ is vertically integrated with only positive concentrations considered (negative $\mathrm{C}_{\text {ant }}$ concentrations occur with $\operatorname{TrOCA}$ and $\Delta \mathrm{C}^{*}$, but are ignored here).

The global $\mathrm{C}_{\text {ant }}$ total estimated by $\Delta \mathrm{C}^{*}$ from the GLODAP dataset is $104.0 \mathrm{PgC}$. The $\mathrm{C}_{\text {ant }}$ inventory is highest in the North Atlantic Ocean and Southern Ocean where deep 
water is formed and absorbed $\mathrm{C}_{\mathrm{ant}}$ is transferred to the ocean interior. The inventory is much lower at equatorial latitudes and in the North Pacific Ocean, regions where deep water is not directly ventilated. The corresponding TrOCA estimate is significantly higher at $155.6 \mathrm{Pg} \mathrm{C}(+50 \%)$, although its distribution largely follows that of the $\Delta C^{*}$ estimate (an exception being the seasonal sea-ice zone around Antarctica).

In contrast, while OCCAM simulates a distribution and quantity of $\mathrm{C}_{\text {ant }}$ very similar to that of the $\Delta \mathrm{C}^{*}$ estimate (103.1 Pg C; $-1 \%$ ), the default TrOCA method estimates 238.0 Pg C when supplied fields from the synthetic dataset. While these totals indicate a large discrepancy between $\mathrm{C}_{\mathrm{ant}}$ simulated and that estimated, the default TrOCA method does, at least on a qualitative basis, correctly identify many regions of high (e.g. northern Atlantic Ocean; Southern Ocean) and low (e.g. Indian Ocean; Arctic Sea; equatorial Atlantic Ocean) $\mathrm{C}_{\text {ant }}$ accumulation. However, on a quantitative basis, the agreement is poor, with large overestimations in most regions where $\mathrm{C}_{\text {ant }}$ is identified (typically of order $50 \mathrm{mmol} \mathrm{m}^{-3}$ ). In the case of $\mathrm{C}_{\mathrm{ant}}$ in the Pacific Ocean, TrOCA's performance is particularly poor, both qualitatively and quantitatively, with the almost $\mathrm{C}_{\text {ant }}$-free equatorial region instead being evaluated as the most $\mathrm{C}_{\mathrm{ant}}$-rich region in the world.

Figure 3 shows the corresponding vertical profiles of $\mathrm{C}_{\text {ant }}$. $\Delta C^{*}$ and simulated OCCAM $C_{a n t}$ profiles show the best agreement, especially below $200 \mathrm{~m}$. The default TrOCA estimate based on observational fields generally follows these, although it exhibits an anomalous midwater peak $(100 \mathrm{~m})$, and consistently higher deeper water concentrations (2$3 \mathrm{mmol} \mathrm{m}^{-3}$ ). The TrOCA estimate based on OCCAM fields is the least congruent, with a deep $(500 \mathrm{~m})$ peak, and generally increasing (if still low) $\mathrm{C}_{\mathrm{ant}}$ concentrations below $2000 \mathrm{~m}$.

The foregoing disagreement between OCCAM simulated $\mathrm{C}_{\mathrm{ant}}$ and that estimated by the default TrOCA is unsurprising. As with all such models, OCCAM's biogeochemistry is a truncated and simplified representation of the real ocean systems that the TrOCA method assumes. For instance, OCCAM utilises an extremely simple submodel of calcium carbonate production and dissolution that ignores known processes including saturation-dependent dissolution (e.g., Orr et al., 2005) and ballasted sinking (e.g., Armstrong et al., 2002). As a result, OCCAM's biogeochemical fields are liable to systematically differ from those of the real ocean on which default TrOCA was optimised. For these reasons it is a much fairer comparison if the TrOCA parameters were obtained from an optimization using model output.

As a practical sidenote for both observational scientists and modellers, the TrOCA method is sensitive to particular changes in the input variables, and when using it care should be taken to ensure the correct form and units of these variables are used. For example: replacing potential temperature, $\theta$, with in situ temperature, $T$, increases estimated $\mathrm{C}_{\mathrm{ant}}$ in the GLODAP data set to $182.1 \mathrm{Pg} \mathrm{C}(+17 \%)$; substituting a con-

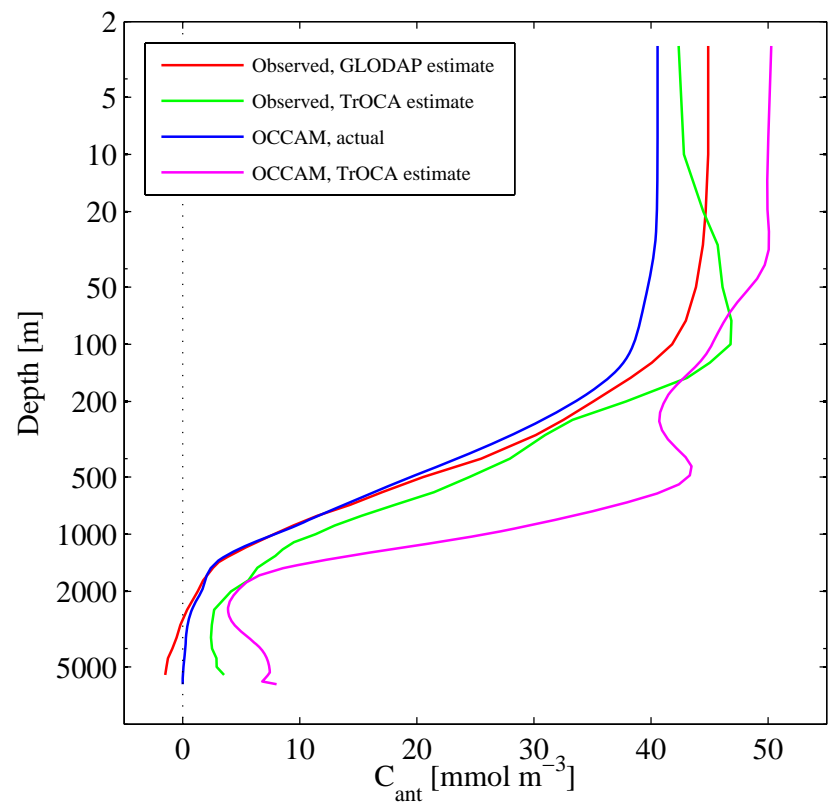

Fig. 3. Globally averaged vertical profiles of observationally-driven GLODAP (red) and default TrOCA (green) estimates of $\mathrm{C}_{\mathrm{ant}}$, together with OCCAM simulated $\mathrm{C}_{\text {ant }}$ (blue) and default TrOCA's corresponding estimate (magenta). Depth is shown on a logarithmic scale to more clearly separate $\mathrm{C}_{\text {ant }}$ concentrations in near-surface waters. Note that the GLODAP and TrOCA fields of estimated $\mathrm{C}_{\mathrm{ant}}$ contain small negative values at depth. These values are uncorrected for the profiles shown.

stant seawater density $\left(1.026 \mathrm{~kg} \mathrm{l}^{-1}\right)$ increases estimated $\mathrm{C}_{\mathrm{ant}}$ to $170.5 \mathrm{Pg} \mathrm{C}(+10 \%)$. Introducing $\pm 1 \%$ offsets to the biogeochemical tracers provides an indication of the sensitivity of the TrOCA method's $\mathrm{C}_{\text {ant }}$ estimates to measurement accuracy: DIC, 41.7-483.8 Pg C; alkalinity, 59.7-373.2 Pg C; oxygen, $140.0-172.2 \mathrm{Pg} \mathrm{C}$.

\subsection{Optimising $\operatorname{TrOCA}^{0}$ variants}

As described above, physical and biogeochemical aspects of the OCCAM simulation used here may prevent the successful application of the default TrOCA method. In this section, the optimisation approach used by Touratier et al. (2007) to tune the TrOCA method using observational data has been applied to output from the OCCAM simulation to "custom-tune" TrOCA variants. This approach aims to examine the role of different domains on the results of the TrOCA method, and to decrease the importance of particular details of OCCAM's simulated hydrography and biogeochemistry.

To examine the importance of domain size on the applicability of optimised instances of the TrOCA method, OCCAM output was divided into idealised regions at three different scales: "Global" includes the full OCCAM domain (1 region); "Basin" divides the World Ocean into Atlantic, 

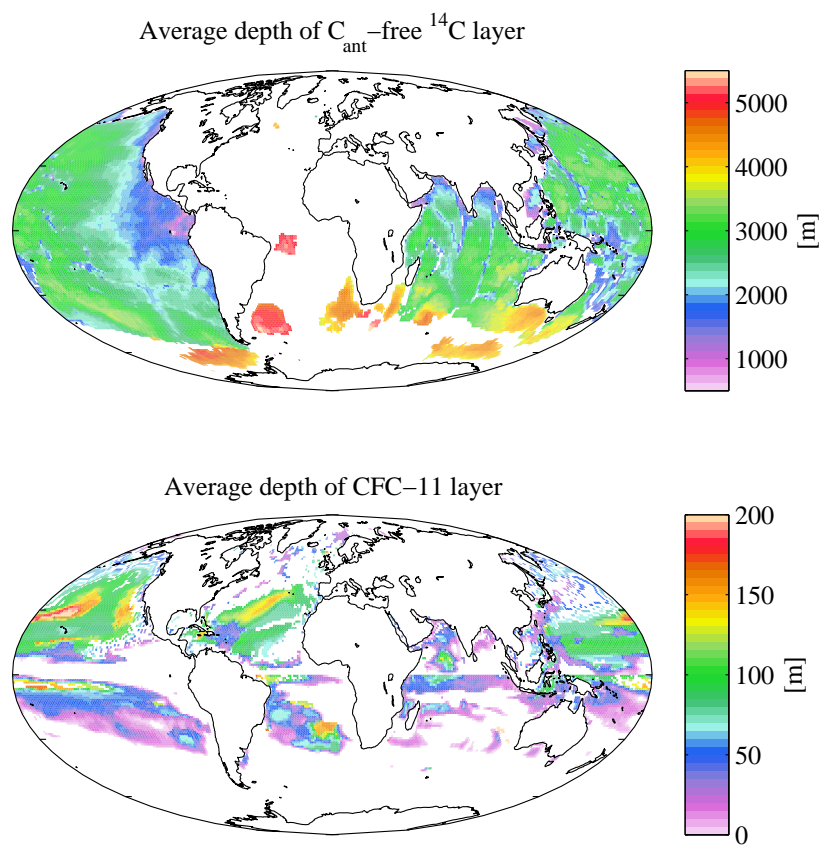

Fig. 4. Average depth of OCCAM grid cells from which tracer output is pooled for TrOCA optimisation. The upper panel shows the data pool (ostensibly $\mathrm{C}_{\text {ant }}$-free) derived from ${ }^{14} \mathrm{C}$ distribution. The lower panel shows the data pool (ostensibly $\mathrm{C}_{\text {ant }}$ contaminated) derived from CFC-11 distribution. The weak discontinuity between the northern and Southern Hemispheres is due to the use of slightly different CFC-11 criteria in these regions. This is because CFC-11 atmospheric time history is slightly lagged in the southern hemisphere. Depth in $\mathrm{m}$.

Pacific, Indian and Southern oceans (4 regions); "Latitudinal" divides the basins into $30^{\circ}$ bands, $90^{\circ} \mathrm{S} \rightarrow 60^{\circ} \mathrm{S}, 60^{\circ} \mathrm{S}$ $\rightarrow 30^{\circ} \mathrm{S}, 30^{\circ} \mathrm{S} \rightarrow 0^{\circ} \mathrm{N}, 0^{\circ} \mathrm{N} \rightarrow 30^{\circ} \mathrm{N}, 30^{\circ} \mathrm{N} \rightarrow 60^{\circ} \mathrm{N}$ and $60^{\circ} \mathrm{N} \rightarrow 90^{\circ} \mathrm{N}$. Optimisations were undertaken for all of the above, with their performance assessed both within a particular domain and at the global domain.

For each domain, appropriate OCCAM output (potential temperature, oxygen, alkalinity and DIC) was pooled from locations that satisfied either the radiocarbon $\left(\Delta^{14} \mathrm{C}<-175 \%\right.$ ) or CFC-11 (263-271 pptv) criteria. Figure 4 shows the horizontal distribution and average depth of the resulting $\Delta^{14} \mathrm{C}$ and CFC-11 layers. The $\Delta^{14} \mathrm{C}$ criterion selects very old watermasses, so is confined to deep water in the Pacific and Indian oceans, and small pockets of very deep water in the well-ventilated Atlantic and Southern oceans. In contrast, the CFC-11 criterion instead selects very young watermasses close to the ocean's surface. For the time period selected (end of northern summer), these waters are generally noticeably deeper in the water column in the Northern Hemisphere than in the south. Regions with strong mixing, such as the high latitudes and upwelling zones, do not have a strong CFC-11 signal to identify appropriate watermasses.

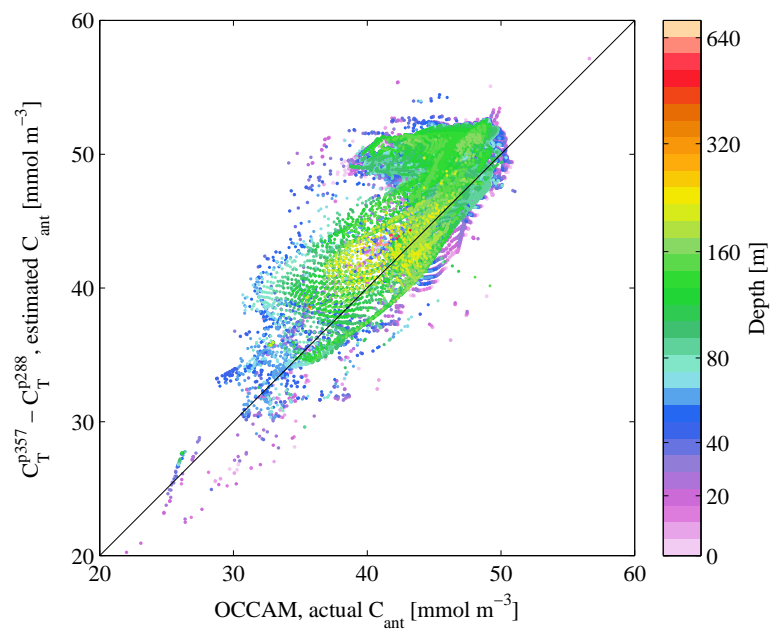

Fig. 5. A comparison of estimated $C_{a n t}\left(C_{T}^{p 357}-C_{T}^{p 288}\right)$ with OCCAM actual $\mathrm{C}_{\mathrm{ant}}$ for the CFC-11 waters identified in Figure 4. Colour denotes the depth from which the sample is drawn. The solid line indicates the 1:1 relationship. Concentrations in $\mathrm{mmol} \mathrm{m}^{-3}$.

Estimated $\mathrm{C}_{\mathrm{ant}}$ was calculated for the CFC-11 locations according to Eq. (8) using the same carbonate chemistry equations as used by OCCAM, and assuming $\mathrm{CO}_{2}$ saturation under the model's "pre-industrial" (288.4 $\mu \mathrm{atm})$ and 1995 $(357.4 \mu \mathrm{atm})$ atmospheric concentrations. Figure 5 shows the comparison between $\mathrm{C}_{\text {ant }}$ estimated this way and actual, OCCAM-simulated $\mathrm{C}_{\text {ant }}$. As expected from the relatively slow equilibriation time of $\mathrm{CO}_{2}$ with seawater (e.g. Matsumoto and Gruber, 2005; see later), estimated $\mathrm{C}_{\mathrm{ant}}$ is slightly (RMS error $=3.64 \mathrm{mmol} \mathrm{m}^{-3}$ ) greater than actual $\mathrm{C}_{\mathrm{ant}}$, although the discrepancy generally decreases with depth (i.e. values at greater depth approach the 1:1 line more closely). $\mathrm{C}_{\text {ant }}$ in locations satisfying the radiocarbon criterion was assumed to be at zero concentration. The resulting fields were used together with Eq. (10) to optimise the TrOCA method by minimising RMS error (using the fminsearch algorithm of MATLAB; Lagarias et al., 1998).

The exact procedure followed includes a small alteration from that described by Touratier et al. (2007). Their optimisation procedure involved selecting a value of parameter $a$ within a defined range $(1.0<a<1.5)$, and then optimising the values of parameters $b, c$ and $d$ at this value. The value of $a$ that resulted in the lowest error was then selected (together with the corresponding values of $b, c$ and $d$ ). In early tests using OCCAM output, we found that error minima were often not localised within the range for parameter $a$ suggested (i.e. minimum error was frequently found at the lower limit of the range sampled). Consequently, rather than optimise $a$ separately and constrain it, we have included it within the error optimisation process and have allowed it to adopt any value. 
Table 1. TrOCA optimisation using estimated $\mathrm{C}_{\text {ant }}$ at peak CFC-11 locations. Optimised values of TrOCA parameters $a, b, c$ and $d$ are shown for a range of geographical domains, together with the regional and global $\mathrm{C}_{\text {ant }}$ inventories that result from their use. The table also includes the corresponding actual $\mathrm{C}_{\mathrm{ant}}$ simulated by OCCAM. $\mathrm{C}_{\mathrm{ant}}$ inventories are in $\mathrm{Pg} \mathrm{C}$, with negative values of TrOCA estimates set to zero.

\begin{tabular}{llccccccc}
\hline \multicolumn{2}{c}{ Domain } & \multicolumn{3}{c}{ TrOCA parameters } & \multicolumn{3}{c}{ Cant inventory } \\
& & $a$ & $b$ & $c$ & $d$ & \multicolumn{2}{c}{ Regional } & Global \\
& & & & $\times 10^{-2}$ & $\times 10^{5}$ & TrOCA & Actual & TrOCA \\
\hline Default TrOCA & & 1.279 & 7.511 & -1.087 & 7.810 & - & - & 232.4 \\
World Ocean & & 0.966 & 7.042 & -1.008 & 4.494 & 264.8 & 103.5 & 264.8 \\
Atlantic Ocean & & 1.192 & 7.480 & -1.090 & -9.068 & 41.6 & 33.9 & 155.5 \\
Pacific Ocean & & 0.945 & 6.967 & -1.015 & 7.652 & 119.3 & 48.4 & 267.4 \\
Indian Ocean & & 1.208 & 7.396 & -1.113 & -4.129 & 39.1 & 21.3 & 229.4 \\
Atlantic & $\left(60^{\circ} \mathrm{N} \rightarrow 90^{\circ} \mathrm{N}\right)$ & 0.716 & 7.112 & -1.418 & -8.431 & 1.3 & 2.7 & 94.8 \\
& $\left(30^{\circ} \mathrm{N} \rightarrow 60^{\circ} \mathrm{N}\right)$ & 1.073 & 7.375 & -1.134 & -7.851 & 11.8 & 10.5 & 136.9 \\
& $\left(0^{\circ} \mathrm{N} \rightarrow 30^{\circ} \mathrm{N}\right)$ & 0.269 & 6.438 & -1.094 & -7.378 & 9.9 & 6.7 & 285.9 \\
& $\left(30^{\circ} \mathrm{S} \rightarrow 0^{\circ} \mathrm{N}\right)$ & 1.001 & 7.419 & -1.047 & -14.164 & 10.1 & 4.2 & 220.9 \\
Pacific & $\left(60^{\circ} \mathrm{S} \rightarrow 30^{\circ} \mathrm{S}\right)$ & 1.328 & 7.469 & -1.149 & -3.144 & 8.6 & 8.3 & 147.1 \\
& $\left(30^{\circ} \mathrm{N} \rightarrow 60^{\circ} \mathrm{N}\right)$ & 1.145 & 7.228 & -1.197 & 2.970 & 9.6 & 5.9 & 167.6 \\
& $\left(0^{\circ} \mathrm{N} \rightarrow 30^{\circ} \mathrm{N}\right)$ & 0.903 & 6.878 & -1.055 & 10.404 & 28.7 & 9.8 & 322.1 \\
& $\left(30^{\circ} \mathrm{S} \rightarrow 0^{\circ} \mathrm{N}\right)$ & 0.810 & 6.890 & -0.898 & 3.980 & 29.5 & 11.8 & 463.8 \\
Indian & $\left(60^{\circ} \mathrm{S} \rightarrow 30^{\circ} \mathrm{S}\right)$ & 1.029 & 7.070 & -1.092 & 6.365 & 32.2 & 17.9 & 189.9 \\
& $\left(0^{\circ} \mathrm{N} \rightarrow 30^{\circ} \mathrm{N}\right)$ & 1.098 & 7.424 & -0.993 & -11.208 & 3.1 & 2.0 & 432.9 \\
& $\left(30^{\circ} \mathrm{S} \rightarrow 0^{\circ} \mathrm{N}\right)$ & 1.264 & 7.438 & -1.137 & -4.178 & 11.6 & 8.2 & 227.0 \\
Southern & $\left(60^{\circ} \mathrm{S} \rightarrow 30^{\circ} \mathrm{S}\right)$ & 1.322 & 7.294 & -1.184 & 6.336 & 10.7 & 10.3 & 187.3 \\
& $\left(90^{\circ} \mathrm{S} \rightarrow 60^{\circ} \mathrm{S}\right)$ & 1.274 & 7.384 & -1.391 & -0.486 & 4.8 & 5.2 & 304.0 \\
\hline
\end{tabular}

Table 1 shows the results of this optimisation process for each of the regions identified above. The values of the four TrOCA parameters are shown, together with the default TrOCA parameter values determined by Touratier et al. (2007). To assess the skill of the optimisations, each variant is then used to calculate the $\mathrm{C}_{\text {ant }}$ inventory for the region used to optimise it, and then the total inventory when applied to the World Ocean. The actual $\mathrm{C}_{\mathrm{ant}}$ inventories for each region are also shown for comparison.

In terms of TrOCA parameter values, parameters $a$ and $d$ show the largest shifts from those of default TrOCA. In deriving the TrOCA method, Touratier et al. (2007) suggest a range for $a$ of 1.0 to 1.5 because of its Redfieldian roots. Most optimised variants here fall within this range, though several prefer values slightly below 1.0, and one favoured a very low value of 0.288 , considerably at odds with the biogeochemical relationships embodied by the parameter. In the case of parameter $d$, as well as ranging widely, optimised values also switched sign from default TrOCA. Across all of the optimised parameters, no discernible patterns emerged between the various regions (e.g. one might naïvely expect within-basin patterns because of biogeochemical gradients).

Turning to the performance of the optimised variants, as Table 1 shows, there are often very large discrepancies between actual, OCCAM simulated $\mathrm{C}_{\mathrm{ant}}$ and that estimated by the variants, both at the regional and global scales. A small number of variants produce regional estimates close to that simulated, but these successes typically do not translate to the global scale. Perhaps unsurprisingly, the variants generally perform better at the regional scale at which they were optimised rather than the global scale. Excluding the variant optimised using global fields, regional estimates average at 1.595 times actual $\mathrm{C}_{\mathrm{ant}}$, while at the global scale the average is 2.290. An exception is the northernmost Atlantic region, where a significant underestimate at the regional scale translates to the best estimate at the global scale.

The $\mathrm{C}_{\text {ant }}$ inventories presented in Table 1 are summary statistics that omit structure and detail from the results. Figure 6 shows a pair of Taylor diagrams (Taylor, 2001) to illustrate the performance of the TrOCA variants at capturing OCCAM's actual $\mathrm{C}_{\text {ant }}$ distribution. These diagrams present the standard deviations (radial axis distance) and correlation coefficients (angle) of the estimated $\mathrm{C}_{\text {ant }}$ distributions. The standard deviations are normalised to that of actual, OCCAM simulated $\mathrm{C}_{\mathrm{ant}}$, shown by the reference symbol at $\sigma=1$. In the case of regional fields, a number of TrOCA variants share similar variability to that of OCCAM (0.9 to 1.2$)$, of which some southern hemisphere regions also correlate strongly $(>0.9)$. By these measures, the worst TrOCA variant, optimised to the equatorial North Atlantic $\left(0^{\circ} \mathrm{N} \rightarrow 30^{\circ} \mathrm{N}\right)$, exhibits more than twice the variability of the OCCAM $\mathrm{C}_{\mathrm{ant}}$ field, and with a very poor correlation $(<0.4)$. At the global scale, the TrOCA variants exhibit markedly more variability, and none correlate as strongly (all are $<0.9$ ). Beyond the relative success of southern hemisphere regions at the regional scale, there are no obvious patterns or trends in the 

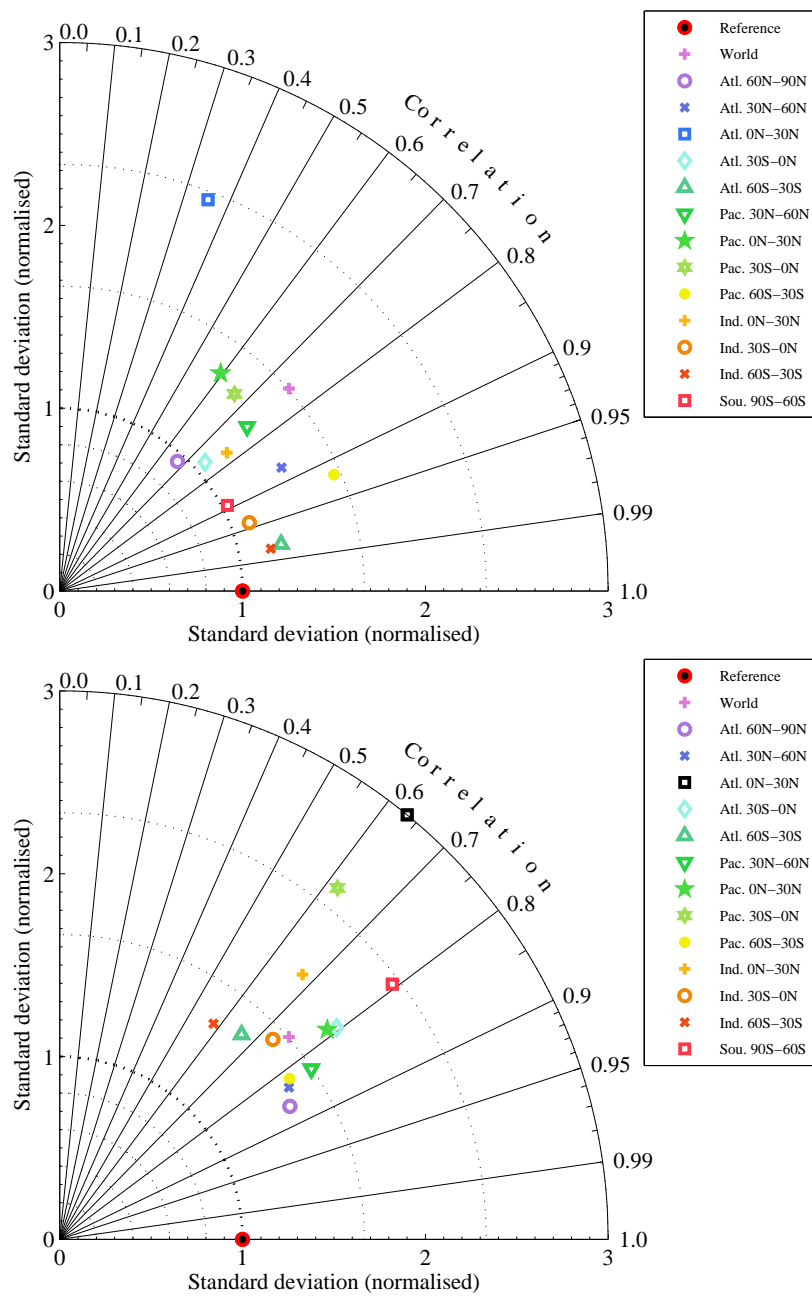

Fig. 6. Taylor diagrams of regional (top) and global (bottom) performance of TrOCA variants optimised using estimated $\mathrm{C}_{\text {ant }}$. Symbols refer to variants optimised using regional calibration datasets. Standard deviations are normalised such that actual, OCCAM simulated $\mathrm{C}_{\mathrm{ant}}$ (labelled here as reference) is exactly 1 . This reference value is singular in the case of the global plot (i.e. only one global domain), but multiple in the case of the regional plot (i.e. one per regional domain; because of normalisation, these all overlie one another). Black symbols denote variants with standard deviations outside the plotted range; the symbols are shown at the limit of this range to illustrate correlation.

performance of the variants. Table 2 includes the values used in these figures.

Finally, Figs. 7 and 8 present graphical representations of variant TrOCA $\mathrm{C}_{\text {ant }}$ estimates. Figure 7 shows global zonal average $\mathrm{C}_{\text {ant }}$ for a selection of the TrOCA variants. While the foregoing description has generally presented single metrics of variant performance, the subplots indicate how TrOCA $\mathrm{C}_{\mathrm{ant}}$ is actually distributed. A consistent feature of variants that overestimate global $\mathrm{C}_{\mathrm{ant}}$ inventory is erroneously high concentrations at higher latitudes $\left(>45^{\circ}\right)$. This is frequently accompanied by unrealistic detection of $\mathrm{C}_{\mathrm{ant}}$ in deep waters. Another feature poorly resolved by several variants is the relatively shallow penetration depth of $\mathrm{C}_{\mathrm{ant}}$ at equatorial latitudes. Generally, models which exhibit this latter feature are separate from those with anomalous high latitude concentrations, suggesting systematic patterns of variant failure.

Figure 8 shows the global distributions of simulated $\mathrm{C}_{\mathrm{ant}}$ together with estimated $\mathrm{C}_{\mathrm{ant}}$ for three cases using optimised variants. The first panel shows estimated $\mathrm{C}_{\mathrm{ant}}$ using the TrOCA variant optimised using global model fields with appropriate $\Delta \mathrm{C}^{*}$ and $\mathrm{CFC}-11$ signatures (total $=262.4 \mathrm{PgC}$ ). The second panel shows the same but the estimates for each basin are derived using the TrOCA variants optimised for the same basin (total=204.6PgC). The third panel repeats this with estimates derived using regional TrOCA variants (total $=170.0 \mathrm{Pg}$ C). Relative to that estimated by default TrOCA, all three panels show substantial deficiencies in their $\mathrm{C}_{\text {ant }}$ distributions, although there are also some small improvements. As already noted, all three panels estimate totals considerably in excess of that actually simulated, with the global panel's overestimate larger than that of default TrOCA (238.7 Pg C). One area of improvement in all three cases is the eastern Pacific basin, where $\mathrm{C}_{\text {ant }}$ concentrations now more closely resemble that simulated, although they are still markedly elevated. Equatorial Atlantic concentrations of $\mathrm{C}_{\mathrm{ant}}$ are also improved in the basin and regional panels, particularly the former where North Atlantic Deep Water (NADW) is correctly estimated as relatively uncontaminated with $\mathrm{C}_{\text {ant }}$.

Nonetheless, despite these limited improvements, it is clear that none of the optimised TrOCA variants reliably estimates OCCAM simulated $\mathrm{C}_{\mathrm{ant}}$ even at regional scales.

\subsection{Sensitivity to TrOCA parameters}

To estimate the variance of the optimised TrOCA parameters, a bootstrapping procedure was used with the global, basin and regional calibration datasets. Each calibration dataset was randomly resampled with replacement to produce 1000 alternative calibration datasets that were then used in optimisation.

Table 3 lists the resulting means and ranges of TrOCA parameters from the bootstrap procedure. With a small number of exceptions, the mean values recovered from the bootstrap populations are identical (to four significant figures) to those determined using the full calibration dataset. Also with a small number of exceptions, parameters $a, b$ and $c$ show narrow ranges of variability about these mean values. These variability ranges are considerably smaller than the range of parameter estimates generated between all of the regional calibration datasets, suggesting that there are robust biogeochemical differences between the regions. Parameter $d$, however, is exceptional in that its bootstrap ranges are much larger relative to bootstrap means (though still narrow relative to the optimised range of values of $d$ ). This, coupled 
Table 2. Estimated $\mathrm{C}_{\text {ant }}$ statistics (mean, standard deviation, RMS error and correlation coefficient) for TrOCA variants optimised using regional calibration datasets (est. columns). The statistics are calculated for the same optimisation regions. Corresponding statistics for the actual, OCCAM-simulated $\mathrm{C}_{\mathrm{ant}}$ are also shown (act. columns). Optimisations here make use of estimated $\mathrm{C}_{\mathrm{ant}}$ at $\mathrm{CFC}-11$ locations. Negative $\mathrm{C}_{\text {ant }}$ estimates set to zero prior to statistic calculation.

\begin{tabular}{|c|c|c|c|c|c|c|c|c|c|}
\hline \multirow{2}{*}{\multicolumn{2}{|c|}{ Domain }} & \multicolumn{2}{|c|}{ Mean $C_{\text {ant }}$} & \multicolumn{2}{|c|}{ St. dev. $\mathrm{C}_{\mathrm{ant}}$} & \multirow{3}{*}{$\begin{array}{c}\begin{array}{c}\text { RMS } \\
\text { error } \\
\mathrm{mmol} \mathrm{m}^{-3}\end{array} \\
16.925\end{array}$} & \multirow{3}{*}{$\begin{array}{c}\begin{array}{c}\text { Correl. } \\
\text { coeff. } \\
-\end{array} \\
0.750\end{array}$} & \multicolumn{2}{|c|}{ Calibration data } \\
\hline & & \multicolumn{2}{|c|}{$\mathrm{mmol} \mathrm{m}^{-3}$} & \multicolumn{2}{|c|}{$\mathrm{mmol} \mathrm{m}^{-3}$} & & & \multirow{2}{*}{$\begin{array}{c}\text { Samples } \\
\# \\
394988\end{array}$} & \multirow{2}{*}{$\begin{array}{c}\text { CFC frac. } \\
-\end{array}$} \\
\hline World Oc & & 16.639 & 6.504 & 19.960 & 11.931 & & & & \\
\hline Atlantic & & 9.832 & 8.008 & 15.063 & 11.848 & 7.113 & 0.897 & 19069 & 0.852 \\
\hline Pacific $\mathrm{O}$ & & 13.589 & 5.509 & 18.993 & 11.566 & 15.558 & 0.723 & 312067 & 0.124 \\
\hline Indian O & & 13.427 & 7.318 & 17.750 & 12.814 & 10.308 & 0.902 & 63852 & 0.153 \\
\hline \multirow[t]{5}{*}{ Atlantic } & $\left(60^{\circ} \mathrm{N} \rightarrow 90^{\circ} \mathrm{N}\right)$ & 5.575 & 11.423 & 12.348 & 12.902 & 11.781 & 0.673 & 797 & 1.000 \\
\hline & $\left(30^{\circ} \mathrm{N} \rightarrow 60^{\circ} \mathrm{N}\right)$ & 16.759 & 14.826 & 18.295 & 13.179 & 9.526 & 0.874 & 1502 & 0.978 \\
\hline & $\left(0^{\circ} \mathrm{N} \rightarrow 30^{\circ} \mathrm{N}\right)$ & 9.229 & 6.213 & 25.755 & 11.255 & 24.366 & 0.354 & 3393 & 1.000 \\
\hline & $\left(30^{\circ} \mathrm{S} \rightarrow 0^{\circ} \mathrm{N}\right)$ & 10.558 & 4.456 & 10.958 & 10.324 & 9.726 & 0.748 & 7796 & 0.939 \\
\hline & $\left(60^{\circ} \mathrm{S} \rightarrow 30^{\circ} \mathrm{S}\right)$ & 8.473 & 8.191 & 13.975 & 11.292 & 3.759 & 0.978 & 5571 & 0.586 \\
\hline \multirow[t]{4}{*}{ Pacific } & $\left(30^{\circ} \mathrm{N} \rightarrow 60^{\circ} \mathrm{N}\right)$ & 7.588 & 4.633 & 14.733 & 10.812 & 10.156 & 0.752 & 62184 & 0.046 \\
\hline & $\left(0^{\circ} \mathrm{N} \rightarrow 30^{\circ} \mathrm{N}\right)$ & 10.431 & 3.566 & 14.838 & 10.023 & 13.819 & 0.594 & 109912 & 0.088 \\
\hline & $\left(30^{\circ} \mathrm{S} \rightarrow 0^{\circ} \mathrm{N}\right)$ & 12.919 & 5.180 & 16.914 & 11.744 & 14.846 & 0.663 & 98293 & 0.249 \\
\hline & $\left(60^{\circ} \mathrm{S} \rightarrow 30^{\circ} \mathrm{S}\right)$ & 15.907 & 8.838 & 21.657 & 13.290 & 12.873 & 0.921 & 39676 & 0.047 \\
\hline \multirow[t]{3}{*}{ Indian } & $\left(0^{\circ} \mathrm{N} \rightarrow 30^{\circ} \mathrm{N}\right)$ & 7.078 & 4.489 & 12.314 & 10.383 & 8.318 & 0.770 & 15170 & 0.119 \\
\hline & $\left(30^{\circ} \mathrm{S} \rightarrow 0^{\circ} \mathrm{N}\right)$ & 9.314 & 6.595 & 14.627 & 13.278 & 5.672 & 0.941 & 39302 & 0.182 \\
\hline & $\left(60^{\circ} \mathrm{S} \rightarrow 30^{\circ} \mathrm{S}\right)$ & 9.944 & 9.632 & 15.567 & 13.222 & 3.692 & 0.980 & 9152 & 0.093 \\
\hline Southern & $\left(90^{\circ} \mathrm{S} \rightarrow 60^{\circ} \mathrm{S}\right)$ & 5.655 & 6.137 & 9.220 & 8.957 & 4.286 & 0.891 & 2240 & 0.000 \\
\hline
\end{tabular}

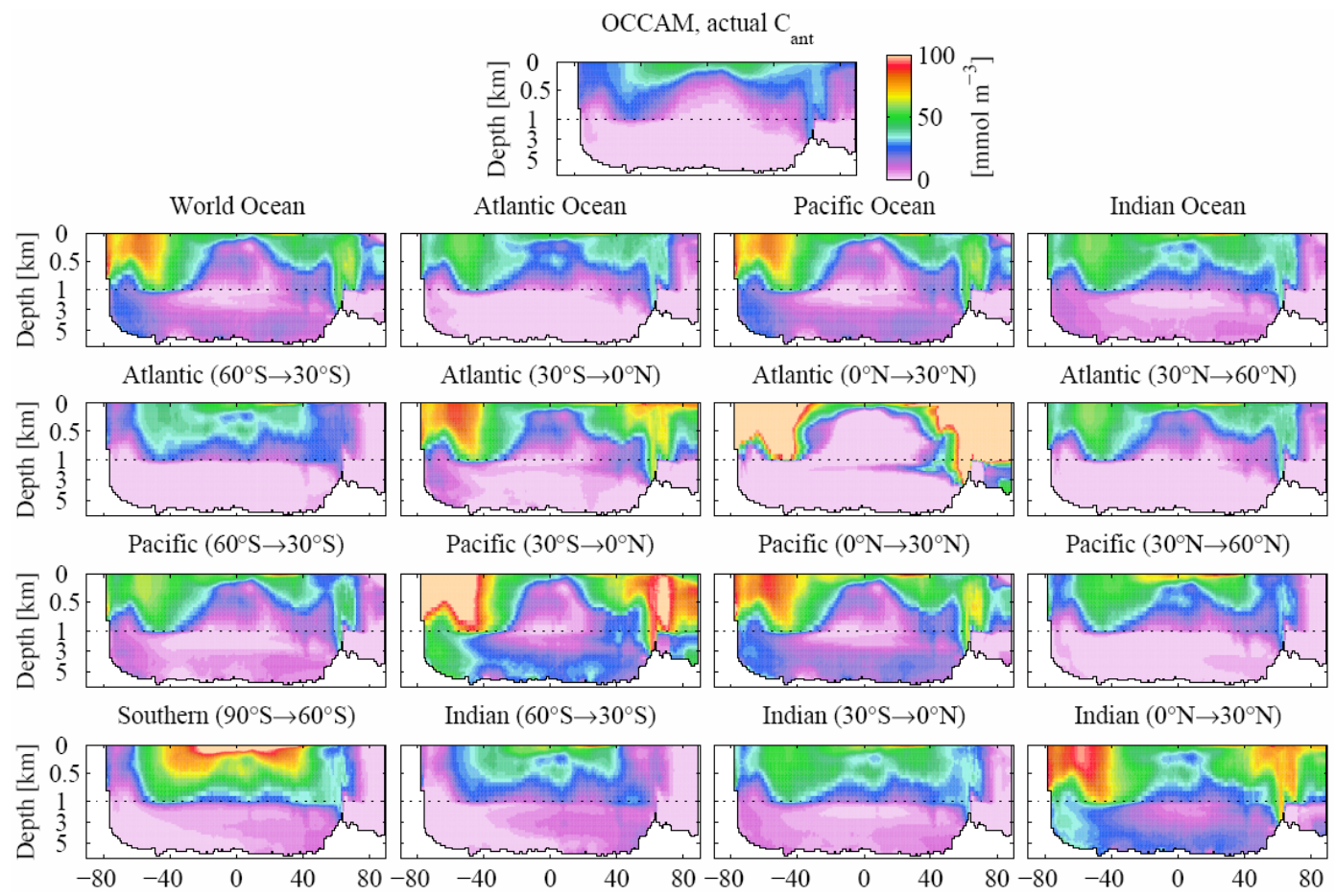

Fig. 7. World Ocean zonally averaged $\mathrm{C}_{\text {ant }}$ for OCCAM and a selection of TrOCA variant estimates (optimised using estimated $\mathrm{C}_{\text {ant }}$ ). Actual, OCCAM simulated $\mathrm{C}_{\mathrm{ant}}$ is shown in the top panel, with subsequent rows of panels showing TrOCA variants. $\mathrm{C}_{\mathrm{ant}}$ in $\mathrm{mmol}^{-3}$. Note that negative $\mathrm{C}_{\mathrm{ant}}$ concentrations in the TrOCA estimates were set to zero prior to averaging. 
Table 3. The results from bootstrap optimisation of TrOCA using estimated $\mathrm{C}_{\text {ant }}$ at peak CFC-11 locations. Mean (left columns) and range (right columns) values of TrOCA parameters $a, b, c$ and $d$ are shown for a range of geographical domains. Range here is the width of the distribution that encompasses the region $5 \%$ to $95 \%$ of the optimised parameters.

\begin{tabular}{|c|c|c|c|c|c|c|c|c|c|}
\hline \multirow{3}{*}{ Domain } & & \multicolumn{8}{|c|}{ TrOCA parameters } \\
\hline & & Mean & Range & Mean & Range & Mean & Range & Mean & Range \\
\hline & & \multicolumn{2}{|c|}{ a } & \multicolumn{2}{|c|}{$b$} & \multicolumn{2}{|c|}{$\mathrm{c} \times 10^{-2}$} & \multicolumn{2}{|c|}{$\mathrm{d} \times 10^{5}$} \\
\hline World Ocean & & 0.966 & 0.005 & 7.042 & 0.009 & -1.008 & 0.003 & 4.500 & 0.399 \\
\hline Atlantic Ocean & & 1.192 & 0.010 & 7.480 & 0.011 & -1.090 & 0.003 & -9.071 & 0.329 \\
\hline Pacific Ocean & & 0.945 & 0.005 & 6.967 & 0.008 & -1.015 & 0.002 & 7.652 & 0.255 \\
\hline Indian Ocean & & 1.208 & 0.008 & 7.396 & 0.011 & -1.113 & 0.003 & -4.124 & 0.466 \\
\hline \multirow[t]{5}{*}{ Atlantic } & $\left(60^{\circ} \mathrm{N} \rightarrow 90^{\circ} \mathrm{N}\right)$ & 0.714 & 0.200 & 7.109 & 0.221 & -1.422 & 0.128 & -8.422 & 1.885 \\
\hline & $\left(30^{\circ} \mathrm{N} \rightarrow 60^{\circ} \mathrm{N}\right)$ & 1.071 & 0.083 & 7.374 & 0.078 & -1.134 & 0.019 & -7.840 & 1.185 \\
\hline & $\left(0^{\circ} \mathrm{N} \rightarrow 30^{\circ} \mathrm{N}\right)$ & 0.162 & 0.092 & 6.194 & 0.237 & -1.198 & 0.116 & -5.060 & 2.845 \\
\hline & $\left(30^{\circ} \mathrm{S} \rightarrow 0^{\circ} \mathrm{N}\right)$ & 1.001 & 0.022 & 7.419 & 0.020 & -1.047 & 0.005 & -14.164 & 0.237 \\
\hline & $\left(60^{\circ} \mathrm{S} \rightarrow 30^{\circ} \mathrm{S}\right)$ & 1.325 & 0.100 & 7.464 & 0.152 & -1.148 & 0.026 & -2.990 & 4.720 \\
\hline \multirow[t]{4}{*}{ Pacific } & $\left(30^{\circ} \mathrm{N} \rightarrow 60^{\circ} \mathrm{N}\right)$ & 1.145 & 0.003 & 7.228 & 0.010 & -1.197 & 0.015 & 2.984 & 0.596 \\
\hline & $\left(0^{\circ} \mathrm{N} \rightarrow 30^{\circ} \mathrm{N}\right)$ & 0.903 & 0.008 & 6.878 & 0.012 & -1.055 & 0.007 & 10.398 & 0.501 \\
\hline & $\left(30^{\circ} \mathrm{S} \rightarrow 0^{\circ} \mathrm{N}\right)$ & 0.810 & 0.007 & 6.890 & 0.011 & -0.898 & 0.005 & 3.985 & 0.408 \\
\hline & $\left(60^{\circ} \mathrm{S} \rightarrow 30^{\circ} \mathrm{S}\right)$ & 1.030 & 0.038 & 7.071 & 0.071 & -1.092 & 0.014 & 6.343 & 2.199 \\
\hline \multirow[t]{3}{*}{ Indian } & $\left(0^{\circ} \mathrm{N} \rightarrow 30^{\circ} \mathrm{N}\right)$ & 1.099 & 0.014 & 7.424 & 0.011 & -0.993 & 0.007 & -11.198 & 0.367 \\
\hline & $\left(30^{\circ} \mathrm{S} \rightarrow 0^{\circ} \mathrm{N}\right)$ & 1.264 & 0.003 & 7.438 & 0.005 & -1.137 & 0.002 & -4.177 & 0.305 \\
\hline & $\left(60^{\circ} \mathrm{S} \rightarrow 30^{\circ} \mathrm{S}\right)$ & 1.322 & 0.011 & 7.294 & 0.018 & -1.184 & 0.007 & 6.335 & 0.627 \\
\hline Southern & $\left(90^{\circ} \mathrm{S} \rightarrow 60^{\circ} \mathrm{S}\right)$ & 1.274 & 0.002 & 7.388 & 0.047 & -1.384 & 0.073 & -0.716 & 2.552 \\
\hline
\end{tabular}

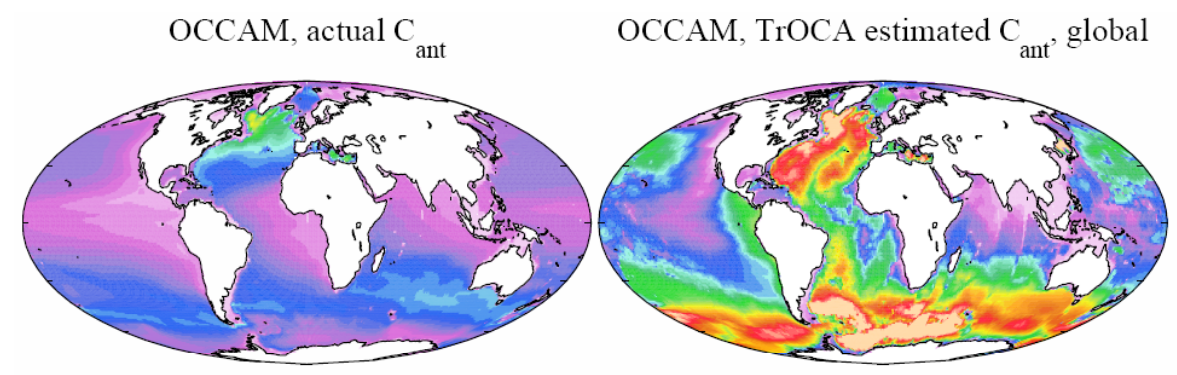

OCCAM, TrOCA estimated $\mathrm{C}_{\text {ant }}$, basin OCCAM, TrOCA estimated $\mathrm{C}_{\text {ant }}$, region

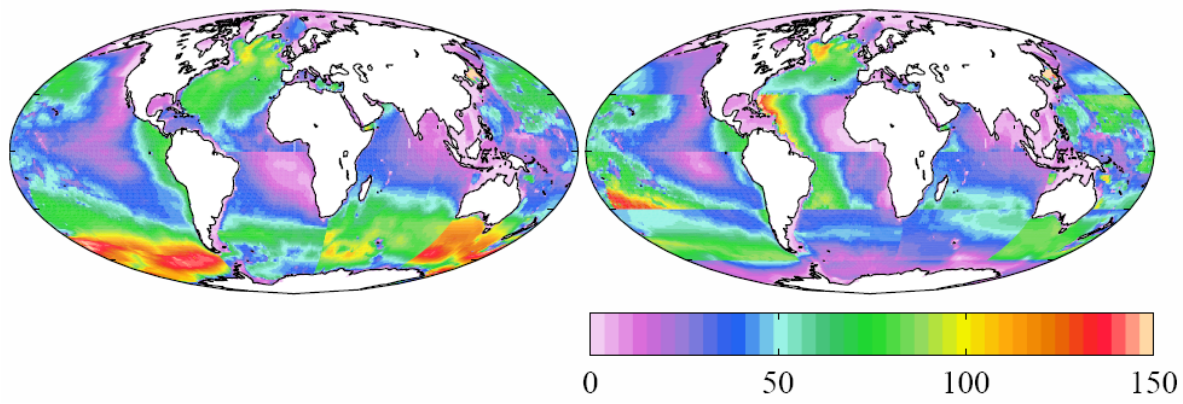

Fig. 8. As Fig. 2 but showing vertically-integrated $C_{\text {ant }}$ based on global (top right), basin (bottom left) and regional (bottom right) optimisations. Actual, OCCAM simulated $\mathrm{C}_{\text {ant }}$ is shown in the top left panel on the same scale. The basin and regional panels show composite maps that combine $\mathrm{C}_{\mathrm{ant}}$ estimates for particular regions based on the optimised TrOCA variants generated for those regions. $\mathrm{C}_{\mathrm{ant}}$ in mol $\mathrm{m}^{-2}$. Note that negative values of estimated $\mathrm{C}_{\mathrm{ant}}$ are set to zero before integration. 

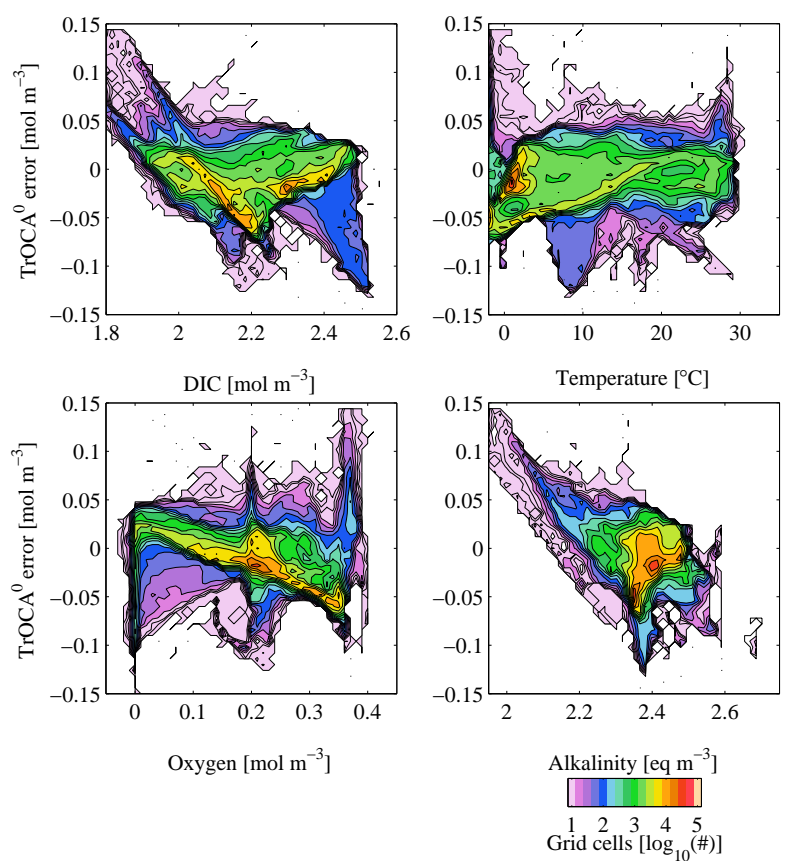

Fig. 9. Error in $\operatorname{TrOCA}^{0}$ (estimated - simulated) plotted against actual DIC (top left), potential temperature (top right) oxygen (bottom left) and alkalinity (bottom right). Estimated $\operatorname{TrOCA}^{0}$ here is based on the TrOCA variant optimised with the full global calibration dataset. In each case the colour scale is identical and denotes the logarithmic density of OCCAM grid cells (cell volume is ignored here). The plots indicate relationships between TrOCA variant error and the ocean properties used in the TrOCA equation.

to its large range of optimised values, suggests that parameter $d$, the dependence of TrOCA on alkalinity, is only weakly constrained in TrOCA.

\subsection{Errors in $\operatorname{TrOCA}^{0}$}

Given Eq. (10) and the relatively good agreement between estimated and simulated $\mathrm{C}_{\text {ant }}$ in the calibration dataset shown in Fig. 5, the errors in estimated $\mathrm{C}_{\text {ant }}$ stem from discrepancies in the estimates of preformed, pre-industrial DIC. In turn, pre-industrial DIC is derived from $\mathrm{TrOCA}^{0}$ :

$\mathrm{C}_{\mathrm{T}}^{0, \text { TrOCA }}=\frac{1}{a}\left(\operatorname{TrOCA}^{0}-\mathrm{O}_{2}+\frac{\mathrm{A}_{\mathrm{T}}}{2}\right)$

Equation (6) defines the pre-industrial TrOCA tracer, $\mathrm{TrOCA}^{0}$, as a function of oxygen, pre-industrial DIC and alkalinity. Using a calibration dataset of observations identified by $\Delta^{14} \mathrm{C}$ and CFC-11 signatures, TrOCA ${ }^{0}$ is approximated with an exponential function of potential temperature and alkalinity (Eq. 9). Subtracting this pre-industrial approximation from the field of TrOCA calculated from observed tracer concentrations forms the basis of the TrOCA method's separation of the $\mathrm{C}_{\text {ant }}$ signal from observed DIC (Eq. 7).

Here we evaluate the accuracy of this approximation by comparing the estimated fields of $\operatorname{TrOCA}^{0}$ (cf. Eq. 9) with those actually calculated from the simulated tracer fields of pre-industrial DIC, alkalinity and oxygen (cf. Eq. 6). Table 4 presents the resulting comparison for each of the optimised TrOCA variants. Average $\mathrm{TrOCA}^{0}$ estimates, and the spatial variability of these estimates, show good agreement with actual $\mathrm{TrOCA}^{0}$, and the correlation between them is high (with the exception of the equatorial North Atlantic region). However, as the $\mathrm{C}_{\text {ant }}$ results already imply, RMS errors, while small relative to $\operatorname{TrOCA}^{0}$, are significant relative to the magnitude of $\mathrm{C}_{\text {ant }}$. This is not unsurprising, since the dynamic range of $\operatorname{TrOCA}^{0}$ is large because it has to capture large changes in the influence of the air-sea exchange of oxygen (primarily) and natural $\mathrm{CO}_{2}$ (secondary). This dynamic range of several hundreds of $\mathrm{mmol} \mathrm{m}^{-3}$ is much larger than the dynamic range of $\mathrm{C}_{\mathrm{ant}}$, which is from 0 to about $60 \mathrm{mmol} \mathrm{m}^{-3}$. And as cross-referencing with Table 1 shows, even the lowest errors (e.g. the Southern Ocean) are still associated with large discrepancies in integrated ocean $\mathrm{C}_{\mathrm{ant}}$.

These errors are not distributed randomly within the model domain or between model variables, and Fig. 9 shows correlations between the error in the $\mathrm{TrOCA}^{0}$ approximation and the tracer variables used in calculating TrOCA and approximating $\mathrm{TrOCA}^{0}$ (Fig. A4 shows the corresponding error in pre-industrial DIC). The panels show how the errors in the $\mathrm{TrOCA}^{0}$ approximation vary with simulated DIC, potential temperature, oxygen and alkalinity for the TrOCA variant optimised with the full global calibration dataset. In each case, the panels show the (logarithmic) density of OCCAM grid cells that occur over the ranges of the properties sampled. In the case of DIC and, especially, potential temperature, the errors in approximated $\mathrm{TrOCA}^{0}$ are distributed fairly evenly over these variables. There are small regions in which errors are focused, but any relationships are generally weak. Alkalinity similarly shows no strong relationship with the error in $\operatorname{TrOCA}^{0}$, although for low alkalinity values there appears to be a bias to overestimation (though the total number of grid cells in this relationship is low). However, oxygen exhibits a more distinct relationship with the error TrOCA ${ }^{0}$, which traces out a "N"-shaped pattern in the plot. Water masses with low oxygen range in $\operatorname{TrOCA}^{0}$ error from -100 to $50 \mathrm{mmol} \mathrm{m}^{-3}$, while high oxygen water masses range -50 to $100 \mathrm{mmol} \mathrm{m}^{-3}$, with intermediate water masses falling from 50 to $-50 \mathrm{mmol} \mathrm{m}^{-3}$ as oxygen concentrations rise. This pattern is broadly repeated for other TrOCA variants as Fig. 10 shows (comparable analysis of the $\mathrm{TrOCA}^{0}$ error and the other TrOCA variables finds that they also behave similarly across TrOCA variants; results not shown).

Since the magnitude of estimated $\mathrm{C}_{\mathrm{ant}}$ is related to the TrOCA tracer by parameter $a$, these errors in the approximations of $\mathrm{TrOCA}^{0}$ are broadly comparable in magnitude to the concentrations of $\mathrm{C}_{\mathrm{ant}}$ found in present day seawater (cf. Fig. A4). Since the relatively small signal of $\mathrm{C}_{\mathrm{ant}}$ is the focus of the TrOCA method, this interferes with its efficiency at deconvoluting $\mathrm{C}_{\text {ant }}$ from background DIC. 
Table 4. Estimated $\operatorname{TrOCA}^{0}$ statistics (mean, standard deviation, RMS error and correlation coefficient) for TrOCA variants optimised using regional calibration datasets ( est. columns). The statistics are calculated for the same optimisation regions. Corresponding statistics for the actual, OCCAM-simulated $\operatorname{TrOCA}^{0}$ are also shown (act. columns).

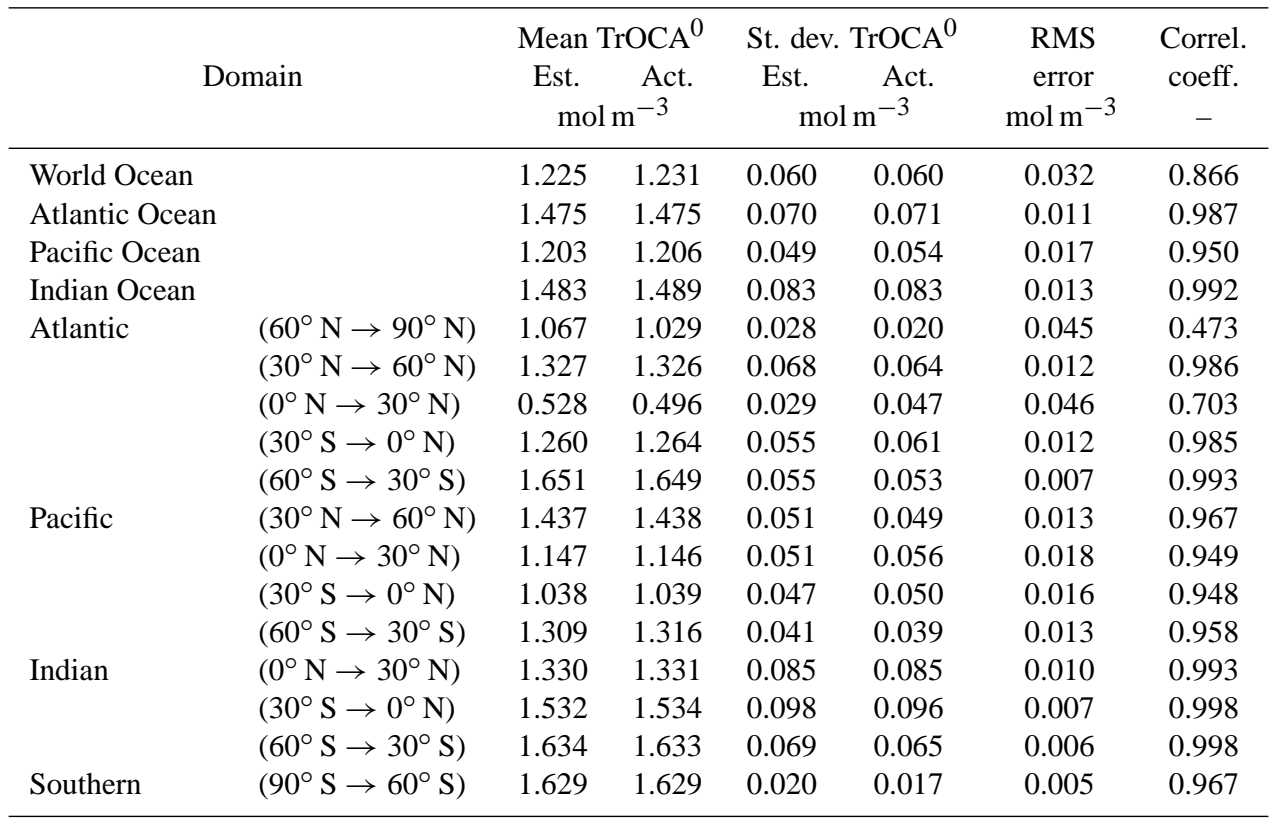
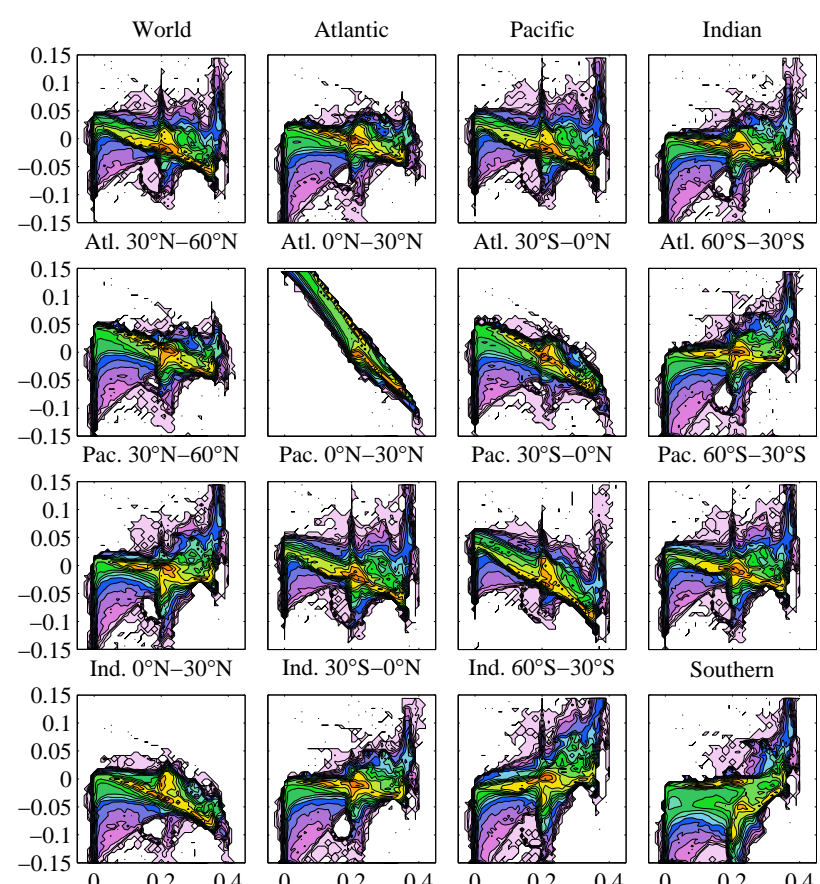

Southern

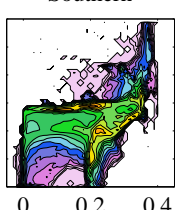

Fig. 10. As Fig. 9 except focusing solely on error in $\operatorname{TrOCA}^{0}$ (estimated - simulated) plotted against oxygen concentration. Each panel represents the results from the global application of different TrOCA variants. In each case the colour scale is identical and denotes the logarithmic density of OCCAM grid cells (cell volume is ignored here).

\subsection{Impact of changes in surface disequilibrium}

One potential source of error in the optimisation process described in the preceding section is the use of estimated $\mathrm{C}_{\mathrm{ant}}$ at locations identified as possessing a peak CFC-11 signature. Estimates are based on the difference between saturation DIC concentrations under "pre-industrial" and 1995 atmospheric $\mathrm{CO}_{2}$ concentrations. This method assumes that although DIC concentrations may change in response to the anthropogenic transient, surface disequilibrium is constant. Essentially, a given location's current DIC concentration is out of equilibrium with atmospheric $p \mathrm{CO}_{2}$ to the same degree as it was under pre-industrial conditions.

Figure 11 shows globally averaged, surface disequilibrium for the duration of the simulation period (1864-2004). The control simulation shows the magnitude of interannual variability in disequilibrium, and the repeating cycles of this variability as the forcing data (1958-2004) is reused. While the transient simulation begins with the same disequilibrium as the control, approximately $-11 \mathrm{mmol} \mathrm{m}^{-3}$, this gradually grows, particularly after 1950 , to reach a disequilibrium of around $-16.5 \mathrm{mmol} \mathrm{m}^{-3}$ by 2004 (an increase of slightly more than 50\%). Consistent with Fig. 5, these results suggest that the TrOCA method's approach for estimating the $\mathrm{C}_{\text {ant }}$ signal in recently ventilated waters (those with the peak CFC-11 signature) may overlook a change in disequilibrium. The neglect of this increase in disequilibrium by about $5 \mathrm{mmol} \mathrm{m}^{-3}$ may explain some part of the generally too high $\mathrm{C}_{\text {ant }}$ values estimated by the TrOCA method. 
Table 5. As Table 1 except TrOCA optimisation using actual $\mathrm{C}_{\mathrm{ant}}$ at peak CFC-11 locations. Optimised values of TrOCA parameters $a$, $b, c$ and $d$ are shown for a range of geographical domains, together with the regional and global $\mathrm{C}_{\text {ant }}$ inventories that result from their use. The table also includes the corresponding actual $\mathrm{C}_{\text {ant }}$ simulated by OCCAM. $\mathrm{C}_{\text {ant }}$ inventories are in Pg C, with negative values of TrOCA estimates set to zero.

\begin{tabular}{llccccccc}
\hline \multicolumn{1}{c}{ Domain } & \multicolumn{3}{c}{ TrOCA parameters } & \multicolumn{3}{c}{$C_{\text {ant }}$ inventory } \\
& & $a$ & $b$ & $c$ & $d$ & \multicolumn{2}{c}{ Regional } & Global \\
& & & & $\times 10^{-2}$ & $\times 10^{5}$ & TrOCA & Actual & TrOCA \\
\hline Default TrOCA & & 1.279 & 7.511 & -1.087 & 7.810 & - & - & 232.4 \\
World Ocean & & 0.971 & 7.059 & -0.992 & 3.771 & 263.5 & 103.5 & 263.5 \\
Atlantic Ocean & & 1.130 & 7.417 & -1.058 & -8.199 & 44.7 & 33.9 & 151.1 \\
Pacific Ocean & & 0.950 & 6.987 & -0.997 & 6.776 & 118.5 & 48.4 & 266.2 \\
Indian Ocean & & 1.212 & 7.412 & -1.093 & -4.904 & 38.7 & 21.3 & 229.1 \\
Atlantic & $\left(60^{\circ} \mathrm{N} \rightarrow 90^{\circ} \mathrm{N}\right)$ & 0.556 & 6.926 & -1.492 & -7.222 & 1.2 & 2.7 & 87.3 \\
& $\left(30^{\circ} \mathrm{N} \rightarrow 60^{\circ} \mathrm{N}\right)$ & 1.005 & 7.326 & -1.122 & -7.857 & 10.4 & 10.5 & 115.7 \\
& $\left(0^{\circ} \mathrm{N} \rightarrow 30^{\circ} \mathrm{N}\right)$ & 0.232 & 6.328 & -1.153 & -4.305 & 6.7 & 6.7 & 248.0 \\
& $\left(30^{\circ} \mathrm{S} \rightarrow 0^{\circ} \mathrm{N}\right)$ & 0.867 & 7.233 & -0.976 & -10.629 & 11.3 & 4.2 & 231.0 \\
Pacific & $\left(60^{\circ} \mathrm{S} \rightarrow 30^{\circ} \mathrm{S}\right)$ & 1.312 & 7.462 & -1.151 & -3.330 & 9.0 & 8.3 & 149.1 \\
& $\left(30^{\circ} \mathrm{N} \rightarrow 60^{\circ} \mathrm{N}\right)$ & 1.147 & 7.238 & -1.188 & 2.548 & 9.6 & 5.9 & 167.0 \\
& $\left(0^{\circ} \mathrm{N} \rightarrow 30^{\circ} \mathrm{N}\right)$ & 0.910 & 6.895 & -1.038 & 9.756 & 28.0 & 9.8 & 316.3 \\
& $\left(30^{\circ} \mathrm{S} \rightarrow 0^{\circ} \mathrm{N}\right)$ & 0.816 & 6.910 & -0.882 & 3.214 & 28.8 & 11.8 & 459.2 \\
Indian & $\left(60^{\circ} \mathrm{S} \rightarrow 30^{\circ} \mathrm{S}\right)$ & 1.035 & 7.091 & -1.103 & 5.475 & 33.3 & 17.9 & 197.2 \\
& $\left(0^{\circ} \mathrm{N} \rightarrow 30^{\circ} \mathrm{N}\right)$ & 1.109 & 7.456 & -0.965 & -12.541 & 2.8 & 2.0 & 434.5 \\
& $\left(30^{\circ} \mathrm{S} \rightarrow 0^{\circ} \mathrm{N}\right)$ & 1.253 & 7.435 & -1.116 & -4.532 & 11.0 & 8.2 & 226.4 \\
Southern & $\left(60^{\circ} \mathrm{S} \rightarrow 30^{\circ} \mathrm{S}\right)$ & 1.311 & 7.256 & -1.179 & 8.061 & 10.2 & 10.3 & 183.9 \\
& $\left(90^{\circ} \mathrm{S} \rightarrow 60^{\circ} \mathrm{S}\right)$ & 1.273 & 7.384 & -1.404 & -0.510 & 4.8 & 5.2 & 312.4 \\
\hline
\end{tabular}

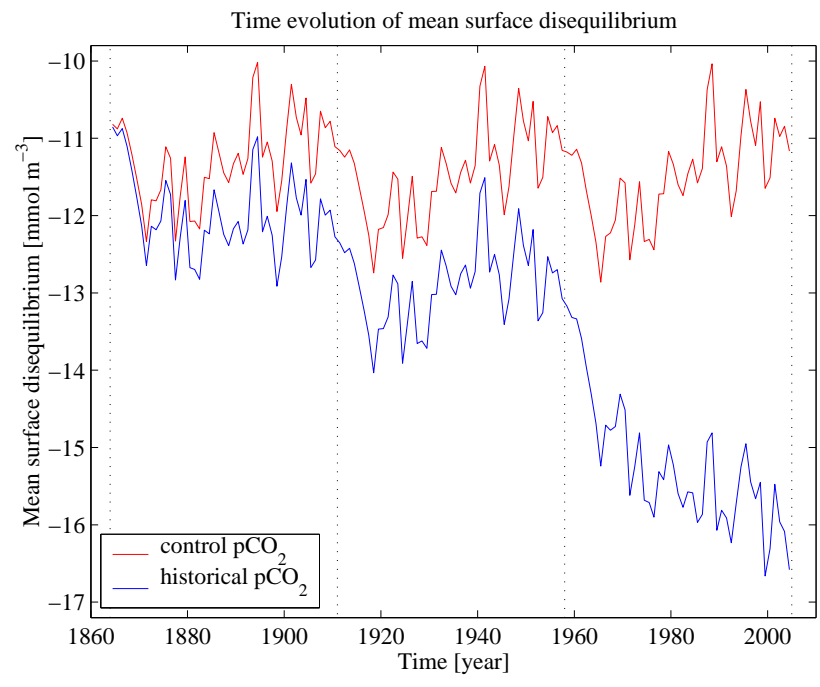

Fig. 11. Globally averaged, surface ocean DIC disequilibrium for control $\left(288 \mu \mathrm{atm}\right.$; red) and historical (blue) atmospheric $p \mathrm{CO}_{2}$ concentrations. Because of the relatively slow equilibriation time of $\mathrm{CO}_{2}$, the surface ocean is undersaturated in DIC given atmospheric $p \mathrm{CO}_{2}$. This disequilibrium increases as atmospheric $p \mathrm{CO}_{2}$ increases due to anthropogenic emissions. The dotted vertical lines denote separate forcing cycles (1958-2004).
To examine the importance of errors introduced by the estimated $\mathrm{C}_{\text {ant92/95 }}^{\text {TrOCA }}$ of Eq. (8), the TrOCA method was optimised as before, but with actual, OCCAM simulated $\mathrm{C}_{\text {ant }}$ substituted for estimated (or assumed zero) $\mathrm{C}_{\text {ant }}^{\mathrm{TrOCA}} / 95$. The global/basin/region optimisation was otherwise repeated identically using the same calibration datasets.

Table 5 and Appendix Figs. A5 and A6 repeat earlier representations of the performance of the TrOCA variants. While the optimised values of the TrOCA parameters are not identical to those of the earlier variants, they are typically very close, and the estimated $\mathrm{C}_{\mathrm{ant}}$ inventories are frequently nearly identical. Unsurprisingly, congruence is greatest where the $\mathrm{CFC}-11$ fraction of the calibration dataset is at its lowest (i.e. where near-zero $\mathrm{C}_{\mathrm{ant}}$ values dominate the calibration dataset). Comparing Figs. 6 and A5 finds nearly indistinguishable performances of the actual and estimated $\mathrm{C}_{\text {ant }}$ variants.

\subsection{Biogeochemistry and TrOCA parameter $a$}

TrOCA's parameter $a$ has a specific meaning, since it is defined in relation to the basic stoichiometry of primary production and organic matter remineralisation. Equation (5) explicitly expresses parameter $a$ as a function of the stoichiometry of carbon, oxygen, hydrogen and phosphorus. Since the relationships between these elements is broadly conservative across the modern ocean (and is wholly 
conservative in the OCCAM ecosystem model), the approach of allowing TrOCA variants to adopt any value favoured by optimisation is somewhat counter-intuitive. From the values given in Eq. (1) parameter $a$ should take a value of 1.205. Differences in the stoichiometry of oxygen in OCCAM's ecosystem $\left(151 \mathrm{~mol} \mathrm{O}_{2}\right.$ are evolved per $106 \mathrm{molC}$ instead of $138 \mathrm{~mol} \mathrm{O}_{2}$ ) mean that a value of 1.319 should apply to the simulation. As shown in Table 1, the TrOCA variants optimised here actually range from 0.269 to 1.328 in their values of parameter $a$, with the majority having values less than that expected.

Here we repeat the optimisation procedure but fix parameter $a$ to that shown above, 1.319. The procedure is otherwise identical, and uses estimated $\mathrm{C}_{\mathrm{ant}}$. Table 6 shows the optimised parameter values, and the regional and global performances of the resulting TrOCA variants.

Of the 17 areas examined, the new variants are superior at the regional scale in 10 cases, and when extrapolated to the global scale, this increases to 12 cases. The new best variant is the most northerly Pacific region $\left(30^{\circ} \mathrm{N} \rightarrow 60^{\circ} \mathrm{N}\right)$, which performs well at both regional and global scales, and estimates a global $\mathrm{C}_{\text {ant }}$ inventory much closer to that simulated than the best variant of the earlier optimisation $(105.8 \mathrm{Pg} \mathrm{C}$ compared to $103.5 \mathrm{Pg} \mathrm{C}$ simulated). However, the new worst variant is also much worse than that optimised previously (1195.5 Pg C compared to $463.8 \mathrm{Pg} \mathrm{C}$ ), and in general the new variants exhibit similar performance issues to the original variants. Overall, these results suggest that this decrease in the degree of freedom available to the TrOCA variants does not decrease their performance, and may even increase it while forcing the best-constrained parameter to remain close to its theoretical value.

\section{7 $\quad C_{a n t}-$ free calibration dataset}

This work makes use of an OCCAM simulation of duration 188 years $(=4 \times 47$ years $)$. However, gauged from radiocarbon measurements, the ventilation timescale of the deep ocean is up to 2000 years (Ostlund and Stuiver, 1980). As a result, the simulated ocean and carbon cycle are unlikely to be in equilibrium with one another. In particular, deep water masses identified as $\mathrm{C}_{\mathrm{ant}}$-free using $\Delta{ }^{14} \mathrm{C}$ are generally older than the duration of the simulation and the biogeochemical signals in them are liable to be dominated by initial conditions rather than the activity of OCCAM. As these $\mathrm{C}_{\text {ant }}$-free water masses play an important role in TrOCA calibration, the preceding optimisations may be compromised by incorporating a mixture of initial conditions and simulated biogeochemistry.

To examine this potential problem, ostensibly $\mathrm{C}_{\mathrm{ant}}$-free calibration data were selected using the ventilation tracer to identify water masses that were ventilated last during the course of the spin-up phase of the simulation (i.e. prior to the exposure of the ocean to $\mathrm{C}_{\text {ant }}$ ). The specific age range used selected water masses of between 156 and 173 years in age.
The lower age limit excluded water masses with $\mathrm{C}_{\text {ant }}$ concentrations of more than $2 \mathrm{mmol} \mathrm{m}^{-3}$. The upper age limit excluded watermasses with ages within 5 years of the simulation initiation (as previously, analysis focused on September 1995 rather than the end point of the simulation). This criterion narrowed the $\mathrm{C}_{\mathrm{ant}}$-free calibration dataset from 394988 grid cells to 220810 grid cells. The resulting dataset was then used in conjunction with the CFC-11 calibration dataset to optimise the TrOCA parameters in the manner already described.

Table 7 shows the result of this procedure. As with the original optimisations, the skill of the resulting TrOCA variants is still relatively poor and extremely variable. While the new calibration dataset has generally improved the largescale variants ( 3 out of 4 are better), the regionally-optimised variants are generally worse ( 8 out of 13 are worse). Considering global scale performance, the range of these optimised variants $(88.2-1357.8 \mathrm{Pg} \mathrm{C})$ is much broader than than that of the original optimised variants (93.3-461.4 Pg C), although generally the misfit with simulated $\mathrm{C}_{\mathrm{ant}}$ is broadly comparable between the two optimisation efforts. The best performing variant is the same between both optimisation efforts $\left(60^{\circ} \mathrm{N} \rightarrow 90^{\circ} \mathrm{N}\right.$ Atlantic), and the worse performing variants are still those in the equatorial Pacific, although in all of these cases the new optimisations are worse. In terms of the estimated TrOCA parameters between the two optimisation efforts, these show weak correlations with the exception of parameter $d$. In the original optimised variants, this ranged widely between large positive and negative values, but here only negative values (i.e. opposite in sign from those found by Touratier et al., 2007) are estimated.

As a further test of the significance of unventilated water masses for TrOCA-estimated $\mathrm{C}_{\mathrm{ant}}$, water masses with an age greater than 173 years were excluded when $C_{a n t}$ was integrated to regional and global scales. Table 8 shows resulting $\mathrm{C}_{\mathrm{ant}}$ integrals. In general, the differences are slight, indicating that the TrOCA variants are not estimating large quantities of $\mathrm{C}_{\mathrm{ant}}$ in unventilated regions of the model domain. The exceptions are those variants which already massively overestimate $\mathrm{C}_{\text {ant }}$ (e.g. those derived using equatorial Pacific calibration data). For these variants, the figures in Table 8 differ significantly from those in Table 7 , and the variant estimates significant $\mathrm{C}_{\text {ant }}$ where near zero occurs.

Overall, the results of this alternative optimisation suggest that filtering the calibration dataset to exclude unventilated water masses does not significantly alter the success of the optimised variants. While the use of "clean" calibration data is preferable on theoretical grounds, "contamination" of the model domain by its initial condition does not appear a major factor in the poor performance of the TrOCA variants. 
Table 6. As Table 1 except TrOCA optimisation uses a fixed value of parameter $a, 1.319$. Optimised values of remaining TrOCA parameters $b, c$ and $d$ are shown for a range of geographical domains, together with the regional and global $\mathrm{C}_{\text {ant }}$ inventories that result from their use. The table also includes the corresponding actual $\mathrm{C}_{\text {ant }}$ simulated by OCCAM. $\mathrm{C}_{\text {ant }}$ inventories are in Pg C, with negative values of TrOCA estimates set to zero.

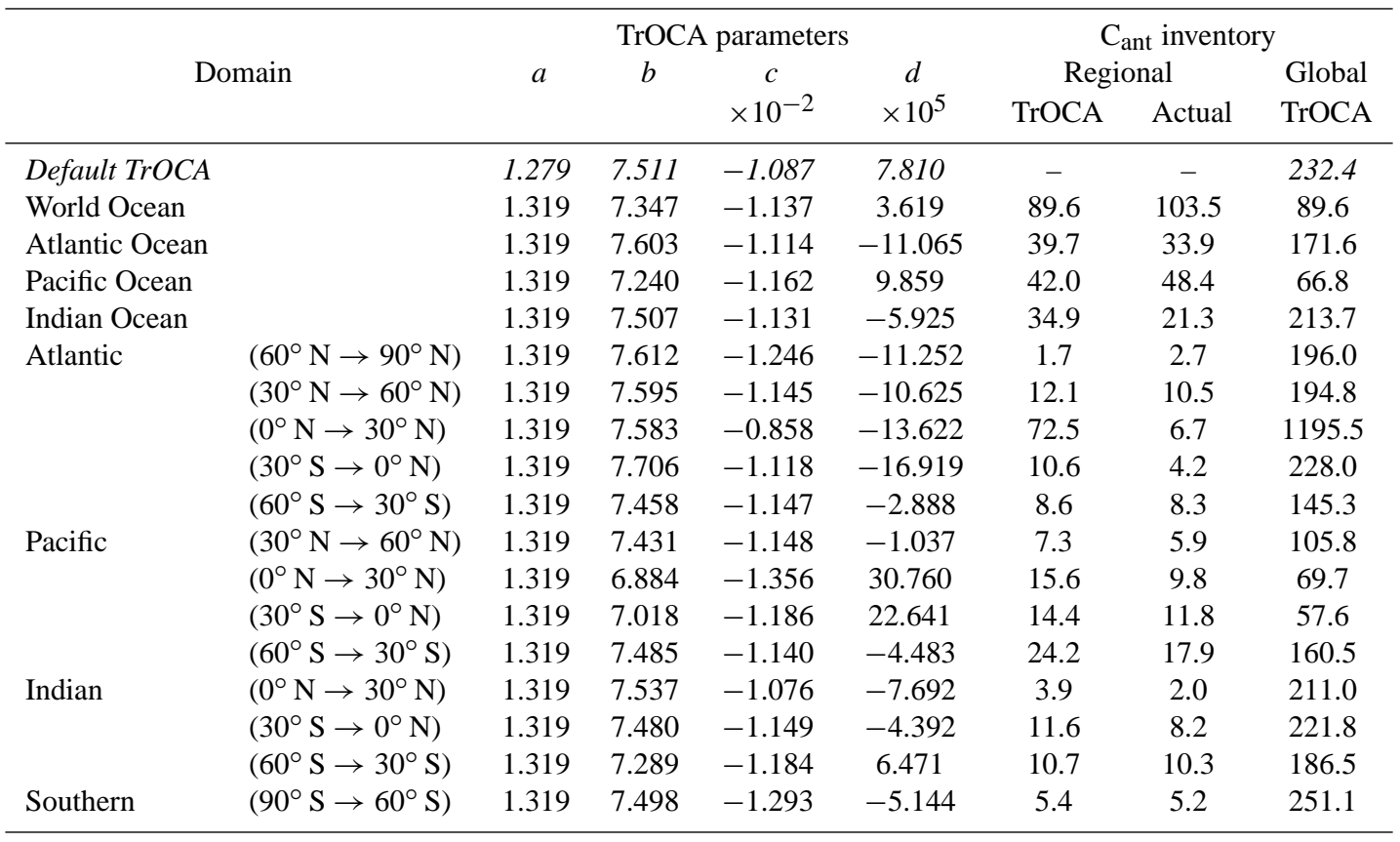

Table 7. As Table 1 except TrOCA optimisation using " $\mathrm{C}_{\mathrm{ant}}$-free" regions defined by ventilation age tracer. $\mathrm{C}_{\mathrm{ant}}$ is assumed zero in these regions and is estimated at peak CFC-11 locations. Optimised values of TrOCA parameters $a, b, c$ and $d$ are shown for a range of geographical domains, together with the regional and global $\mathrm{C}_{\mathrm{ant}}$ inventories that result from their use. The table also includes the corresponding actual $\mathrm{C}_{\text {ant }}$ simulated by OCCAM. $\mathrm{C}_{\text {ant }}$ inventories are in Pg C, with negative values of TrOCA estimates set to zero.

\begin{tabular}{llccccccc}
\hline \multicolumn{2}{c}{ Domain } & \multicolumn{3}{c}{ TrOCA parameters } & \multicolumn{3}{c}{C$_{\text {ant }}$ inventory } \\
\multicolumn{1}{c}{} & & $a$ & $b$ & $c$ & $d$ & \multicolumn{2}{c}{ Regional } & Global \\
& & & & $\times 10^{-2}$ & $\times 10^{5}$ & TrOCA & Actual & TrOCA \\
\hline Default TrOCA & & 1.279 & 7.511 & -1.087 & 7.810 & - & - & 232.4 \\
World Ocean & & 1.099 & 7.221 & -1.073 & 1.132 & 180.1 & 103.5 & 180.1 \\
Atlantic Ocean & & 1.125 & 7.506 & -1.084 & -13.320 & 56.5 & 33.9 & 182.8 \\
Pacific Ocean & & 1.068 & 7.135 & -1.075 & 4.523 & 89.4 & 48.4 & 179.4 \\
Indian Ocean & & 1.241 & 7.363 & -1.142 & -0.787 & 31.2 & 21.3 & 185.0 \\
Atlantic & $\left(60^{\circ} \mathrm{N} \rightarrow 90^{\circ} \mathrm{N}\right)$ & 0.880 & 7.087 & -0.694 & -1.887 & 6.2 & 2.7 & 108.0 \\
& $\left(30^{\circ} \mathrm{N} \rightarrow 60^{\circ} \mathrm{N}\right)$ & 1.238 & 7.525 & -1.138 & -9.704 & 12.1 & 10.5 & 173.3 \\
& $\left(0^{\circ} \mathrm{N} \rightarrow 30^{\circ} \mathrm{N}\right)$ & 1.261 & 7.622 & -1.119 & -14.269 & 9.2 & 6.7 & 189.0 \\
& $\left(30^{\circ} \mathrm{S} \rightarrow 0^{\circ} \mathrm{N}\right)$ & 1.285 & 7.654 & -1.124 & -15.090 & 5.9 & 4.2 & 181.7 \\
Pacific & $\left(60^{\circ} \mathrm{S} \rightarrow 30^{\circ} \mathrm{S}\right)$ & 1.340 & 7.551 & -1.135 & -7.382 & 10.9 & 8.3 & 166.8 \\
& $\left(30^{\circ} \mathrm{N} \rightarrow 60^{\circ} \mathrm{N}\right)$ & 1.155 & 7.248 & -1.199 & 2.336 & 9.8 & 5.9 & 168.4 \\
& $\left(0^{\circ} \mathrm{N} \rightarrow 30^{\circ} \mathrm{N}\right)$ & 1.000 & 7.015 & -1.100 & 7.916 & 25.0 & 9.8 & 236.8 \\
& $\left(30^{\circ} \mathrm{S} \rightarrow 0^{\circ} \mathrm{N}\right)$ & 0.977 & 7.137 & -0.993 & -0.392 & 26.7 & 11.8 & 308.7 \\
Indian & $\left(60^{\circ} \mathrm{S} \rightarrow 30^{\circ} \mathrm{S}\right)$ & 1.257 & 7.432 & -1.149 & -3.899 & 27.5 & 17.9 & 175.5 \\
& $\left(0^{\circ} \mathrm{N} \rightarrow 30^{\circ} \mathrm{N}\right)$ & 1.118 & 7.436 & -1.004 & -10.885 & 3.2 & 2.0 & 411.0 \\
& $\left(30^{\circ} \mathrm{S} \rightarrow 0^{\circ} \mathrm{N}\right)$ & 1.242 & 7.393 & -1.139 & -2.528 & 11.2 & 8.2 & 215.9 \\
Southern & $\left(60^{\circ} \mathrm{S} \rightarrow 30^{\circ} \mathrm{S}\right)$ & 1.374 & 7.469 & -1.190 & -1.594 & 13.2 & 10.3 & 207.3 \\
\hline & $\left(90^{\circ} \mathrm{S} \rightarrow 60^{\circ} \mathrm{S}\right)$ & 1.339 & 7.449 & -1.347 & -1.653 & 3.6 & 5.2 & 283.7 \\
\hline
\end{tabular}


Table 8. As Table 7 except $C_{\text {ant }}$ is integrated only in regions where ventilation age is below 173 years.

\begin{tabular}{|c|c|c|c|c|c|c|c|c|}
\hline \multirow{3}{*}{\multicolumn{2}{|c|}{ Domain }} & \multicolumn{4}{|c|}{ TrOCA parameters } & \multicolumn{3}{|c|}{$\mathrm{C}_{\text {ant }}$ inventory } \\
\hline & & \multirow[t]{2}{*}{$a$} & \multirow[t]{2}{*}{$b$} & \multirow{2}{*}{$\begin{array}{c}c \\
\times 10^{-2}\end{array}$} & \multirow{2}{*}{$\begin{array}{c}d \\
\times 10^{5}\end{array}$} & \multicolumn{2}{|c|}{ Regional } & \multirow{2}{*}{$\begin{array}{l}\text { Global } \\
\text { TrOCA }\end{array}$} \\
\hline & & & & & & TrOCA & Actual & \\
\hline Default $T$ & & 1.279 & 7.511 & -1.087 & 7.810 & - & - & 232.4 \\
\hline World Oc & & 1.031 & 7.281 & -1.060 & -5.161 & 190.8 & 103.5 & 190.8 \\
\hline Atlantic C & & 1.229 & 7.556 & -1.100 & -11.867 & 47.3 & 33.9 & 175.8 \\
\hline Pacific $\mathrm{O}$ & & 0.968 & 7.143 & -1.039 & -0.669 & 91.3 & 48.4 & 215.1 \\
\hline Indian Oc & & 1.241 & 7.531 & -1.125 & -10.052 & 31.9 & 21.3 & 186.4 \\
\hline \multirow[t]{5}{*}{ Atlantic } & $\left(60^{\circ} \mathrm{N} \rightarrow 90^{\circ} \mathrm{N}\right)$ & 0.865 & 7.086 & -0.753 & -2.314 & 5.6 & 2.7 & 91.4 \\
\hline & $\left(30^{\circ} \mathrm{N} \rightarrow 60^{\circ} \mathrm{N}\right)$ & 1.129 & 7.417 & -1.117 & -8.093 & 12.8 & 10.5 & 156.4 \\
\hline & $\left(0^{\circ} \mathrm{N} \rightarrow 30^{\circ} \mathrm{N}\right)$ & 1.295 & 7.542 & -1.104 & -8.707 & 9.2 & 6.7 & 190.3 \\
\hline & $\left(30^{\circ} \mathrm{S} \rightarrow 0^{\circ} \mathrm{N}\right)$ & 1.279 & 7.668 & -1.131 & -16.024 & 5.8 & 4.2 & 182.0 \\
\hline & $\left(60^{\circ} \mathrm{S} \rightarrow 30^{\circ} \mathrm{S}\right)$ & 1.380 & 7.576 & -1.144 & -7.361 & 10.6 & 8.3 & 178.2 \\
\hline \multirow[t]{4}{*}{ Pacific } & $\left(30^{\circ} \mathrm{N} \rightarrow 60^{\circ} \mathrm{N}\right)$ & 1.127 & 7.330 & -1.107 & -3.511 & 8.5 & 5.9 & 158.7 \\
\hline & $\left(0^{\circ} \mathrm{N} \rightarrow 30^{\circ} \mathrm{N}\right)$ & 0.645 & 6.762 & -0.636 & -2.337 & 108.7 & 9.8 & 1359.5 \\
\hline & $\left(30^{\circ} \mathrm{S} \rightarrow 0^{\circ} \mathrm{N}\right)$ & 0.781 & 7.040 & -0.833 & -6.806 & 43.1 & 11.8 & 673.1 \\
\hline & $\left(60^{\circ} \mathrm{S} \rightarrow 30^{\circ} \mathrm{S}\right)$ & 1.267 & 7.482 & -1.137 & -6.302 & 28.0 & 17.9 & 175.2 \\
\hline \multirow[t]{3}{*}{ Indian } & $\left(0^{\circ} \mathrm{N} \rightarrow 30^{\circ} \mathrm{N}\right)$ & 0.960 & 7.310 & -0.883 & -12.453 & 5.6 & 2.0 & 748.3 \\
\hline & $\left(30^{\circ} \mathrm{S} \rightarrow 0^{\circ} \mathrm{N}\right)$ & 1.175 & 7.512 & -1.085 & -12.048 & 11.4 & 8.2 & 269.9 \\
\hline & $\left(60^{\circ} \mathrm{S} \rightarrow 30^{\circ} \mathrm{S}\right)$ & 1.393 & 7.467 & -1.190 & -0.831 & 12.8 & 10.3 & 215.5 \\
\hline Southern & $\left(90^{\circ} \mathrm{S} \rightarrow 60^{\circ} \mathrm{S}\right)$ & 1.386 & 7.519 & -1.295 & -3.882 & 3.6 & 5.2 & 263.6 \\
\hline
\end{tabular}

\section{Summary and conclusions}

Using theoretical considerations, we have demonstrated that the TrOCA method is a classical back-calculation technique, and that the TrOCA tracer itself is actually identical (except for a constant factor) to the $\mathrm{C}^{*}$ tracer introduced by Gruber et al. (1996). Variations in this tracer reflect the combined impact of the air-sea exchange of $\mathrm{CO}_{2}$ and $\mathrm{O}_{2}$. The challenge, as is the case with all back-calculation techniques, is the estimation of the pre-industrial, preformed value of TrOCA. It turns out that the TrOCA method is potentially exceptionally prone to errors in this estimation for two reasons. Firstly, any parameterization for the pre-industrial, preformed value of TrOCA needs to accurately capture a large dynamic range of this tracer, a range that is several times larger than the $\mathrm{C}_{\mathrm{ant}}$ signal that should be determined. Secondly, the relationship of TrOCA with temperature and alkalinity is likely much more complex than a simple four parametric curve would suggest, primarily because the air-sea exchange of $\mathrm{CO}_{2}$ scales very poorly with temperature (and also alkalinity).

Using biogeochemical tracer distributions derived from an ocean general circulation model, we have examined the impact of these challenges for the TrOCA method in a quantitative manner. We find that the standard TrOCA method considerably overestimates the model's "true" anthropogenic $\mathrm{CO}_{2}$ by about a factor of 2. Applying default TrOCA to global fields of observed ocean properties from the GLODAP and World Ocean Atlas climatologies also produces a large (about 50\%) overestimate of the ocean's anthropogenic $\mathrm{CO}_{2}$ content relative to other established methods of deconvolution (Gruber et al., 1996) and the most recent estimate of Khatiwala et al. (2009).

In order to test how sensitive these results are to possible deficiencies of our model, we followed the approach outlined by Touratier et al. (2007) and re-parameterised the TrOCA method utilising a range of different calibration data sets in the optimisation process. While the results showed regional differences for different calibration data sets, the overall conclusion that TrOCA tends to considerably overestimate anthropogenic $\mathrm{CO}_{2}$ remains unchanged. Furthermore, the results of this procedure suggest that no single TrOCA parameter set can operate "universally" across the world ocean. However, given that the TrOCA method is optimised in Touratier et al. (2007) using global-scale data, it is difficult to justify its applicability at other scales. Within the framework of our model, we also show that TrOCA's inherent assumption of similar surface $p \mathrm{CO}_{2}$ disequilibrium in the 1990s and in the pre-industrial world is not critical.

According to our model-based analysis, the main error in the TrOCA estimates comes from the errors associated with estimating the pre-industrial value of the approximately conservative TrOCA tracer, $\operatorname{TrOCA}^{0}$, consistent with the theoretical arguments. Assuming no anthropogenic impact on oxygen and alkalinity, this directly corresponds to errors in the estimate of natural DIC, $\mathrm{C}_{\mathrm{T}}^{0 \text {, TrOCA }}$ (Eq. 21). Although the relative errors of $\mathrm{C}_{\mathrm{T}}^{0, \mathrm{TrOCA}}$ are small, the absolute errors are of comparable magnitude to the total anthropogenic $\mathrm{CO}_{2}$ 


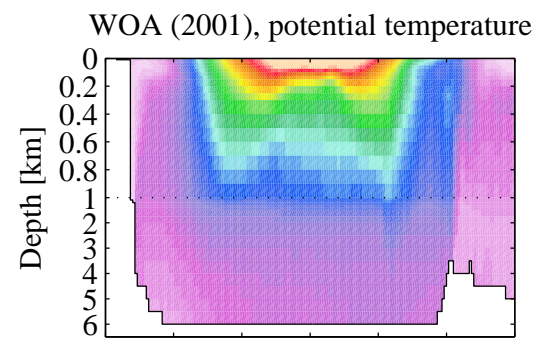

OCCAM, potential temperature
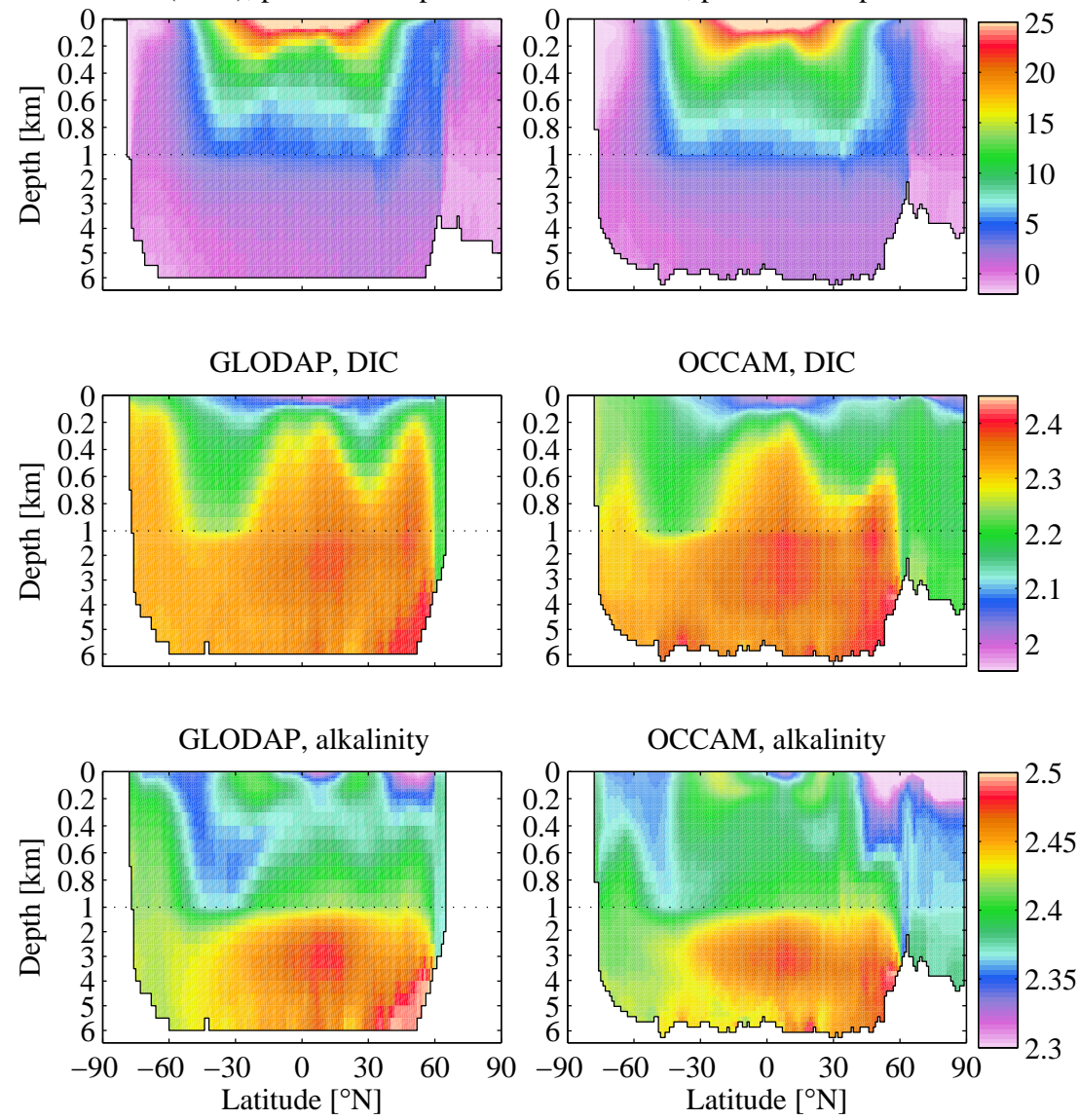

Fig. A1. Zonal average comparison of observational (left column) and OCCAM simulated biogeochemical fields. Potential temperature (top; ${ }^{\circ} \mathrm{C}$ ) is derived from the World Ocean Atlas (2001; Conkright et al., 2002). DIC (middle; mol m ${ }^{-3}$ ) and alkalinity (bottom; eq ${ }^{-3}$ ) are derived from the GLODAP climatology (Key et al., 2004). Note that the vertical scale on each panel is non-linear to emphasise the upper $1000 \mathrm{~m}$ of the ocean, and that the GLODAP climatology does not include any data at latitudes greater than $65^{\circ} \mathrm{N}$.

signal, preventing the TrOCA method from recovering $\mathrm{C}_{\mathrm{ant}}$ in our OCCAM simulation. Consequently, the failure of the application of synthetic data from OCCAM in the creation of TrOCA variants is unsurprising.

In conclusion, our theoretical and model-based analyses suggest that the TrOCA method cannot be recommended to reconstruct anthropogenic $\mathrm{CO}_{2}$ on the basis of DIC observations. The potential errors are substantially larger than those associated with alternative methods, for which similar model-based assessments suggested biases of less than $10 \%$.

Looking ahead, the issue of estimating $\mathrm{C}_{\text {ant }}$ from one-time survey data is becoming less of an issue, as we increasingly have data available from repeated occupations of longtransects (see Sabine and Tanhua, 2010 for a recent summary). The identification of the changes in DIC, and the underlying changes in $\mathrm{C}_{\mathrm{ant}}$ and natural DIC represent a substantial remaining challenge, although several methods, such as the extended MLR (e.g. Friis et al., 2005) have been proposed. However, a model-based assessment of such methods by Levine et al. (2008) demonstrated that each of these methods have substantial potential biases, requiring further investigations to fully characterize the errors associated with estimates of decadal changes in the ocean carbon cycle. Thus, whether the goal is to estimate the oceanic uptake of $\mathrm{C}_{\mathrm{ant}}$ since pre-industrial times from one-time survey data, or the change in $\mathrm{C}_{\mathrm{ant}}$ content over decadal time-scales on the basis of repeat data, substantial challenges remain to not only determine the best estimate, but also to fully characterize the associated errors.

\section{Appendix A}

The following equations describe the tendency terms operating on the biogeochemical tracers in the model. 

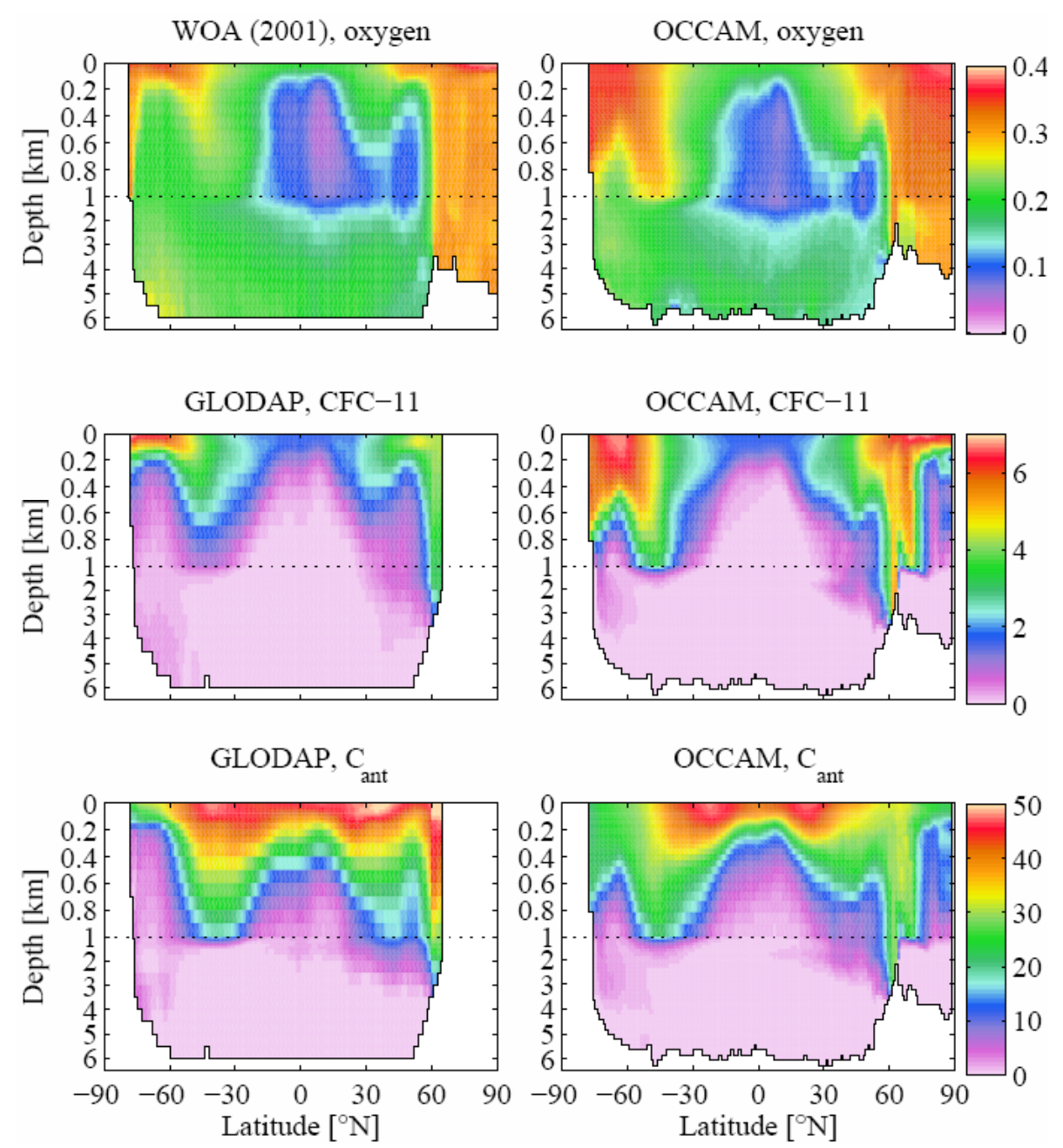

Fig. A2. Zonal average comparison of observational (left column) and OCCAM simulated biogeochemical fields. Oxygen (top; ${ }^{\circ} \mathrm{C}$ ) is derived from the World Ocean Atlas (2001; Conkright et al., 2002). CFC-11 (middle; $\mathrm{nmol} \mathrm{m}^{-3}$ ) and $\mathrm{C}_{\text {ant }}\left(\right.$ bottom; eq $\mathrm{m}^{-3}$ ) are derived from the GLODAP climatology (Key et al., 2004). Note that the vertical scale on each panel is non-linear to emphasise the upper $1000 \mathrm{~m}$ of the ocean, and that the GLODAP climatology does not include any data at latitudes greater than $65^{\circ} \mathrm{N}$.

$$
\begin{gathered}
\frac{\partial P}{\partial t}=+\underbrace{\left[F_{\mathrm{PP}}\left(J, Q_{N}\right) \cdot P\right]}_{\text {primary production }}-\underbrace{\left[G_{P}\right]}_{\text {grazing loss }}-\underbrace{\left[\mu_{P 1}\right]}_{\text {metabolic loss }}-\underbrace{\left[\mu_{P 2}\right]}_{\text {nat. mortali }} \\
\frac{\partial Z}{\partial t}=+\underbrace{\left[F_{Z}\right]}_{\text {grazing }}-\underbrace{\left[\mu_{Z 1}\right]}_{\text {metabolic loss }}-\underbrace{\left[\mu_{Z 2}\right]}_{\text {predation }} \\
\frac{\partial D_{N}}{\partial t}=+\underbrace{\left[\left(1-\beta_{N}\right) \cdot I_{N}\right]}_{\text {Z egestion }}+\underbrace{\left[\mu_{P 2}\right]}_{\text {P nat. mortality }}+\underbrace{\left[\mu_{Z 2}\right]}_{\text {Z predation }} \\
-\underbrace{\left[\mu_{D N}\right]}_{\text {remin. }}+\underbrace{\left[S\left(D_{N}\right)\right]}_{\text {D sinking }}
\end{gathered}
$$

$$
\begin{aligned}
\frac{\partial N}{\partial t} & =-\underbrace{\left[F_{\mathrm{PP}}\left(J, Q_{N}\right) \cdot P\right]}_{\text {primary production }}+\underbrace{\left[E_{Z}\right]}_{\text {Zexcretion }}+\underbrace{\left[\phi \cdot G_{P}\right]}_{\text {messy feeding }} \\
& +\underbrace{\left[\mu_{P 1}\right]}_{\text {P metab. loss }}+\underbrace{\left[\mu_{Z 1}\right]}_{\text {Z metab. loss }}+\underbrace{\left[\mu_{D N}\right]}_{\text {D remin. }}
\end{aligned}
$$

$$
\begin{gathered}
\frac{\partial D_{C}}{\partial t}=+\underbrace{\left[\left(1-\beta_{C}\right) \cdot I_{C}\right]}_{\text {Zegestion }}+\underbrace{\left[\theta_{P} \cdot \mu_{P 2}\right]}_{\text {P nat. mortality }}+\underbrace{\left[\theta_{Z} \cdot \mu_{Z 2}\right]}_{\text {Z predation }} \\
-\underbrace{\left[\mu_{D C}\right]}_{\text {remin. }}+\underbrace{\left[S\left(D_{C}\right)\right]}_{\text {D sinking }}
\end{gathered}
$$



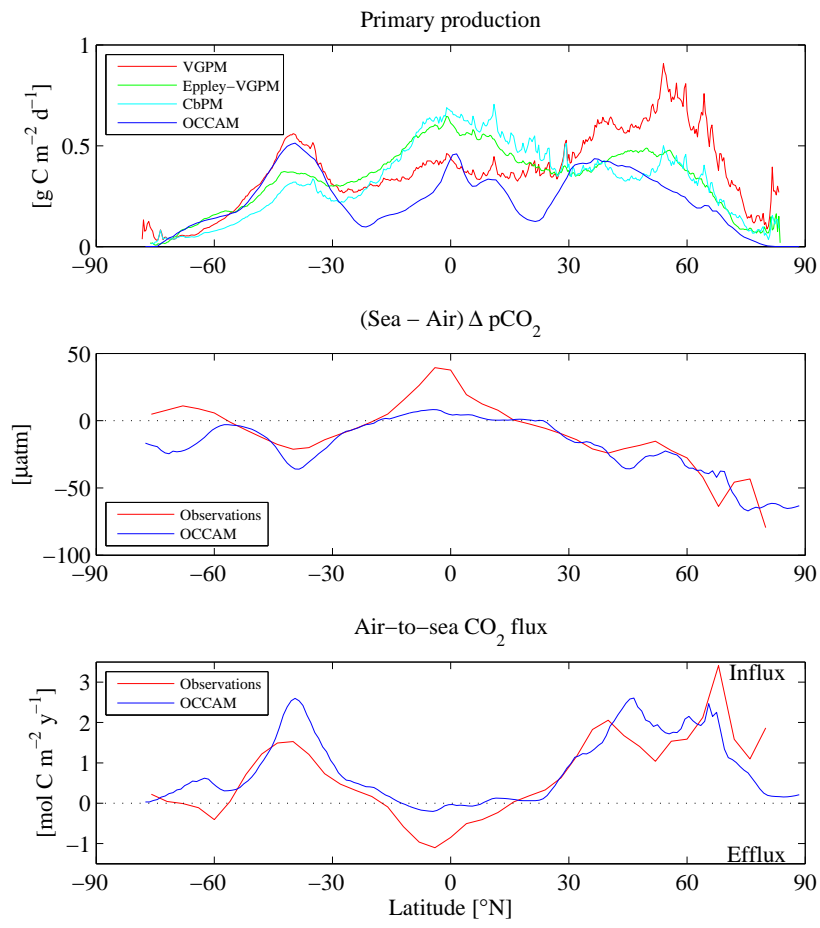

Fig. A3. Comparison of zonally-averaged observational and model fields of primary production (top), (sea-air) $\Delta p \mathrm{CO}_{2}$ (middle) and air-sea $\mathrm{CO}_{2}$ flux (lower). Primary production observations are derived by applying the VGPM (Behrenfeld and Falkowski, 1997), Eppley-VGPM (Carr et al., 2006) and CbPM (Westberry et al., 2008) productivity models to SeaWIFS fields of surface chlorophyll for the period 2003 to 2004. (Sea-air) $\Delta p \mathrm{CO}_{2}$ and air-sea $\mathrm{CO}_{2}$ flux observations are those estimated by Takahashi et al. (2009) for the standardised year 2000. The corresponding model output are the averages of these fields for the matching periods.

$$
\begin{aligned}
& \frac{\partial \mathrm{DIC}}{\partial t}=-\underbrace{\left[F_{\mathrm{PP}}\left(J, Q_{N}\right) \cdot \theta_{P} \cdot P\right]}_{\text {organic production }}+\underbrace{\left[\phi \cdot \theta_{P} \cdot G_{P}\right]}_{\text {messy feeding }} \\
& -\underbrace{\left[F_{\mathrm{Ca}} \cdot F_{\mathrm{PP}}\left(J, Q_{N}\right) \cdot \theta_{P} \cdot P\right]}_{\text {inorganic production }}+\underbrace{\left[R_{Z}\right]}_{\text {Z respiration }}+\underbrace{\left[\theta_{P} \cdot \mu_{P 1}\right]}_{\text {P metab. loss }} \\
& +\underbrace{\left[\theta_{Z} \cdot \mu_{Z 1}\right]}_{\text {Z metab. loss }} \\
& +\underbrace{\left[\mu_{D C}\right]}_{\text {D remin }}+\underbrace{\left[R_{\mathrm{Ca}}(k) \cdot T_{\mathrm{Ca}}\right]}_{\text {inorganic remin. }}+\underbrace{\left[F_{\text {atm }, C}\right]}_{\text {air-sea flux }}
\end{aligned}
$$

$$
\begin{aligned}
\frac{\partial \mathrm{ALK}}{\partial t} & =-\underbrace{\left[2 \cdot F_{\mathrm{Ca}} \cdot F_{\mathrm{PP}}\left(J, Q_{N}\right) \cdot \theta_{P} \cdot P\right]}_{\text {inorganic production }} \\
& +\underbrace{\left[2 \cdot R_{\mathrm{Ca}}(k) \cdot T_{\mathrm{Ca}}\right]}_{\text {inorganic remin. }}
\end{aligned}
$$
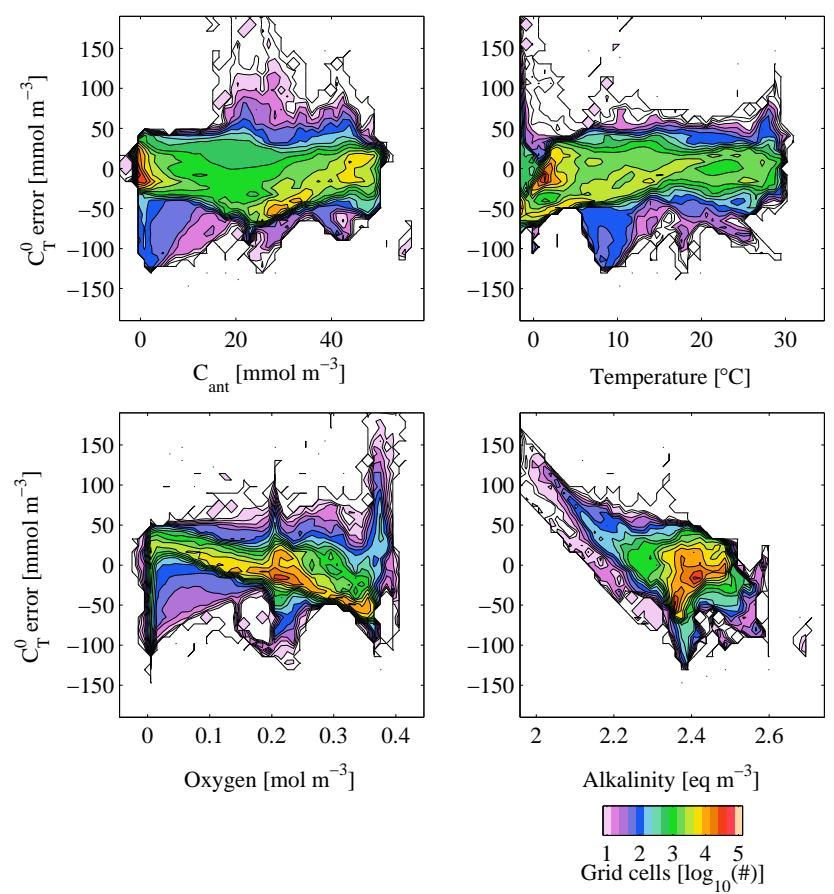

Fig. A4. As Fig. 9 but showing error in $\mathrm{C}_{\mathrm{T}}^{0}$ (estimated - simulated) plotted against actual $\mathrm{C}_{\mathrm{ant}}$ (top left), potential temperature (top right) oxygen (bottom left) and alkalinity (bottom right). Estimated $\mathrm{C}_{\mathrm{T}}^{0}$ here is based on the TrOCA variant optimised with the full global calibration dataset. In each case the colour scale is identical and denotes the logarithmic density of OCCAM grid cells (cell volume is ignored here). The plots indicate relationships between TrOCA variant error and the ocean properties used in the TrOCA equation.

$$
\begin{aligned}
& \frac{\partial O_{2}}{\partial t}=+\underbrace{\left[\theta_{\text {phy }} \cdot F_{\mathrm{PP}}\left(J, Q_{N}\right) \cdot P\right]}_{\text {primary production }}-\underbrace{\left[\theta_{\text {phy }} \cdot \phi \cdot G_{P}\right]}_{\text {messy feeding }} \\
& -\underbrace{\left[\theta_{\text {nit }} \cdot E_{Z}\right]}_{\text {Z excretion }}-\underbrace{\left[\theta_{\text {rem }} \cdot R_{Z}\right]}_{\mathrm{Z} \text { respiration }}-\underbrace{\left[\theta_{\text {phy }} \cdot \mu_{P 1}\right]}_{\text {P metab. loss }}-\underbrace{\left[\theta_{\text {zoo }} \cdot \mu_{Z 1}\right]}_{\text {Z metab. loss }} \\
& -\underbrace{\left[\theta_{\text {nit }} \cdot \mu_{D N}\right]}_{D_{N} \text { remin }}-\underbrace{\left[\theta_{\text {rem }} \cdot \mu_{D C}\right]}_{D_{C} \text { remin }}+\underbrace{\left[F_{\text {atm }, \mathrm{O}_{2}}\right]}_{\text {air-sea flux }}
\end{aligned}
$$

where,

$$
\begin{aligned}
& J(k)=\int_{z_{k}}^{z_{k+1}} F\left(I_{z_{k}} \cdot \exp \left\{-\left(k_{w}+\left(k_{c} \cdot P(k)\right)\right) \cdot z\right\}\right) d z \\
& F_{I}=\frac{\left(V_{t} \cdot \alpha \cdot I\right)}{\sqrt{\left(V_{t}^{2}+\left(\alpha^{2} \cdot I^{2}\right)\right)}} \\
& V_{t}=V_{p} \cdot 1.066^{\theta} \\
& Q_{N}=\frac{N}{k_{N}+N}
\end{aligned}
$$



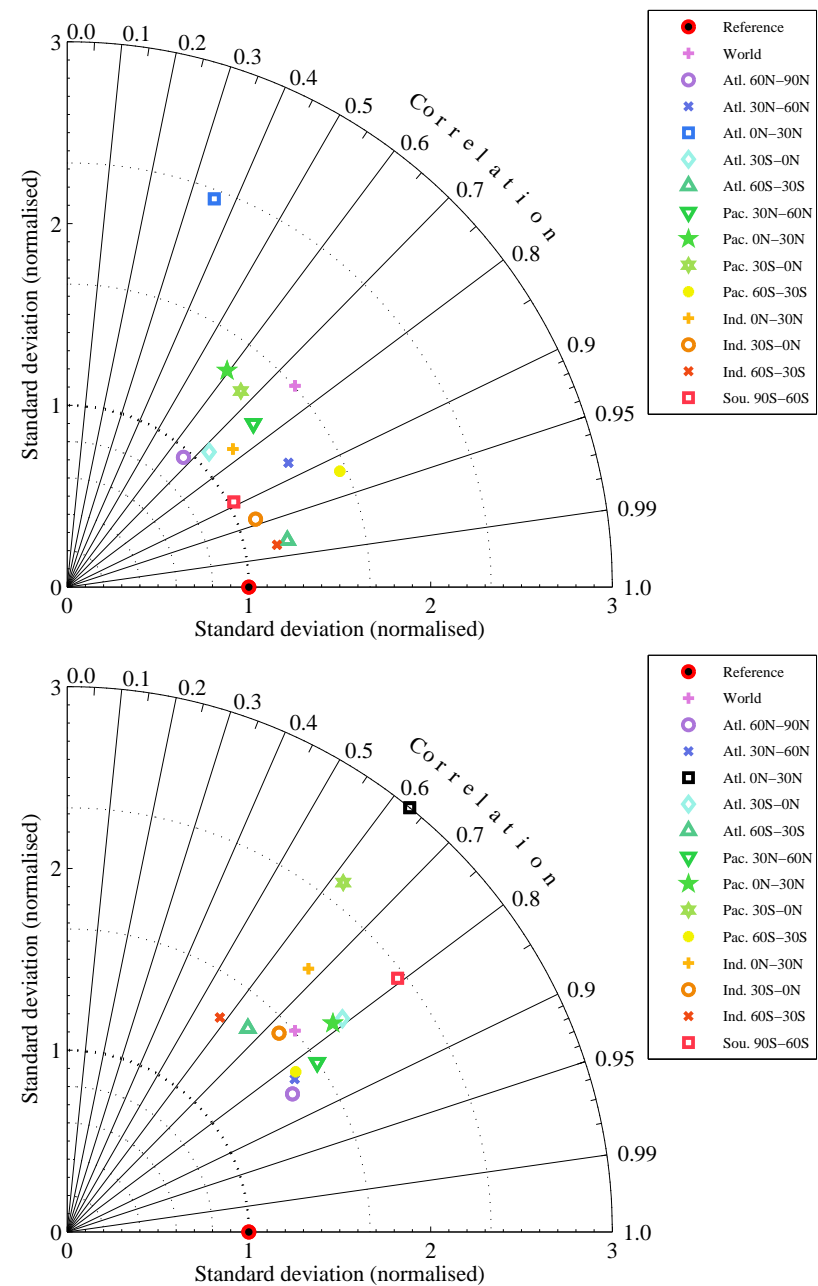

Fig. A5. As Fig. 7 but showing TrOCA variants optimised using actual $\mathrm{C}_{\text {ant }} . \mathrm{C}_{\mathrm{ant}}$ in $\mathrm{mmol} \mathrm{m}^{-3}$.

$F_{\mathrm{PP}}\left(J, Q_{N}\right)=\min \left(J, V_{t} \cdot Q_{N}\right)$

$G_{P}=\frac{g \cdot k_{g} P^{2} \cdot Z}{g+\left(k_{g} \cdot P^{2}\right)}$

$\mu_{P 1}=\phi_{P 1} \cdot P$

$\mu_{P 2}=\phi_{P 2} \cdot P^{2}$

$I_{N}=(1-\phi) \cdot G_{P}$

$I_{C}=(1-\phi) \cdot\left(\theta_{P} \cdot G_{P}\right)$

$\theta_{F}=\frac{I_{C}}{I_{N}}$

$$
\begin{aligned}
& F_{Z}=\frac{\beta_{C} \cdot k_{C} \cdot I_{C}}{\theta_{Z}} \\
& E_{Z}=I_{C} \cdot\left(\frac{\beta_{N}}{\theta_{F}}-\frac{\beta_{C} \cdot k_{C}}{\theta_{Z}}\right) \\
& R_{Z}=\left(\beta_{C} \cdot I_{C}\right)-\left(\theta_{Z} \cdot F_{Z}\right) \\
& \mu_{Z 1}=\phi_{Z 1} \cdot Z \\
& \mu_{Z 1}=\phi_{Z 2} \cdot Z^{2} \\
& \mu_{D N}=\mu_{D} \cdot D_{N} \\
& \mu_{D C}=\mu_{D_{C}} \cdot D_{C}
\end{aligned}
$$$$
F_{\mathrm{Ca}}=\text { Fixed fraction of primary production }
$$$$
T_{\mathrm{Ca}}=\int_{k=1}^{k=66} F_{\mathrm{Ca}} \cdot F_{\mathrm{PP}}\left(J, Q_{N}\right) \cdot \theta_{P} \cdot P
$$$$
f_{\mathrm{Ca}}(k)=\exp \left(-\frac{z(k)-z_{\mathrm{Ca}}}{d_{\mathrm{Ca}}}\right)
$$$$
R_{\mathrm{Ca}}(k)=f_{\mathrm{Ca}}(k-1)-f_{\mathrm{Ca}}(k)
$$$$
\theta_{\text {phy }}=\frac{32}{16}+\left(\theta_{P} \cdot \frac{119}{106}\right)
$$

$\theta_{\mathrm{zoo}}=\frac{32}{16}+\left(\theta_{Z} \cdot \frac{119}{106}\right)$

$\theta_{\text {nit }}=\frac{32}{16}$

$\theta_{\text {rem }}=\frac{119}{106}$

$V_{z}=V_{0}+(0.02 \cdot z)$

where,

$\begin{array}{cl} & \text { Phytoplankton } \\ V_{p} & \text { Maximum growth rate }\left(\text { at } 0^{\circ} \mathrm{C}\right) \\ \alpha & \text { Initial slope of P-I curve } \\ k_{w} & \text { Background attenuation coefficient } \\ k_{c} & \text { Phytoplankton self-shading coefficent } \\ K_{N} & \text { DIN uptake half-saturation concentration } \\ \phi_{P 1} & \text { Density-independent loss rate } \\ \phi_{P 2} & \text { Density-dependent loss rate } \\ F_{\mathrm{Ca}} & \mathrm{CaCO} \text { fraction of total primary production } \\ \theta_{P} & \mathrm{C}: \mathrm{N} \text { ratio }\end{array}$

$0.6 \mathrm{~d}^{-1}$ $0.025\left(\mathrm{~W} \mathrm{~m}^{-2}\right)^{-1} \mathrm{~d}^{-1}$ $0.04 \mathrm{~m}^{-1}$ $0.03 \mathrm{~m}^{-1}\left(\mathrm{mmol} \mathrm{N} \mathrm{m}^{-3}\right)^{-1}$ $0.5 \mathrm{mmol} \mathrm{N} \mathrm{m}^{-3}$ $0.05 \mathrm{~d}^{-1}$ $\left.0.05 \mathrm{~d}^{-1}(\mathrm{mmol} \mathrm{N} \mathrm{m})^{-3}\right)^{-1}$ $0.01-$ $6.625 \mathrm{~mol} \mathrm{C}(\mathrm{mol} \mathrm{N})^{-1}$ 


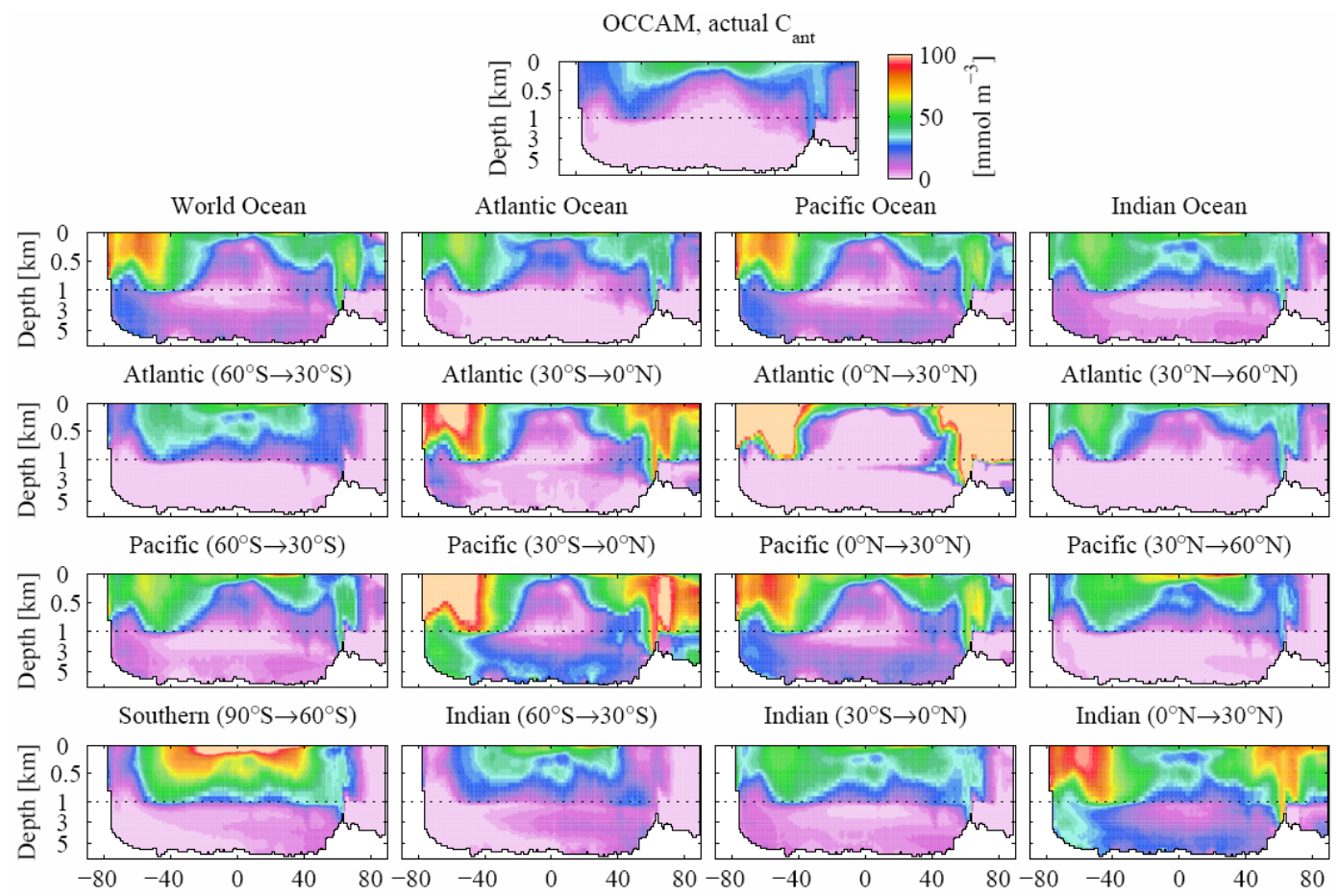

Fig. A6. As Fig. 7 but showing TrOCA variants optimised using actual $\mathrm{C}_{\text {ant }} \cdot \mathrm{C}_{\mathrm{ant}}$ in $\mathrm{mmol} \mathrm{m}^{-3}$.

\begin{tabular}{|c|c|c|}
\hline & Zooplankton & \\
\hline$g$ & Maximum grazing rate & $2.0 \mathrm{~d}^{-1}$ \\
\hline$k_{g}$ & Prey capture rate & $1.0 \mathrm{~m}^{6}(\mathrm{mmol} \mathrm{N})^{-2} \mathrm{~d}^{-1}$ \\
\hline$\beta_{N}^{\circ}$ & $\mathrm{N}$ assimilation efficiency & $0.77-$ \\
\hline$\beta_{C}$ & $\mathrm{C}$ assimilation efficiency & $0.64-$ \\
\hline$k_{C}$ & Net $\mathrm{C}$ growth efficiency & $0.80-$ \\
\hline$\phi$ & Grazing inefficiency (messy feeding) & $0.23-$ \\
\hline$\phi_{Z 1}$ & Density-independent loss rate & $0.03 \mathrm{~d}^{-1}$ \\
\hline$\phi_{Z 2}$ & Density-dependent loss rate & $0.20 \mathrm{~d}^{-1}\left(\mathrm{mmol} \mathrm{N} \mathrm{m}^{-3}\right)^{-1}$ \\
\hline$\theta_{Z}$ & $\mathrm{C}: \mathrm{N}$ ratio & $5.625 \mathrm{~mol} \mathrm{C}(\mathrm{mol} \mathrm{N})^{-1}$ \\
\hline & Other parameters & \\
\hline$\mu_{D}$ & Detrital $\mathrm{N}$ remineralisation rate & $0.05 \mathrm{~d}^{-1}$ \\
\hline$\mu_{D_{C}}$ & Detrital C remineralisation rate & $0.04 \mathrm{~d}^{-1}$ \\
\hline$V_{\min }$ & Detrital sinking speed at $0 \mathrm{~m}$ & $3.5 \mathrm{~m} \mathrm{~d}^{-1}$ \\
\hline$z_{\mathrm{Ca}}$ & Minimum $\mathrm{CaCO}_{3}$ dissolution depth & $127 \mathrm{~m}$ \\
\hline$d_{\mathrm{Ca}}$ & $\mathrm{CaCO}_{3}$ dissolution e-folding length scale & $3500 \mathrm{~m}$ \\
\hline$O_{\min }$ & Aerobic remineralisation $\mathrm{O}_{2}$ minimum & $4.0 \mathrm{mmol} \mathrm{O}_{2} \mathrm{~m}^{-3}$ \\
\hline$\theta_{\text {phy }}$ & Oxygen evolution/consumption via $\mathrm{P}$ & $9.4375 \mathrm{~mol} \mathrm{O}_{2}(\mathrm{~mol} \mathrm{~N})^{-1}$ \\
\hline$\theta_{\text {zoo }}$ & Oxygen consumption via $\mathrm{Z}$ & $8.3149 \mathrm{~mol} \mathrm{O}_{2}(\mathrm{~mol} \mathrm{~N})^{-1}$ \\
\hline$\theta_{\text {rem }}$ & Oxygen consumption by $\mathrm{C}$ remineralisation & $1.1226 \mathrm{~mol} \mathrm{O}_{2}(\mathrm{~mol} \mathrm{C})^{-1}$ \\
\hline$\theta_{\text {nit }}$ & Oxygen consumption by $\mathrm{N}$ nitrification & $2.0 \mathrm{~mol} \mathrm{O}_{2}(\mathrm{~mol} \mathrm{~N})^{-1}$ \\
\hline
\end{tabular}

\section{Appendix B}

Prior to using simulation output with the TrOCA method, OCCAM's performance in representing the period 18642004 was assessed, with particular regard to the model's carbon cycle and its simulated $\mathrm{C}_{\text {ant }}$ and CFC-11 distributions.

The distribution of CFC-11 for the mid-1990s from the GLODAP climatology (Key et al., 2004) was compared to the corresponding annual average OCCAM output from 1995. While OCCAM generally captures the (primarily temperature-dependent) patterns of surface CFC-11 distribu- tion, concentrations are generally elevated over those from GLODAP. This is most noticeable in the Southern Ocean, where isolines of CFC- 11 are shifted up to $10^{\circ}$ northwards. Integrating through the full water column, the GLODAP climatology estimates a total CFC- 11 inventory of $0.540 \mathrm{Gmol}$, while OCCAM simulates a significantly greater uptake of $0.790 \mathrm{Gmol}(+49 \%$; this figure is corrected for the data gaps in the GLODAP climatology). This high oceanic inventory of CFC-11 places OCCAM near the top of the range (approximately $0.45-0.85 \mathrm{Gmol}$ ) of OGCMs surveyed by the OCMIP-2 project (Dutay et al., 2002; OCCAM uses the same CFC-11 protocol as the OCMIP-2 OGCMs).

Figure 2 shows vertically-integrated $\mathrm{C}_{\mathrm{ant}}$ for the GLODAP climatology (Key et al., 2004) and the OCCAM simulation (see also Fig. 3 for corresponding vertical distribution). The GLODAP field shown here is an estimate of the distribution of $\mathrm{C}_{\mathrm{ant}}$ based on indirect observations and the $\Delta C^{*}$ method (Gruber et al., 1996; Sabine et al., 2004). As such, it is an estimate based upon an alternative technique to the TrOCA method examined here. Generally, OCCAM's $\mathrm{C}_{\mathrm{ant}}$ distribution is broadly in agreement with that of GLODAP, but with a number of regional discrepancies. Most notably, OCCAM estimates a much lower inventory of $\mathrm{C}_{\text {ant }}$ in North Atlantic Deep Water (NADW). While OCCAM still identifies this water mass as that most penetrated by $\mathrm{C}_{\mathrm{ant}}$, model concentrations are noticeably lower than in GLODAP. The waters of the Pacific basin show much greater agreement between the two estimates, though the Pacific sector of the Southern Ocean (and the Southern Ocean in general) 
shows differences. The extent of $\mathrm{C}_{\mathrm{ant}}$ penetration of Southern Ocean waters is broader in OCCAM, particularly with regards to the most southern waters adjacent to Antarctica. OCCAM also estimates lower $\mathrm{C}_{\mathrm{ant}}$ in the equatorial regions of both the Atlantic and Indian basins. The estimates of the GLODAP climatology in these regions are considerably more variable than in OCCAM. Nonetheless, integrating $\mathrm{C}_{\mathrm{ant}}$ at the global scale finds totals of 8.66 Pmol (GLODAP) and 8.11 Pmol (OCCAM; $-6.4 \%$ ) in relatively close agreement. This underestimation of oceanic uptake is in part related to the initiation of the historical simulation in 1864. As noted in the main text, this "short-cut" skips approximately 100 years during which the ocean absorbed $\mathrm{C}_{\mathrm{ant}}$. To estimate the significance of this omission, we compared OCCAM with output derived from an earlier in-house simulation that included the full industrial period and which utilised the same carbon cycle sub-model embedded in a different, lower resolution GCM (the "SOC" model; see Matsumoto et al., 2004). We found that by 1864 the ocean contained approximately $15 \%$ of the total $\mathrm{C}_{\mathrm{ant}}$ absorbed by the 1990s. This suggests that OCCAM's small underestimate of the $\mathrm{C}_{\mathrm{ant}}$ inventory would most likely overestimate were this earlier period also simulated.

Figures A1 and A2 present the zonally averaged distributions of the model tracers relevant to TrOCA (potential temperature, DIC, alkalinity, oxygen, CFC-11 and $\mathrm{C}_{\text {ant }}$ ) alongside those from the World Ocean Atlas and GLODAP climatologies. These show OCCAM's generally good agreement with observational (or derived, in the case of $\mathrm{C}_{\mathrm{ant}}$ ) fields, but also indicate some systematic problems with the simulation. As mentioned above, OCCAM significantly overestimates the CFC-11 inventory of the ocean, and this can be seen at high latitudes (particularly in the southern hemisphere) in Fig. A2. This is caused by excessive ventilation of deeper waters in these regions, and can also be seen in the fields of oxygen and $\mathrm{C}_{\mathrm{ant}}$. In the case of the latter, its distinct zonal distribution (higher surface concentrations occur in warm, tropical waters) contrasts with that of CFC-11 (higher surface concentrations occur in cold, polar waters), and excessive high latitude ventilation acting on these distributions may explain OCCAM's elevated uptake of CFC-11 relative to $\mathrm{C}_{\text {ant }}$.

Finally, Fig. A3 compares observational and OCCAM primary production (Behrenfeld and Falkowski, 1997; Carr et al., 2006; Westberry et al., 2008) and (sea-air) $\Delta p \mathrm{CO}_{2}$ and air-sea $\mathrm{CO}_{2}$ flux (Takahashi et al., 2009; including October 2009 corrections). In terms of primary production, the model shows the greatest discrepancy with observations in the subtropics. In these regions, the model typically underestimates production in the gyre centres and shows a more pronounced "equatorial stripe" of higher productivity. The model is generally in better agreement at higher latitudes, although it underestimates productivity in the northern hemisphere (especially with respect to the VGPM model). The model shows greater agreement with observational (sea-air) $\Delta p \mathrm{CO}_{2}$ and related air-sea $\mathrm{CO}_{2}$ flux, and generally captures the zonal trends of both. The greatest discrepancy in these fields lies in the equatorial region, where the model underestimates the air-sea gradient of $p \mathrm{CO}_{2}$ and the outgassing of $\mathrm{CO}_{2}$ to the atmosphere.

Notwithstanding the deficiencies described above, we judged that OCCAM's performance was still adequate for it to serve as a synthetic data set for the TrOCA method.

\section{Appendix C}

In the following, we show that $\mathrm{C}^{*}$ is approximately equal to the sum of $\Delta \mathrm{C}_{\text {gasex }}$ and (scaled) $\mathrm{O}_{2}^{*}$. Since TrOCA and $\mathrm{C}^{*}$ are equivalent (see Eq. 18), this demonstrates the approximate equivalence of pre-industrial $\operatorname{TrOCA}\left(\operatorname{TrOCA}^{0}\right)$ to this scaled sum, and allows us to understand variations in $\mathrm{TrOCA}^{0}$ as reflecting the impacts of the air-sea fluxes of $\mathrm{CO}_{2}$ and $\mathrm{O}_{2}$ on the seawater concentrations of DIC and $\mathrm{O}_{2}$.

$\Delta \mathrm{C}_{\text {gasex }}=\mathrm{C}_{\mathrm{T}}-r_{\mathrm{C}: \mathrm{P}} \cdot \mathrm{P}-\frac{1}{2} \cdot\left(\mathrm{A}_{\mathrm{T}}+r_{\mathrm{N}: \mathrm{P}} \cdot \mathrm{P}\right)-\mathrm{C}_{\text {ant }}-\mathrm{C}_{\text {ref }}$

$\mathrm{O}_{2}^{*}=\mathrm{O}_{2}-r_{\mathrm{O}_{2}: \mathrm{P}} \cdot \mathrm{P}$

Making the simplifying assumption that we are in the preindustrial period (i.e. $\mathrm{C}_{\mathrm{ant}}=0$ ), we can compute the scaled sum (with $\mathrm{C}_{\mathrm{ref}}=0$, and $\alpha=\frac{-r_{\mathrm{C}: \mathrm{P}}}{r_{\mathrm{O}_{2}}: \mathrm{P}}=-r_{\mathrm{C}: \mathrm{O}_{2}}$ ) as follows:

$$
\begin{aligned}
& \Delta \mathrm{C}_{\text {gasex }}+\alpha \cdot \mathrm{O}_{2}^{*}=\mathrm{C}_{\mathrm{T}}-r_{\mathrm{C}: \mathrm{P}} \cdot \mathrm{P}-\frac{1}{2} \cdot\left(\mathrm{A}_{\mathrm{T}}+r_{\mathrm{N}: \mathrm{P}} \cdot \mathrm{P}\right) \\
& \quad+\left(\alpha \cdot\left(\mathrm{O}_{2}-r_{\mathrm{O}_{2}: \mathrm{P}} \cdot \mathrm{P}\right)\right)
\end{aligned}
$$

$$
\begin{aligned}
& \Delta \mathrm{C}_{\text {gasex }}-r_{\mathrm{C}: \mathrm{O}_{2}} \cdot \mathrm{O}_{2}^{*}=\mathrm{C}_{\mathrm{T}}-r_{\mathrm{C}: \mathrm{P}} \cdot \mathrm{P} \\
& \quad-\frac{1}{2} \cdot\left(\mathrm{A}_{\mathrm{T}}+r_{\mathrm{N}: \mathrm{P}} \cdot \mathrm{P}\right)-\left(\frac{r_{\mathrm{C}: \mathrm{P}}}{r_{\mathrm{O}_{2}: \mathrm{P}}} \cdot\left(\mathrm{O}_{2}-r_{\mathrm{O}_{2}: \mathrm{P}} \cdot \mathrm{P}\right)\right) \\
& =\mathrm{C}_{\mathrm{T}}-r_{\mathrm{C}: \mathrm{P}} \cdot \mathrm{P}-\frac{1}{2} \cdot\left(\mathrm{A}_{\mathrm{T}}+r_{\mathrm{N}: \mathrm{P}} \cdot \mathrm{P}\right) \\
& -\left(\frac{r_{\mathrm{C}: \mathrm{P}}}{r_{\mathrm{O}_{2}: \mathrm{P}}} \cdot \mathrm{O}_{2}\right)+\left(\frac{r_{\mathrm{C}: \mathrm{P}}}{r_{\mathrm{O}_{2}: \mathrm{P}}} \cdot r_{\mathrm{O}_{2}: \mathrm{P}} \cdot \mathrm{P}\right) \\
& =\mathrm{C}_{\mathrm{T}}-\frac{1}{2} \cdot\left(\mathrm{A}_{\mathrm{T}}+r_{\mathrm{N}: \mathrm{P}} \cdot \mathrm{P}\right)-r_{\mathrm{C}: \mathrm{O}_{2}} \cdot \mathrm{O}_{2}
\end{aligned}
$$

The soft tissue correction in the alkalinity term, $\left(r_{\mathrm{N}: \mathrm{P}} \cdot \mathrm{P}\right)$, can also be approximated as $\left(r_{\mathrm{N}: \mathrm{O}_{2}} \cdot \mathrm{O}_{2}\right)$, transforming the resulting equation such that it approximates $\mathrm{C}^{*}$ (Eq. 12) and TrOCA (Eq. 18):

$$
\begin{aligned}
& \Delta \mathrm{C}_{\text {gasex }}-r_{\mathrm{C}: \mathrm{O}_{2}} \cdot \mathrm{O}_{2}^{*} \approx \mathrm{C}_{\mathrm{T}}-r_{\mathrm{C}: \mathrm{O}_{2}} \cdot \mathrm{O}_{2} \\
& -\frac{1}{2} \cdot\left(\mathrm{A}_{\mathrm{T}}+r_{\mathrm{N}: \mathrm{O}_{2}} \cdot \mathrm{O}_{2}\right)
\end{aligned}
$$


$\approx \mathrm{C}^{*}$

$$
\approx \frac{1}{a} \cdot \operatorname{TrOCA}
$$

Acknowledgements. The authors would like to thank Bablu Sinha, Beverly de Cuevas and Andrew Coward for technical assistance with OCCAM; Catherine Goyet and Franck Touratier for assistance with the TrOCA method; Adrian Martin for advice and assistance concerning bootstrap optimisation; Guillaume Charria for providing MATLAB scripts for Taylor diagrams; Robert O’Malley for providing observational primary production estimates; Peter Brown, Marta Álvarez and Elaine McDonagh for general discussions of the TrOCA method; and the WOCE community for making their observational archive both available and easily accessible. The authors are also grateful to Catherine Goyet and an anonymous referee for their detailed comments on an earlier version of this manuscript. The authors would additionally like to acknowledge the assistance of the editorial staff of Biogeosciences in the production of this publication. $A Y$ is funded on a UK National Environment Research Council (NERC) standard grant (NE/C00387X/1). NG acknowledges support by ETH Zürich. The authors declare that they have no competing interests.

Edited by: J. Middelburg

\section{References}

Álvarez, M., Lo Monaco, C., Tanhua, T., Yool, A., Oschlies, A., Bullister, J. L., Goyet, C., Metzl, N., Touratier, F., McDonagh, E., and Bryden, H. L.: Estimating the storage of anthropogenic carbon in the subtropical Indian Ocean: a comparison of five different approaches, Biogeosciences, 6, 681-703, 2009, http://www.biogeosciences.net/6/681/2009/.

Anderson, L. A.: On the hydrogen and oxygen content of marine phytoplankton, Deep-Sea Res. I, 42, 1675-1680, 1995.

Anderson, T. R. and Pondaven, P.: Non-redfield carbon and nitrogen cycling in the Sargasso Sea: pelagic imbalances and export flux, Deep-Sea Res. I, 50, 573-591, 2003.

Archer, D.: Fate of fossil fuel $\mathrm{CO}_{2}$ in geologic time, J. Geophys. Res., 110, C09S05, doi:10.1029/2004JC002625, 2005.

Armstrong, R. A., Lee, C., Hedges, J. I., Honjo, S., and Wakeham, S. G.: A new, mechanistic model for organic carbon fluxes in the ocean: based on the quantitative association of POC with ballast minerals, Deep-Sea Res. II, 49, 219-236, 2002.

Behrenfeld, M. J. and Falkowski, P. G.: Photosynthetic rates derived from satellite-based chlorophyll concentration, Limnol. Oceanogr., 42, 1-20, 1997.

Brewer, P. G.: Direct observations of the oceanic $\mathrm{CO}_{2}$ increase, Geophys. Res. Lett., 5, 997-1000, 1978.

Brewer, P. G., Friederich, G., Peltzer, E. T., and Orr, F. M.: Direct experiments on the ocean disposal of fossil fuel $\mathrm{CO}_{2}$, Science, 284, 943-945, 1999.

Broecker, W. S., Takahashi, T., and Peng, T.-H.: Reconstruction of Past Atmospheric $\mathrm{CO}_{2}$ Contents from the Chemistry of the Contemporary Ocean: An Evaluation, DOE/OR-857, US Dept. of Energy, 79 pp., 1985.
Broecker, W. S., Ledwell, J. R., Takahashi, T., Weiss, R., Merlivat, L., Memery, L., Peng, T.-H., Jäne, B., and Munnich, K. O.: Isotope versus micrometeorological ocean $\mathrm{CO}_{2}$ fluxes: an order of magnitude conflict, J. Geophys. Res., 91, 10517-10527, 1986.

Carr, M.-E., Friedrichs, M. A. M., Schmeltz, M., et al.: A comparison of global estimates of marine primary production from ocean color, Deep-Sea Res. II, 53, 741-770, 2006.

Chen, G.-T. and Millero, F. J.: Gradual increase of oceanic carbon dioxide, Nature, 277, 205-206, 1979.

Chen, C.-T. A. and Pytkowicz, R. M.: On the total $\mathrm{CO}_{2}$-titration alkalinity-oxygen system in the Pacific Ocean, Nature, 281, 362365, 1979.

Conkright, M. E., Locarnini, R. A., Garcia, H. E., O’Brien, T. D., Boyer, T. P., Stephens, C., and Antonov, J. I.: World Ocean Atlas 2001: Objective Analyses, Data Statistics, and Figures, CDROM Documentation. National Oceanographic Data Center, Silver Spring, MD, USA, 17 pp., 2002.

Cox, P. M., Betts, R. A., Jones, C. D., Spall, S. A., and Totterdell, I. J.: Acceleration of global warming due to carbon-cycle feedbacks in a coupled climate model, Nature, 408, 184-187, 2000.

Dickson, A. G. and Goyet, C. (eds.): Handbook of methods for the analysis of the various parameters of the carbon dioxide system in sea water; version 2, US Department of Energy, ORNL/CDIAC-74, 1994.

Dutay, J.-C., Bullister, J. L., Doney, S. C., et al.: Evaluation of ocean model ventilation with CFC-11: comparison of 13 global ocean models, Ocean Modell., 4, 89-120, 2002.

Fallon, S. J., Guilderson, T. P., and Caldeira, K.: Carbon isotope constraints on vertical mixing and air-sea $\mathrm{CO}_{2}$ exchange. Geophys. Res. Lett., 30, 2289, doi:10.1029/2003GL018049, 2003.

Friedlingstein, P., Cox, P., Betts, R., et al.: Climate-Carbon Cycle Feedback Analysis: Results from the $\mathrm{C}^{4} \mathrm{MIP}$ Model Intercomparison, J. Climate, 19, 3337-3353, 2006.

Friis, K., Körtzinger, A., Pätsch, J., and Wallace, D. W. R.: On the temporal increase of anthropogenic $\mathrm{CO}_{2}$ in the subpolar North Atlantic, Deep Sea Res. I, 52, 681-698, 2005.

Gerber, M., Joos, F., Vázquez-Rodríguez, M., Touratier, F., and Goyet, C.: Regional air-sea fluxes of anthropogenic carbon inferred with an Ensemble Kalman Filter, Global Biogeochem. Cy., 23, GB1013, doi:10.1029/2008GB003247, 2009.

Glessmer, M. S., Oschlies, A., and Yool, A.: Simulated impact of double-diffusive mixing on physical and biogeochemical upper ocean properties, J. Geophys. Res., 113, C08029, doi:10.1029/2007JC004455, 2008.

Gloor, M., Gruber, N., Sarmiento, J., Sabine, C. L., Feely, R. A., and Rodenbeck, C.: A first estimate of present and preindustrial air-sea $\mathrm{CO}_{2}$ flux patterns based on ocean interior carbon measurements and models, Geophys. Res. Lett., 30, 1010, doi:10.1029/2002GL0155941010, 2003.

Goyet, C. and Brewer, P. G.: Biochemical properties of the oceanic carbon cycle. Modelling Oceanic Climate Interactions. NATO ASI Series, I 11, edited by: Willebrand, J. and Anderson, D. L. T., 271-297, 1993.

Gruber, N.: Anthropogenic $\mathrm{CO}_{2}$ in the Atlantic Ocean, Global Biogeochem. Cy., 12, 165-191, 1998.

Gruber, N., Sarmiento, J. L., and Stocker, T. F.: An improved method for detecting anthropogenic $\mathrm{CO}_{2}$ in the oceans, Global Biogeochem. Cy., 10, 809-837, 1996.

Gruber, N., Gloor, M., Fan, S.-M., and Sarmiento, J. L.: air-sea flux 
of oxygen estimated from bulk data: Implications for the marine and atmospheric oxygen cycles, Global Biogeochem. Cy., 15, 783-803, 2001.

Gruber, N. and Sarmiento, J. L.: Biogeochemical/Physical Interactions in Elemental Cycles, in: The Sea: Biological-Physical Interactions in the Oceans, edited by: Robinson, A. R., McCarthy, J. J., and Rothschild, B. J., John Wiley and Sons, volume 12, 337-399, 2002.

Huertas, I. E., Ríos, A. F., García-Lafuente, J., Makaoui, A., Rodríguez-Gálvez, S., Sánchez-Román, A., Orbi, A., Ruíz, J., and Pérez, F. F.: Anthropogenic and natural $\mathrm{CO}_{2}$ exchange through the Strait of Gibraltar, Biogeosciences, 6, 647-662, 2009 ,

http://www.biogeosciences.net/6/647/2009/.

Indermühle, A., Stocker, T. F., Fischer, H., Smith, H. J., Wahlen, M., Deck, B., Mastroianni, D., Tschumi, J., Blunier, T., Meyer, R., and Stauffer, B.: Holocene carbon-cycle dynamics based on $\mathrm{CO}_{2}$ trapped in ice at Taylor Dome, Antarctica, Nature, 398, 121-126, 1999.

IPCC, 2007: Climate Change 2007: The Physical Science Basis. Contribution of Working Group I to the Fourth Assessment Report of the Intergovernmental Panel on Climate Change, edited by: Solomon, S., Qin, D., Manning, M., Chen, Z., Marquis, M., Averyt, K. B., Tignor, M., and Miller, H. L., Cambridge University Press, Cambridge, United Kingdom, 996 pp., 2007.

Joos, F., Plattner, G.-K., Stocker, T. F., Marchal, O., and Schmittner, A.: Global warming and marine carbon cycle feedbacks on future atmospheric $\mathrm{CO}_{2}$, Science, 284, 464-467, 1999.

Khatiwala, S., Primeau, F., and Hall, T.: Reconstruction of the history of anthropogenic $\mathrm{CO}_{2}$ concentrations in the ocean, Nature, 462, 346-349, doi:10.1038/nature08526, 2009.

Key, R. M., Kozyr, A., Sabine, C. L., et al.: A global ocean carbon climatology: Results from Global Data Analysis Project (GLODAP), Global Biogeochem. Cy., 18, GB4031, doi:10.1029/2004GB002247, 2004.

Lagarias, J. C., Reeds, J. A., Wright, M. H., and Wright, P. E.: Convergence properties of the Nelder-Mead simplex method in low dimensions, SIAM J. Optimization, 9, 112-147, 1998.

Large, W. and Yeager, S.: Diurnal to decadal global forcing for ocean and sea-ice models: the data sets and flux climatologies. CGD Division of the National Center for Atmospheric Research, NCAR Technical Note: NCAR/TN-460+STR, 2004.

Le Quéré, C., Raupach, M. R., Canadell, J. G., Marland, G., et al.: Trends in the sources and sinks of carbon dioxide, Nature Geoscience, 2, 831-836, 2009.

Levine, N. M., Doney, S. C., Wanninkhof, R., Lindsay, K., and Fung, I. Y.: Impact of ocean carbon system variability on the detection of temporal increases in anthropogenic $\mathrm{CO}_{2}$, J. Geophys. Res., 113, C03019, doi:10.1029/2007JC004153, 2008.

Lo Monaco, C., Metzl, N., Poisson, A., Brunet, C., and Schauer, B.: Anthropogenic $\mathrm{CO}_{2}$ in the Southern Ocean: Distribution and inventory at the Indian-Atlantic boundary (World Ocean Circulation Experiment line I6), J. Geophs. Res., 110, C06010, doi:10.1029/2004JC002643, 2005.

Lo Monaco, C., Goyet, C., Metzl, N., Poisson, A., and Touratier, F.: Distribution and inventory of anthropogenic $\mathrm{CO}_{2}$ in the Southern Ocean: Comparison of three data-based methods, J. Geophys. Res., 110, C09S02, doi:10.1029/2004JC002571, 2005.

Manning, A. C. and Keeling, R. F.: Global oceanic and land biotic carbon sinks from the Scripps atmospheric oxygen flask sampling network, Tellus, 58B, 95-116, 2006.

Marsh, R., de Cuevas, B. A., Coward, A. C., Bryden, H. L., and Alvarez, M.: Thermohaline circulation at three key sections of the North Atlantic over 1985-2002, Geophys. Res. Lett., 32, L10604, doi:10.1029/2004GL022281, 2005.

Matsumoto, K., Sarmiento, J. L., Key, R. M., Aumont, O., Bullister, J. L., Caldeira, K., Campin, J.-M., Doney, S. C., Drange, H., Dutay, J.-C., Follows, M., Gao, Y., Gnanadesikan, A., Gruber, N., Ishida, A., Joos, F., Lindsay, K., Maier-Reimer, E., Marshall, J. C., Matear, R. J., Monfray, P., Mouchet, A., Najjar, R., Plattner, G.-K., Schlitzer, R., Slater, R., Swathi, P. S., Totterdell, I. J., Weirig, M.-F., Yamanaka, Y., Yool, A., and Orr, J. C.: Evaluation of ocean carbon cycle models with data-based metrics, Geophys. Res. Lett., 31, L07303, doi:10.1029/2003GL018970, 2004.

Matsumoto, K. and Gruber, N.: How accurate is the estimation of anthropogenic carbon in the ocean? An evaluation of the $\Delta C^{*}$ method, Global Biogeochem. Cy., 19, GB3014, doi:10.1029/2004GB002397, 2005.

Mikaloff-Fletcher, S. E., Gruber, N., Jacobson, A. R., Doney, S. C., Dutkiewicz, S., Gerber, M., Follows, M., Joos, F., Lindsay, K., Menemenlis, D., Mouchet, A., Müller, S. A., and Sarmiento, J. L.: Inverse estimates of anthropogenic $\mathrm{CO}_{2}$ uptake, transport, and storage by the ocean, Global Biogeochem. Cy., 20, GB2002, doi:10.1029/2005GB002530, 2002.

Najjar, R. G. and Orr, J. C.: Biotic-HOWTO, OCMIP-2 Project, 15 pp., online available at: www.ipsl.jussieu.fr/OCMIP/, 1999.

Najjar, R. G., Jin, X., Louanchi, F., et al.: Impact of circulation on export production, dissolved organic matter, and dissolved oxygen in the ocean: Results from Phase II of the Ocean Carboncycle Model Intercomparison Project (OCMIP-2), Global Biogeochem. Cy., 21, GB3007, doi:10.1029/2006GB002857, 2007.

Orr, J., Dutay, J.-C., Najjar, R., Bullister, J., and Brockmann P.: CFC-HOWTO, OCMIP-2 Project, 12 pp., online available at: www.ipsl.jussieu.fr/OCMIP/, 1999.

Orr, J., Najjar, J., Sabine, C., and Joos, F.: Abiotic-HOWTO, OCMIP-2 Project, 29 pp., online available at: www.ipsl.jussieu. fr/OCMIP/, 1999.

Orr, J. C., Fabry, V. J., Aumont, O., et al.: Anthropogenic ocean acidification over the twenty-first century and its impact on calcifying organisms, Nature, 437, 681-686, 2005.

Oschlies, A.: Model-derived estimates of new production: New results point towards lower values, Deep-Sea Res. II, 48, 21732197, 2001.

Östlund, G. and Stuiver, M.: GEOSECS Pacific radiocarbon, Radiocarbon, 22, 25-53, 1980.

Palmer, J. R. and Totterdell, I. J.: Production and export in a global ocean ecosystem model, Deep-Sea Res. I, 48, 1169-1198, 2001.

Papaud, A. and Poisson, A.: Distribution of dissolved $\mathrm{CO}_{2}$ in the Red Sea and correlation with other geochemical tracers, J. Mar. Res., 44, 385-402, 1986.

Pérez, F. F., Álvarez, M., and Ríos, A. F.: Improvements on the back-calculation technique for estimating anthropogenic $\mathrm{CO}_{2}$, Deep-Sea Res. I, 49, 859-875, 2002.

Raven, J. A. and Falkowski, P. G.: Oceanic sinks for atmospheric $\mathrm{CO}_{2}$, Plant Cell Environ., 22, 741-755, 1999.

Revelle, R. and Suess, H. E.: Carbon Dioxide Exchange between Atmosphere and Ocean and the Question of an Increase of Atmospheric $\mathrm{CO}_{2}$ During the Past Decades, Tellus, 9, 18-27, 1957. 
Sabine, C. L., Key, R. M., Johnson, K. M., Millero, F. J., Poisson, A., Sarmiento, J. L., Wallace, D. W. R., and Winn, C. D.: Anthropogenic $\mathrm{CO}_{2}$ inventory of the Indian Ocean, Global Biogeochem. Cy., 13, 179-198, 1999.

Sabine, C. L., Feely, R. A., Key, R. M., Bullister, J. L., Millero, F. J., Lee, K., Peng, T. H., Tilbrook, B., Ono, T., and Wong, C. S.: Distribution of anthropogenic $\mathrm{CO}_{2}$ in the Pacific Ocean, Global Biogeochem. Cy., 16, GB1083, doi:10.1029/2001GB001639, 2002.

Sabine, C. L., Feely, R. A., Gruber, N., Key, R. M., Lee, K., Bullister, J. L., Wanninkhof, R., Wong, C. S., Wallace, D. W. R., Tilbrook, B., Millero, F. J., Peng, T.-H., Kozyr, A., Ono, T., and Rios, A. F.: The oceanic sink for anthropogenic $\mathrm{CO}_{2}$, Science, 305, 367-371, 2004.

Sabine, C. L. and Tanhua, T.: Estimation of Anthropogenic $\mathrm{CO}_{2}$ Inventories in the Ocean, Annu. Rev. Mar. Sci., 2, 175-198, doi:10.1146/annurev-marine-120308-080947, 2010.

Sandrini, S., Ait-Ameur, N., Rivaro, P., Massolo, S., Touratier, F., Tositti, L., and Goyet, C.: Anthropogenic carbon distribution in the Ross Sea, Antarctica, Antarctic Sci., 19, 395-407, 2007.

Sarmiento, J. L., Orr, J. C., and Siegenthaler, U.: A perturbation simulation of $\mathrm{CO}_{2}$ uptake in an ocean general circulation model, J. Geophys. Res., 97, 3621-3645, 1992.

Sarmiento, J. L., Hughes, T. M. C., Stouffer, R. J., and Manabe, S.: Simulated response of the ocean carbon cycle to anthropogenic climate warming, Nature, 393, 245-249, 1998.

Sarmiento, J. L. and Gruber, N.: Sinks for anthropogenic carbon, Physics Today, 55, 30-36, 2002.

Sarmiento, J. and Gruber, N.: Ocean Biogeochemical Dynamics. Princeton University Press, New Jersey, USA, 2006.

Schmittner, A., Oschlies, A., Giraud, X., Eby, M., and Simmons, H. L.: A global model of the marine ecosystem for long-term simulations: Sensitivity to ocean mixing, buoyancy forcing, particle sinking, and dissolved organic matter cycling, Global Biogeochem. Cy., 19, GB3004, doi:10.1029/2004GB002283, 2005.

Siegenthaler, U. and Sarmiento, J. L.: Atmospheric carbon dioxide and the ocean, Nature, 365, 119-125, 1993.

Sinha, B. and Yool, A.: Extension of the OCCAM $1^{\circ}$ ocean general circulation model to include the biogeochemical cycles of carbon and oxygen, Part I: Technical description. National Oceanography Centre, Southampton, Research and Consultancy Report No. 5, 81 pp. (unpublished manuscript), 2006.

Sonnerup, R. E., McNichol, A. P., Quay, P. D., Gammon, R. H., Bullister, J. L., Sabine, C. L., and Slater, R. D.: Anthropogenic $\delta^{13} \mathrm{C}$ changes in the North Pacific Ocean reconstructed using a multiparameter mixing approach (MIX), Tellus B, 59, 303-317, 2007.

Takahashi, T., Sutherland, S. C., Wanninkhof, R., et al.: Climatological mean and decadal changes in surface ocean $p \mathrm{CO}_{2}$, and net sea-air $\mathrm{CO}_{2}$ flux over the global oceans, Deep-Sea Res. II, 56, 554-577, 2009.

Taylor, K. E.: Summarizing multiple aspects of model performance in a single diagram, J. Geophys. Res., 106, 7183-7192, 2001.
Touratier, F. and Goyet, C.: Definition, properties, and Atlantic Ocean distribution of the new tracer TrOCA, J. Mar. Sys., 46, 169-179, 2004.

Touratier, F. and Goyet, C.: Applying the new TrOCA approach to assess the distribution of anthropogenic $\mathrm{CO}_{2}$ in the Atlantic Ocean, J. Mar. Sys., 46, 181-197, 2004.

Touratier, F., Goyet, C., Coatanoan, C., and Andrie, C.: Assessments of anthropogenic $\mathrm{CO}_{2}$ distribution in the tropical Atlantic Ocean, Deep-Sea Res. I, 52, 2275-2284, 2005.

Touratier, F., Azouzi, L., and Goyet, C.: CFC-11, $\Delta^{14} \mathrm{C}$ and ${ }^{3} \mathrm{H}$ tracers as a means to assess anthropogenic $\mathrm{CO}_{2}$ concentrations in the ocean, Tellus B, 59, 318-325, 2007.

Tsunogai, S., Ono, T., and Watanabe, S.: Increase in total carbonate in the Western North Pacific water and a hypothesis on the missing sink of anthropogenic carbon, J. Oceanogr., 49, 305315, 1993.

Vázquez-Rodríguez, M., Touratier, F., Lo Monaco, C., Waugh, D. W., Padin, X. A., Bellerby, R. G. J., Goyet, C., Metzl, N., Ríos, A. F., and Pérez, F. F.: Anthropogenic carbon distributions in the Atlantic Ocean: data-based estimates from the Arctic to the Antarctic, Biogeosciences, 6, 439-451, 2009, http://www.biogeosciences.net/6/439/2009/.

Walker, S. J., Weiss, R. F., and Salameh, P. K.: Reconstructed histories of the annual mean atmospheric mole fractions for the halocarbons CFC-11, CFC-12, CFC-113 and carbon tetrachloride, J. Geophys. Res., 105, 14285-14296, 2000.

Warner, M. J. and Weiss, R. F.: Solubilities of chlorofluorocarbons 11 and 12 in water and sea water, Deep-Sea Res., 32, 1485-1497, 1985.

Waugh, D. W., Haine, T. W. N., and Hall, T. M.: Transport times and anthropogenic carbon in the subpolar North Atlantic Ocean, Deep Sea Res. I, 51, 1475-1491, 2004.

Westberry, T., Behrenfeld, M. J., Siegel, D. A., and Boss, E.: Carbon-based primary productivity modeling with vertically resolved photoacclimation, Global Biogeochem. Cy., 22, GB2024, doi:10.1029/2007GB003078, 2008.

Yool, A. and Sinha, B.: Extension of the OCCAM $1^{\circ}$ ocean general circulation model to include the biogeochemical cycles of carbon and oxygen, Part II: Initial Experiments. National Oceanography Centre, Southampton, Research and Consultancy Report No. 6, 159 pp. (unpublished manuscript), 2006.

Yool, A., Martin, A. P., Fernández, C., and Clark, D. R.: The significance of nitrification for oceanic new production, Nature, 447, 999-1002, 2007.

Yool, A., Shepherd, J. G., Bryden, H. L., and Oschlies, A.: Low efficiency of nutrient translocation for enhancing oceanic uptake of carbon dioxide, J. Geophys. Res., 114, C08009, doi:10.1029/2008JC004792, 2009.

Zheng, M., DeBruyn, W. J., and Saltzman, E. S.: Measurements of the diffusion coefficients of CFC-11 and CFC-12 in pure water and seawater, J. Geophys. Res., 103, 1375-1379, 1998. 